\title{
Avaliação de Lesões Periapicais InduZidas Experimentalmente em Camundongos Knockout para Molécula Adaptadora para Ativação DE RECEPTORES TOLL-LIKE(MyD88)
}

Tese apresentada à Faculdade de Odontologia de Ribeirão Preto da Universidade de São Paulo para obtenção do título de Doutor em Ciências. Programa: Odontopediatria Área de Concentração: Odontopediatria

Orientador: Prof. Dr. Paulo Nelson-Filho CoOrientadora: ProF ${ }^{\mathrm{a}}$. DR ${ }^{\mathrm{a}}$. RaQUel AsSed BeZerRA DA Silva 


\section{AUTORIZAÇÃo PARA REPRODUÇÃo}

Autorizo a reprodução e/ou divulgação total ou parcial da presente obra, por qualquer meio convencional ou eletrônico, desde que citada a fonte.

Ficha Catalográfica

Lucisano, Marília Pacífico

Avaliação de lesões periapicais induzidas experimentalmente em camundongos knockout para molécula adaptadora para ativação de receptores Toll-like (MyD88). Ribeirão Preto, 2013.

137p. : il. ; $30 \mathrm{~cm}$

Tese de Doutorado, apresentada à Faculdade de Odontologia de Ribeirão Preto/USP - Área de Concentração: Odontopediatria.

Orientador: Nelson-Filho, Paulo

Coorientadora: da Silva, Raquel Assed Bezerra

1. Lesão periapical 2. Molécula MyD88 3. Receptores Toll-Like 4.Camundongos knockout 


\section{FOLHA DE APROVAÇÃo}

Lucisano MP. Avaliação de lesões periapicais induzidas experimentalmente em camundongos knockout para molécula adaptadora para ativação de receptores Toll-like (MyD88).

Tese apresentada à Faculdade de Odontologia de Ribeirão Preto da Universidade de São Paulo, para obtenção do Título de Doutor em Ciências. Área de Concentração: Odontopediatria.

Data da defesa:

1

BANCA EXAMINADORA

Prof. Dr.

Julgamento Assinatura

Prof. Dr.

Julgamento Assinatura

Prof. Dr.

Julgamento Assinatura

Prof. Dr.

Julgamento Assinatura

Prof. Dr. Julgamento Assinatura 



\section{MARÍlia Pacífico LUCISANo}

\section{Dados Curriculares}

Nascimento 25 de novembro de 1985 - Ribeirão Preto/SP.

Filiação Renilton Nazareno Fontes Lucisano.

Maria Stella Alves Pacífico Lucisano.

2004-2007 Curso de Graduação.

Faculdade de Odontologia de Ribeirão Preto da Universidade de São Paulo - FORP/USP.

2005-2006 Iniciação Científica - Projeto de pesquisa intitulado "Influência do fluxo de água do laser ER:YAG na resistência adesiva da resina composta aos substratos dentais irradiados" (Bolsa FAPESP).

2006-2007

Iniciação Científica - Projeto de pesquisa intitulado "Avaliação da confiabilidade de dois localizadores eletrônicos foraminais de última geração na determinação da odontometria em dentes decíduos - Estudo ex vivo" (Bolsa CNPq).

2009-2010

Curso de Pós-Graduação em Odontopediatria, nível de Mestrado.

Faculdade de Odontologia de Ribeirão Preto da Universidade de São Paulo - FORP/USP Dissertação intitulada "Efeito do uso sistêmico de alendronato sódico no tecido ósseo e nas estruturas dentárias mineralizadas: Estudo químico, mecânico e morfológico, em modelo murino" (Bolsa CAPES).

2009-2011 Curso de Especialização em Odontopediatria.

Associação Odontológica de Ribeirão Preto - AORP - Monografia intitulada "Papel da endotoxina na etiologia da lesão periapical: mecanismos moleculares envolvidos no seu reconhecimento e na ativação celular".

2011-2013 Curso de Pós-Graduação em Odontopediatria, nível Doutorado.

Faculdade de Odontologia de Ribeirão Preto da Universidade de São Paulo - FORP/USP - Tese intitulada "Avaliação de lesões periapicais induzidas experimentalmente em camundongos knockout para molécula adaptadora para ativação de receptores Tolllike (MyD88)". Faculdade de Odontologia de Ribeirão Preto da Universidade de São Paulo - FORP/USP 

A Deus, pela vida e por Tua constante presença. Obrigada por me guiar, me proteger e iluminar o meu caminho.

Obrigada pela esperança que animou meus passos, obrigada pelos exemplos que recebi, obrigada pelo que me fez sofrer, pois nos momentos de desânimo, Tu me enchestes de luz, obrigada pela compreensão e pelo amor que encontrei nas pessoas que Tu pusestes em meu caminho, obrigada por esta conquista.

À Maria, por passar na frente em todos os momentos, por cuidar de todos os detalhes, por proteger os meus passos, por resolver aquilo que eu sou incapaz de resolver, por cuidar de tudo que não está ao meu alcance, por resolver as coisas difíceis e impossiveis. 

Aos meus pais Renilton Nazareno Fontes Lucisano e Maria Stella Alves Pacífico Lucisano, pelo amor incondicional e pela admirável arte de educar. Obrigada por me ensinar a caminhar seguindo os princípios de Deus e por terem me proporcionado uma vida repleta de felicidade. Agradeço a vocês por não medirem esforços para investir na minha educação e me incentivar a continuar estudando sempre. Bem e Mamãe, obrigada pelo amor, segurança, apoio e compreensão que encontro em vocês e, principalmente, pelo porto seguro em momentos de dificuldade.

Esta conquista também é de vocês.

Obrigada por acreditarem em mim! Amo vocês.

À minha querida irmã Marcela Pacífico Lucisano, minha melhor amiga! Obrigada pelo seu amor, força, incentivo e amizade. Agradeço por eu poder dividir com você tudo em minha vida. Você é minha melhor e eterna companheira. Amo você!

Ao meu namorado, Gustavo Luis Politi, meu companheiro para todas as horas. Obrigada por fazer minha vida mais feliz e completa. Gu, agradeço por me apoiar, me incentivar e acreditar na minha capacidade. Amo você!

A todos os familiares e amigos que sempre torceram por mim e me deram carinho! 



\section{A GRADECIMENTOS ESPECiais}

Ao meu orientador Prof. Dr. Paulo Nelson-Filho, por transmitir seus conhecimentos e experiências profissionais e de vida com dedicação e carinho, por me guiar para além das teorias, das filosofias e das técnicas. Expresso meu sincero agradecimento e meu profundo respeito, que sempre serão pouco diante do muito que me ofereceu.

Professor, obrigada por ter se dedicado à minha formação profissional, desde a Graduação, e por caminhar ao meu lado, permitindo-me chegar até aqui. Sem a sua orientação, essa vitória não seria possível. Obrigada pela gentileza especial, compreensão e motivação que sempre vêm tão naturalmente de você. A convivência pautada na atenção, no respeito, na confiança e no carinho, que é inerente a você, foi e sempre será o meu estímulo: o estímulo para começar, o estímulo para superar os obstáculos e enfrentar as dificuldades, o estímulo para crescer, o estímulo para recomeçar, o estímulo para vencer!

Professor, você é meu Mestre, meu exemplo de ser humano. Serei eternamente sua discípula, seguirei seus princípios de humildade, respeito incomparável, lealdade e seu admirável exemplo de dedicação plena e amor ao Ensino.

Agradeço pelas palavras, tempo e atenção dedicados a mim e pela orientação na minha formação profissional.

Tenho muito orgulho de ser sua aluna. Agradeço a Deus por ter você no meu caminho!

\section{Obrigada por ter acreditado em mim.}


À minha coorientadora Profa. Dra . Raquel Assed Bezerra da Silva, pela forma carinhosa e amiga que sempre me recebe. Agradeço pela sua dedicação, apoio e atenção, desde o início, que foram fundamentais para a realização deste trabal ho. Raquel, a forma tão prestativa, alegre e gentil com a qual você se dirige a todas as pessoas é admirável e torna mais motivante a nossa caminhada. Agradeço pelas vezes que dedicou o seu tempo me ajudando e me orientando diretamente durante os experimentos. Obrigada por me incentivar e me ajudar a crescer sempre. Obrigada por seus ensinamentos, conselhos e orientações, ainda durante a Iniciação Científica, que me despertaram o desejo de seguir em frente e chegar até aqui. Rach, essa conquista é nossa!

À Profa.Drá. Léa Assed Bezerra da Silva, por ter me recebido e acolhido na Odontopediatria. Obrigada por acreditar na minha capacidade e pelo incentivo constante ao aprendizado e à Pesquisa. Professora Léa, para mim é uma honra o convívio diário com a senhora, que é um exemplo de amor à vida e à profissão, exemplo de uma pessoa batalhadora e sonhadora! Muito obrigada por todas as experiências compartilhadas, pelos ensinamentos e pela confiança depositada em mim. Professora tem sido um privilégio conviver com a senhora, também porque pude conhecer melhor a pessoa carinhosa e divertida que é. A senhora me transmite muita alegria e segurança nas decisões e torna os nossos trabalhos mais agradáveis. Serei eternamente grata por tudo o que me proporcionou.

À Profa.Dra. Andiara De Rossi, minha Professora, amiga e companheira. Obrigada pelo apoio e incentivo que sempre tenho em você. Obrigada por não medir esforços para me ajudar em tudo que preciso. Agradeço pela sua colaboração e atenção que foram essenciais na realização deste trabalho. Andi, muito obrigada por compartilhar comigo suas experiências profissionais e de vida, pelos conselhos, pelas conversas sinceras e pelo carinho que tem por mim. Agradeço a Deus por colocar pessoas como você no meu caminho.

À Profa. Dra. Alexandra Mussolino de Queiroz, pela forma alegre e carinhosa com que sempre me acolhe. Sou grata pelos seus ensinamentos e pela contribuição na minha formação profissional. Danda, obrigada pela atenciosa e agradável convivência, pela pessoa alegre e divertida quéé. 
À Faculdade de Odontologia de Ribeirão Preto da Universidade de São Paulo, na pessoa do atual diretor Prof. Dr. Valdemar Mallet da Rocha Barros e da Vice-Diretora Prof .Draa. Léa Assed Bezerra da Silva.

À Coordenação do Curso de Pós-Graduação em Odontopediatria da Faculdade de Odontologia de Ribeirão Preto da Universidade de São Paulo, na pessoa da Coordenadora Profá. Drå. Léa Assed Bezerra da Silva e da Vice-Coordenadora Prof́. Dra . Raquel Assed Bezerra da Silva.

À Profá. Drá. Sada Assed, pelos princípios de determinação, amor à vida e dedicação ao Ensino.

À Prof . Dra. Aldevina Campos de Freitas, grande exemplo de dedicação, paciência e amor à profissão. Professora, muito obrigada pelos conhecimentos teóricos e clínicos transmitidos desde a graduação.

Ao Prof. Dr. Mário Roberto Leonardo, exemplo de simpatia, respeito, humildade e amor ao próximo. Meu sincero agradecimento por todos os seus preciosos ensinamentos que serão sempre lembrados por mim.

À Profa.Drả.Kranya Victória Díaz Serrano, pela sua alegria, otimismo e dedicação. Obrigada por estar sempre disponível, pelo incentivo constante e pelas conversas agradáveis.

À Prof́. Drá. Maria Cristina Borsatto, ótima companheira para todas as horas. Exemplo de bom-humor e alegria. Cris, obrigada pelo estímulo e por estar sempre à disposição para ajudar.

Aos Professores da Disciplina de Ortodontia da Faculdade de Odontologia de Ribeirão Preto da Universidade de Sào Paulo, Prof. Dr. Adîlson Thomazinho, Prof. Dr. Fábio Lourenço Romano, Prof. Dr. Josê Tarcísio Lima Ferreira, Profa. Dra. Maria Bernadete Sasso Stuani e Profa. Dra Mírian Aiko Nakane Matsumoto, pela agradável convivência, pelas conversas atenciosas e pelos conhecimentos transmitidos. 
À Profa. Dra . Maria da Conceição Pereira Saraiva, professora da Disciplina de Epidemiologia, pela atenção e pela disponibilidade em ajudar sempre. Obrigada pelas orientações na anălise estatística dos dados deste trabalho.

Aos funcionários do Departamento de Clínica Infantil da Faculdade de Odontologia de Ribeirão Preto, meus colegas de trabalho que tornam os meus dias mais felizes e prazerosos:

Dr. Francisco Wanderley Garcia de Paula e Silva, meu companheiro de sala, muito obrigada por sempre me ajudar em tudo que eu preciso. Obrigada por nossa convivência agradável, por dividir comigo suas experiências e conhecimentos. Agradeço pelas conversas e conselhos que sempre foram muito importantes para mim. Francisco, obrigada pela companhia e por sua amizade.

Dra. Carolina Paes Torres Mantovani, minha amiga e também companheira de sala, obrigada por ser tão atenciosa e gentil comigo e pela disposição em ajudar sempre. Sua bondade, alegria e simpatia tornam os dias mais agradáveis.

Marco Antonio dos Santo, obrigada pela convivência, pelas conversas e pelo carinho desde o início, quando ainda fazia estágio com você no Laboratório. Obrigada por sua participação direta na fase laboratorial deste trabalho e por ter preparado as lâminas histológicas com tanto cuidado. Marco agradeço por ser tão prestativo, alegre e carinhoso comigo.

Nilza Letícia Magalhães, minha companheira de laboratório, obrigada pela ajuda na execução de todas as metodologias realizadas neste trabalho. Obrigada por dividir suas experiências comigo e por estar sempre disposta a ajudar. Nilza é admirável a sua alegria e o seu bom humor diariamente, que mostram o seu prazer em trabalhar aqui, tornando a execução dos experimentos mais agradável.

Fátima Aparecida Jacinto, pela companhia no laboratório, pelas ajudas oferecidas e pelo apoio de sempre. 
Filomena Leli Placciti, obrigada pela alegre convivência, pela forma simpática e carinhosa que me recebe diariamente. Filozinha, agradeço pela atenção e disponibilidade de sempre. Você é um exemplo de ser humano, uma pessoa encantadora.

Matheus Morelli Zanela, obrigada pela paciência, atenção e disponibilidade. Agradeço pelo convívio agradável e pelo carinho.

Micheli Cristina Leite Rovanholo, pela dedicação e apoio durante todo o curso. Mi, obrigada pelo carinho e por me ajudar sempre.

Benedita Viana Rodrigues, Fátima Aparecida Rizoli e Renata Aparecida Fernandes, pela atenção e apoio na Clínica de Pacientes Especiais. Agradeço pela forma amiga, simpática e alegre que sempre me acolhem.

Carmo Euripedes Terra Barretto, pela convivência agradável e disponibilidade em ajudar.

Aos meus amigos e colegas de turma do Doutorado, por compartilhar momentos maravilhosos, por dividir experiências e dificuldades, pelo companheirismo e amizade.

Aos alunos do Programa de Pós-Graduação em Odontopediatria da Faculdade de Odontologia de Ribeirão Preto da Universidade de São Paulo, pela agradável convivência, pelas conversas divertidas e pelos momentos compartilhados.

À minha amiga Késsia Suênia Fidelis de Mesquita, um anjo que Deus colocou na minha vida. Obrigada por sua amizade verdadeira, pelo seu carinho, por me incentivar e ajudar sempre. Obrigada pelos conselhos, pelas conversas, risadas e, principalmente, por me dar forças nos momentos de dificuldade. Ké, é um privilégio tê-la como amiga e saiba que você é e sempre será especial para mim.

Aos funcionários do Biotério Antônio Sérgio Aparecido Mesca, Aline Aparecida Ferraresi Tiballi e Antônio Massaro, pela gentileza e simpatia com que me receberam diariamente. Obrigada por terem sido tão prestativos e atenciosos e pelo cuidado no tratamento dos animais. 
Aos funcionários da Clínica I da Faculdade de Odontologia de Ribeirão Preto da Universidade de São Paulo, José Aparecido Neves do Nascimento, Vera do Nascimento Scandelai e Karina Dadalt Quaglio, obrigada pela prontidão em me atender, pela alegre convivência, pelo apoio e carinho.

Aos funcionários da Seção de Pós-Graduação da Faculdade de Odontologia de Ribeirão Preto da Universidade de São Paulo, Isabel Cristina Galino Sola, Regiane Cristina Moi Sacilloto e Leandro Marin Silva, pela atenção, pelo carinho e por estarem sempre à disposição.

À secretária do Curso de Especialização em Ortodontia, Rosemary Alves de Sá, pela elaboração do fluxograma e formatação deste trabalho. Rose, obrigada pela disponibilidade, atenção e pelo auxîlio constante.

À equipe da Clic Foto e Video, pela montagem das pranchas e impressão do trabalho.

À CAPES (Coordenação de Aperfeiçoamento de Pessoal de Nivel Superior), pela bolsa concedida em 2011. 
SUMÁRIO

\section{RESUMO}

ABSTRACT

INTRODUÇÃO

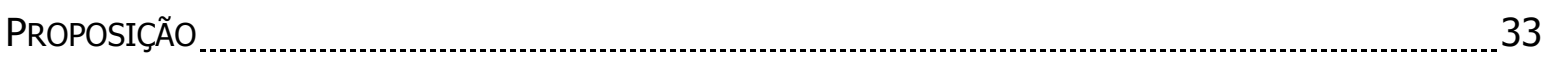

MATERIAL E MÉTODOS

RESULTADOS

DISCUSSÃO 85

CONCLUSÃO 93

REFERÊNCIAS

APÊNDICE 



\section{Resumo}

Lucisano, MP. Avaliação de lesões periapicais induzidas experimentalmente em camundongos knockout para molécula adaptadora para ativação de receptores Toll-like (MyD88). Ribeirão Preto, 2013. 137p. [Tese de Doutorado]. Ribeirão Preto: Faculdade de Odontologia de Ribeirão Preto da Universidade de São Paulo; 2013.

A molécula adaptadora myeloid differentiation primary response gene 88 (MyD88) está envolvida na ativação de receptores Toll-like (TLRs), os quais são responsáveis pelo reconhecimento precoce pelas células do hospedeiro de patógenos invasores e pelo desencadeamento da resposta imunológica. O objetivo do presente estudo foi caracterizar o desenvolvimento e a progressão de lesões periapicais induzidas experimentalmente em dentes de camundongos knockout (KO) para a molécula MyD88 (MyD88 KO), comparados a animais wild-type (WT). Lesões periapicais foram induzidas nos primeiros molares inferiores de 30 camundongos WT e de 30 camundongos MyD88 KO. Decorridos 7, 21 e 42 dias, os animais foram submetidos à eutanásia em câmara de $\mathrm{CO}_{2}$ e as mandíbulas foram removidas e submetidas ao processamento histotécnico. A seguir, cortes representativos foram corados com hematoxilina e eosina (HE), para descrição das características do canal radicular e das regiões apical e periapical e para contagem do número de células inflamatórias (neutrófilos), em microscopia de luz, e para mensuração da área das lesões periapicais, em microscopia de fluorescência. Espécimes sequenciais foram analisados por meio de: histoenzimologia para a atividade da TRAP, para contagem de osteoclastos; coloração de Brown \& Brenn, para localização de bactérias; e imunohistoquímica, para identificação de marcadores da osteoclastogênese (RANK, RANKL e OPG). Os dados foram submetidos à análise estatística por meio dos testes não-paramétricos de Mann-Whitney, Kruskal-Wallis e pós-teste de Dunn, utilizando o programa SPSS (Statistical Package for the Social Sciences) versão 17.0, com nível de significância de $5 \%$. As demais análises foram expressas de maneira qualitativa. Com relação à extensão das lesões periapicais, o grupo MyD88 KO apresentou valores significantemente maiores do que o grupo WT nos períodos de $7(p=0,001)$ e 21 dias $(p=0,05)$, sendo que após 42 dias foi observada tendência de maiores valores, porém sem diferença significante $(p=0,09)$. Foi observada maior quantidade de neutrófilos no grupo MyD88 KO, em comparação aos animais WT ( $p=0,01$ em 7 dias; $p=0,004$ em 21 dias; e $\mathrm{p}<0,001$ em 42 dias). Por outro lado, com relação à quantidade de osteoclastos, não foi observada diferença significante entre ambos os grupos, em todos os períodos experimentais ( $p=0,884$ em 7 dias; $p=0,506$ em 21 dias; e $p=0,211$ em 42 dias). A análise microscópica 
descritiva do grupo MyD88 KO revelou um infiltrado inflamatório mais intenso, com presença abundante de células porlimorfonucleadas e mononucleadas e com grande destruição tecidual, após 7, 21 e 42 dias. A coloração de Brown e Brenn evidenciou uma maior disseminação bacteriana, inclusive nos tecidos periapicais, no grupo MyD88 KO, quando comparado aos animais WT. Com relação à imunohistoquímica, foram observadas marcações para RANK, RANKL e OPG de forma semelhante entre os dois grupos de animais. Com base nas metodologias e nos resultados obtidos no presente estudo pode-se concluir que na ausência da MyD88 os animais apresentaram lesões periapicais mais extensas, com um infiltrado inflamatório severo e com número significantemente maior de neutrófilos, quando comparados aos animais WT, sugerindo o importante papel desta molécula na resposta imune e inflamatória no combate à infecção de origem endodôntica.

Palavras-chaves: lesão periapical; molécula MyD88; receptores toll-like; camundongos knockout. 


\section{Abstract}

Lucisano, MP. Evaluation of experimentally induced periapical lesions in knockout mice for toll-like receptor activation adaptor molecule (MyD88). Ribeirão Preto, 2013. 137p. [Tese de Doutorado]. Ribeirão Preto: Faculdade de Odontologia de Ribeirão Preto da Universidade de São Paulo; 2013.

The adaptor molecule myeloid differentiation primary response gene 88 (MyD88) is involved in the activation of toll-like receptors (TLRs), which are responsible for the early recognition by the host cells of invading pathogens and for triggering the immune response. The aim of the present study was to characterize the formation and progression of experimentally induced periapical lesions in teeth of MyD88 knockout (MyD88 KO) mice compared with wildtype (WT) mice. Periapical lesions were induced in the mandibular first molars of 30 WT and 30 MyD88 KO mice. After 7, 21 and 42 days, the animals were euthanized in a $\mathrm{CO}_{2}$ chamber and the mandibles were removed and subjected to histotechnical processing. Representative histological sections were stained with hematoxylin and eosin (HE) for description of the features of the root canal and the apical and periapical regions, and for counting of inflammatory cells (neutrophils) under conventional light microscopy and for determination of the size of the periapical lesions under fluorescence microscopy. Sequential specimens were evaluated by: TRAP histoenzymology, for osteoclast counting; Brown \& Brenn staining, for localization of bacteria; and immunohistochemistry for identification of osteoclastogenesis markers (RANK, RANKL, OPG). Data were subjected to statistical analysis by the nonparametric Mann-Whitney and Kruskal-Wallis tests and the Dunn post-test, using the SPSS (Statistical Package for the Social Sciences) software, version 17.0. The significance level was set at $5 \%$. The other analyzes were displayed qualitatively. Regarding the periapical lesion size, the MyD88 KO group presented significantly higher values than the WT group in the periods of $7(p=0.001)$ and 21 days $(p=0.05)$. Tendency for higher values was observed after 42 days, though without significant difference $(p=0.09)$. A larger number of neutrophils in the MyD88 KO group were observed compared with the WT animals $(p=0.01$ at 7 days, $p=0.004$ at 21 days and $p<0.001$ at 42 days). On the other hand, regarding the number of osteoclasts, no statistically significant difference was observed between the groups at any of the experimental periods $(p=0.884$ at 7 days, $p=0.506$ at 21 days and $\mathrm{p}=0.211$ at 42 days). Descriptive microscopic analysis of the MyD88 KO group revealed a more intense inflammatory infiltrate, with abundant presence of polymorphonuclear and mononuclear cells and wide tissue destruction, after 7, 21 and 42 days. Brown \& Brenn staining showed an increased bacterial dissemination, including the periapical tissues in the 
MyD88 KO group, when compared with the WT animals. As for immunohistochemistry, RANK, RANKL and OPG immunostainings were similar between the two groups of animals. Based on the employed methodology and the obtained results, it may be concluded that in the absence of MyD88, the animals showed larger periapical lesions, with a severe inflammatory infiltrate and a significantly larger number of neutrophils, when compared with WT animals, suggesting the important role of this molecule during the immune and inflammatory response against infections of endodontic origin.

Key words: periapical lesion; MyD88 molecule; toll-like receptors; knockout mice. 
Introdução 



\section{INTRODUÇ̃̃o}

Conceitualmente, a lesão periapical é caracterizada por um processo infeccioso e imunoinflamatório de longa duração, assim como um desequilíbrio entre o número e a virulência dos micro-organismos presentes no sistema de canais radiculares, com relação à resistência do hospedeiro. O tratamento endodôntico de dentes decíduos e permanentes portadores de necrose pulpar e lesão periapical, denominado didaticamente de Necropulpectomia II, representa um desafio para o profissional, uma vez que seu índice de sucesso é bastante inferior, em torno de $70 \%$, quando comparado ao tratamento de dentes portadores de necrose, porém sem lesão periapical, os quais apresentam taxa de sucesso de 90-95\% (Sjögren et al., 1997; Ferreira, 2011; Leonardo, 2012).

Em função do importante papel dos micro-organismos na etiologia das alterações pulpares e periapicais, a microbiota presente nos canais radiculares de dentes decíduos e permanentes com necrose pulpar tem sido amplamente estudada na literatura específica (Assed et al., 1996; Gomes et al., 2004; Ruviére et al., 2007; Rôças e Siqueira Jr., 2010; Ito et al., 2011; Gomes et al., 2012).

No início da instalação do processo infeccioso no tecido pulpar, observa-se a prevalência de uma microbiota Gram-positiva, composta principalmente por microorganismos aeróbios, com predomínio de cocos sobre os bacilos e filamentosos (Fabricius et al., 1982). Como consequência do comprometimento do suprimento sanguíneo na presença do tecido pulpar necrótico, e em função de fatores como a disponibilidade de nutrientes, a baixa tensão de oxigênio e as interações bacterianas, sequencialmente ocorrem alterações microbiológicas. Desta forma, estabelece-se no sistema de canais radiculares de dentes decíduos e permanentes com necrose pulpar e lesão periapical crônica uma infecção polimicrobiana, composta por uma microbiota mista e complexa, com predominância de micro-organismos anaeróbios estritos, particularmente os Gram-negativos (Seltzer e Farber, 1994; Assed et al., 1996; Rocha et al., 2008; Cogulu et al., 2008; Mohammadi, 2011). Esses micro-organismos encontram-se localizados não apenas na luz do canal principal e nos túbulos dentinários, mas também nas lacunas cementárias, nas crateras apicais, no biofilme apical e na lesão periapical (Leonardo et al., 2002; 2007; Rocha et al., 2008; Leonardo, 2012).

Os micro-organismos Gram-negativos, além de possuírem diferentes fatores de virulência e gerarem produtos e subprodutos tóxicos aos tecidos apicais e periapicais, contêm a endotoxina em sua parede celular. Esse conhecimento é particularmente importante, uma vez que a endotoxina, também conhecida como LPS em função de sua 
natureza lipopolissacarídica, é liberada durante a multiplicação ou morte bacteriana, exercendo uma série de efeitos biológicos importantes (Rietschel e Brade, 1992; McGee et al., 1992; Haimovich et al., 2010).

As moléculas de endotoxina estimulam a liberação de um grande número de citocinas pró-inflamatórias ou mediadores químicos bioativos, tais como Interleucina-1 (IL-1), IL-5, IL6, IL-8, Fator de Necrose Tumoral (TNF-a), linfotoxinas (TNF- $\beta$ ), Interferon-alfa (IF- a) e prostaglandinas (Stashenko et al., 1987; Tronstad, 1992; Stashenko et al., 1992; Hetherington et al., 1999), levando à reação inflamatória e reabsorção óssea periapical (Stashenko, 1990; Nelson-Filho et al., 2002; Silva et al., 2002; Jiang et al., 2003; Silva et al., 2008). Foi demonstrado que o LPS também induz a expressão de moléculas de adesão de leucócitos em células endoteliais, além de estimular a diferenciação osteoclástica, particulamente por meio de interações com o receptor toll-like 4 (TLR4) em células de linhagem osteoblástica (Mohammadi, 2011). Além disso, o processo imunoinflamatório nas lesões de origem endodôntica envolve a participação de diferentes tipos celulares como a ativação de células endoteliais, neutrófilos, macrófagos, linfócitos e osteoclastos, que contribuem para uma rápida destruição do tecido ósseo (Graves et al., 2011).

Assim, os insucessos no tratamento endodôntico vêm sendo atribuídos à persistência de micro-organismos (Nair et al., 1990; Lin et al., 1992; Siqueira e Rôças, 2004; Sakamoto et al., 2008) e de seus subprodutos, devido ao combate insatisfatório da infecção presente nos canais radiculares (Kerekes e Tronstad, 1979; Orstavik, 1996; Regan e Fleury, 2006; Kandaswamy e Venkateshbabu, 2010). Além disso, como já salientado, estudos têm demonstrado que, em várias patologias, os principais aspectos deletérios não estão relacionados diretamente com o agente agressor, mas sim com a resposta imunológica e inflamatória por ele desencadeada na tentativa, pelo hospedeiro, de neutralizar/destruir esses agentes agressores de origem bacteriana (Burgner e Harnden, 2005; Benarafa et al., 2007; Forthal et al., 2007; Helewski et al., 2007; Van Bodegom et al., 2007; Rashid e Ebringer, 2007).

A defesa do organismo contra patógenos se dá por meio da resposta imune inata e adaptativa (Miyake, 2004). Essa ativação da resposta do hospedeiro ocorre por meio de Receptores de Reconhecimento Padrão (PRRs), os quais são expressos em diferentes compartimentos celulares, reconhecendo patógenos intra e extracelulares. Os PRRs identificam os Padrões Moleculares Associados aos Patógenos (PAMPs), porções antigênicas estruturalmente conservadas que estão presentes tanto na superfície quanto na estrutura que compõe os patógenos (Hedayat et al., 2012). Até o momento, foram identificadas três classes de PRRs, dentre as quais destaca-se os receptores Toll-Like (TLRs) (Hirao et al., 
2009; Kawai e Akira, 2009), considerados como PRRs efetivos no reconhecimento precoce dos patógenos invasores e no desencadeamento da resposta imunológica (Hedayat et al., 2012).

Os TLRs, receptores transmembrana tipo I, são assim denominados devido à sua similaridade genética com a proteína Tol/ descrita em drosófilas (Drosophila melanogaster), a qual é essencial para o desenvolvimento dorso-ventral (Medzhitov et al., 1997; Medzhitov, 2001; Underhill e Ozinsky, 2002) e defesa (Lemaitre et al., 1997) desses insetos. Foram identificados 13 tipos de TLRs em camundongos e 11 em humanos (Miggin e O'Neill, 2006; Kawai e Akira, 2009), os quais podem ser classificados de acordo com os tipos de ligantes que reconhecem, sendo que a maioria dos TLRs é expressa na superfície celular (TLRs 1, 2, $4,5,6$, e 11) e os demais (TLRs 3, 7, 8 e 9) são expressos em vesículas intracelulares, tais como os endossomos ou lisossomos e o retículo endoplasmático (Takeda e Akira, 2005; Kawai e Akira, 2009). Esses receptores estão fortemente expressos em múltiplos tipos celulares associados às infecções de origem endodôntica como monócitos/macrófagos, granulócitos, fibroblastos pulpares, precursores de osteoclastos e células mesenquimais (BarShavit, 2008; Hirao et al., 2009).

Os TLRs são compostos por um domínio extracelular (extracellular $N$-terminal domain), formado por uma cadeia rica em leucina (domínio LRR), e outro intracelular (intracellular C-terminal domain) semelhante ao receptor para a IL-1 (IL-1R) denominado Toll/receptor IL-1 (TIR) (Akira e Takeda, 2004). O domínio extracelular está envolvido no reconhecimento do micro-organismo, transdução do sinal e dimerização do receptor (Kobe e Kajava, 2001), enquanto que o domínio intracelular tem a função de mediar interações proteína-proteína entre os TLRs e os componentes de transdução do sinal (Jiang et al., 2003; Armant e Fenton, 2002).

Como exemplo de ligantes dos receptores TLRs derivados de patógenos destacam-se os lipopeptídeos bacterianos, que estimulam o TLR1 e o TLR6 (Takeuchi et al., 2001; Takeuchi et al., 2002; Takeda e Akira, 2005); a flagelina bacteriana, que ativa o TLR5 (Hayashi et al., 2001); a molécula profilin-like do protozoário Toxoplasma gondii, que ativa o TLR11 (Yarovinsky et al., 2005); porções CpG não metiladas (bactérias e vírus) presentes no DNA que estimulam o TLR9 (Hemmi et al., 2000); RNA de dupla fita que ativa o TLR3 (Alexopoulou et al., 2001); RNA de fita simples (vírus) que pode estimular o TLR7 e o TLR8 (Heil et al., 2004); o lípide A, componente do LPS de bactérias Gram-negativas, o qual estimula o TLR4 (Poltorak et al., 1998; Takeda e Akira, 2005), além de lipoproteínas/lipopeptídeos de vários patógenos, peptidoglicanos e ácido lipoteicóico de bactérias Gram-positivas que estimulam o TLR2, o qual também participa da transdução de 
sinais a partir da estimulação via LPS bacteriano por meio da ligação com a molécula auxiliar myeloid differentiation protein-2 (MD-2) (Schwandner et al., 1999; Aliprantis et al., 1999; Dziarski e Gupta, 2000; Takeda e Akira, 2005). Devido a uma inserção de retrovírus, o TLR10 não é funcional em camundongos, e os TLR11, 12 e 13 não apresentam função definida no genoma humano (Kawai e Akira, 2009).

Dentre os TLRs descritos, considerando a etiopatogenia das lesões periapicais, destaca-se a participação dos receptores TLR2 e TLR4, os quais têm demonstrado envolvimento nas respostas ao LPS bacteriano, conduzindo à expressão de citocinas próinflamatórias, como IL-1, TNF-a, IL-6 e IL-8 (Kirschning et al., 1998; Hoshino et al., 1999).

As vias de sinalização intracelulares ativadas por TRLs têm muito em comum com a sinalização do receptor da IL-1 (IL-1R), devido aos seus domínios "TIR" (homologia ao Toll/IL-1R). A ativação dos TLRs induz o recrutamento de proteínas específicas ou moléculas adaptadoras (adaptor proteins), como a myeloid differentiation primary response gene 88 (MyD88), que também apresenta um domínio TIR (Akira e Takeda, 2004; Kawai e Akira, 2006; Fornarino et al., 2011). Essas proteínas são responsáveis pela transdução do sinal do TIR, por meio da ativação de quinases da família IRAK, da degradação do IK-B e translocação do nuclear factor kappa-B (NF-кB) ao núcleo (Underhill e Ozinsky, 2002; Takeda e Akira, 2004).

A estimulação dos TLRs por componentes microbianos desencadeia, por meio de diferentes vias de sinalização, a expressão de genes envolvidos na resposta imune. A proteína adaptadora MyD88 é essencial para respostas contra uma ampla variedade de micro-organismos e participa da ativação de todos os TLRs, exceto do TLR3. A sinalização mediada por TLR4 em resposta ao LPS ocorre tanto pela via dependente quanto pela via independente da MyD88, ao passo que a sinalização por meio dos demais receptores TLRs é completamente dependente desta molécula (Beutler et al., 2003; Takeda e Akira, 2005; Gomes et al., 2012).

A via de sinalização dependente de MyD88, essencial para a indução da liberação de citocinas e quimiocinas pró-inflamatórias, está associada à porção TIR dos TLRs e promove o recrutamento da $I L-1 R$ associated kinase-4 (IRAK-4) e facilita a fosforilação da IRAK-1 que, ativada, associa-se ao TNFR-associated factor 6 (TRAF6), levando à ativação de duas vias distintas de sinalização (Takeda e Akira, 2004). A primeira via leva à ativação de fatores de transcrição activator protein-1 (AP-1) por meio da ativação de mitogen-activated protein kinases (MAPK), enquanto a segunda ativa o complexo transforming growth factor $\beta$ activated kinase 1/ TAK1-binding protein (TAK1/TAB), que potencializa a atividade do complexo IKB kinase (IKK), o qual induz a fosforilação e subsequente degradação de 
inhibitor of $\kappa B(\mathrm{IKB})$, causando a translocação nuclear do fator de transcrição NF-KB e sua ligação em regiões-alvo do DNA. Estes fatores de transcrição, NF-KB e AP-1 induzem a expressão de mediadores bioquímicos importantes, como citocinas pró-inflamatórias, quimiocinas, moléculas de adesão, além de moléculas coestimuladoras e espécies reativas de oxigênio. Paralelamente, a procura por moléculas estruturalmente relacionadas com a MyD88 levou à identificação de uma segunda porção do TIR que contém a molécula TIR domain-containing adaptor protein (TIRAP) ou MyD88-adaptor-like (Mal), que é essencial para a sinalização dependente de MyD88 via TLR2 e TLR4 (Lye et al., 2004; Takeda e Akira, 2005).

Segundo Kawai et al. (1999), em macrófagos deficientes de MyD88 não foi observada a produção de citocinas pró-inflamatórias após estimulação via TLR4. Entretanto, houve uma ativação retardada de NF-kB. Esse fato indicou que, apesar da produção de citocinas inflamatórias mediadas por TLR4 necessitar da via dependente de MyD88, existe um componente independente de tal via.

Desta forma, identificou-se uma terceira porção do TIR contendo a molécula TIR domain-containing adaptor inducing IFN- $\beta$ (TRIF ou TICAM-1), que demonstrou ser essencial para a sinalização independente de MyD88 mediada pelos receptores TLR3 e TLR4. A quarta porção identificada foi denominada TRIF-related adaptor molecules (TRAM ou TICAM-2) e mostrou ser essencial para a sinalização independente de MyD88/dependente de TRIF mediada pelo TLR4. A quinta proteína adaptadora, sterile- $a$ and armadillo-motif-containing protein (SARM), parece atuar como reguladora negativa da sinalização via TRIF (Takeda e Akira, 2005; Doyle e O’Neill, 2006; O’Neill e Bowie, 2007). A cascata de sinalização independente da proteína MyD88 envolve a ativação do fator de transcrição INF regulatory factor-3 (IRF-3) com consequente estimulação de inteferon- $\beta$ (INF- $\beta$ ). Em seguida, INF- $\beta$ leva à ativação de signal transducer and activator of transcription 1 (Stat 1) e, posteriormente, à ativação de genes induzíveis por INF, como o INF-inducible protein 10 (IP10) e inducible NO synthase (iNOS) (Bautler et al., 2003). Foi demonstrado que, nesta via de sinalização, o fator IRF-3 desempenha papel fundamental e encontra-se associado com IKB kinases (IKKs), as quais fosforilam IKBa, conduzindo à ativação de NF-KB (Takeda e Akira, 2004).

Estudos estabeleceram claramente que moléculas adaptadoras contendo domínio TIR são altamente específicas para vias individuais de sinalização mediadas por TLRs. Animais knockout para TRIF apresentaram a via MyD88-independente inibida e exibiram incapacidade na produção de citocinas pró-inflamatórias mediada por TLR4, embora a via MyD88-dependente tenha sido ativada, uma vez que a fosforilação da IRAK-1 e a fase inicial 
de ativação do NF- KB não foram prejudicadas. Sugere-se, dessa forma, que a sinalização por meio do receptor TLR4 requer a ativação das vias dependente e independente da MyD88, para induzir a liberação de mediadores inflamatórios (Takeda e Akira, 2004).

O reconhecimento dos micro-organismos, seus componentes e subprodutos pelos TLRs gera a produção de citocinas pró-inflamatórias e moléculas coestimuladoras, responsáveis pelos eventos imunoinflamatórios desencadeados subsequentemente (Takeda e Akira, 2005). Dentre essas citocinas, destacam-se a IL-1, o TNF-a e a IL-6, que estão associadas com o aumento da produção de receptor activator of nuclear factor kappa-B ligand (RANKL), com o estímulo da osteoclastogênese e consequente reabsorção óssea (BarShavit, 2008; Hirao et al., 2009).

Com relação aos receptores TLR2, sabe-se que esses reconhecem uma variedade de componentes microbianos, dentre os quais destacam-se lipoproteínas/lipopeptídeos de diferentes patógenos, peptidoglicanos e ácido lipoteicóico de bactérias Gram-positivas (Takeuchi et al., 2001; Takeuchi et al., 2002; Takeda e Akira, 2005). Além disso, participam da transdução de sinais a partir da estimulação via LPS bacteriano por meio da interação com a molécula auxiliar MD-2 (Dziarski e Gupta, 2000). Já o TLR4 é considerado o membro da família de TLRs caracterizado como receptor do LPS bacteriano (Underhill e Ozinsky, 2002). O envolvimento tanto de bactérias Gram-negativas quanto de Gram-positivas é de fundamental importância na etiologia de lesão periapical (Jiang et al., 2003), ressaltando o relevante papel do TLR2 e do TLR4 nesse processo. Esses receptores são expressos abundantemente em leucócitos e diferentes células inflamatórias, participando da resposta imune frente a diversos estímulos por meio do aumento da expressão de NF-kB (Akira et al., 2006; Beutler, 2009). Estudos demonstram que neutrófilos (Hayashi et al., 2003; Nilsen et al., 2004), mastócitos (McCurdy et al., 2003), monócitos, macrófagos (Underhill et al., 1999, Nilsen et al., 2004), células T (Komai-Koma et al., 2004), células T reguladoras (Liu et al., 2006) e células B (Vasilevsky et al., 2008) também expressam esses receptores. Além disso, são expressos em fibroblastos pulpares, precursores de osteoclastos e células mesenquimais (Hirao et al., 2009).

Recentemente, da Silva et al. (2012) realizaram um estudo com o objetivo de avaliar a formação e progressão de lesões periapicais induzidas experimentalmente em camundongos knockout para TLR2. Foi demonstrado que a ausência deste receptor ocasionou a formação de lesões periapicais mais extensas e com maior número de osteoclastos, em comparação com camundongos wild-type (WT), indicando a participação do TLR2 durante a resposta imunoinflamatória desencadeada para combater a infecção do sistema de canais radiculares e dos tecidos periapicais. Os autores sugeriram que o 
silenciamento do TLR2, o qual está fortemente relacionado com o reconhecimento de patógenos Gram-positivos e seus subprodutos, levou à ativação mais intensa dos outros TLRs, particularmente do TLR4, cuja atuação pode ter exacerbado os efeitos deletétios do LPS bacteriano.

No entanto, até o momento não há estudos avaliando o efeito da inibição da molécula adaptora MyD88 dos receptores TLRs na formação e progressão de lesões periapicais.

Paralelamente, os progressos mais recentes nas técnicas de biologia molecular, como a produção de animais transgênicos, têm possibilitado o estudo da imunopatogenia das doenças em nível molecular. Uma variação da tecnologia dos animais transgênicos é o knockout do gene de interesse, ou seja, a interrupção na expressão gênica. Os experimentos de manipulação genética em camundongos constituem estratégia promissora na pesquisa biológica e importante ferramenta para elucidar os mecanismos moleculares das doenças, buscando encontrar novos caminhos para o desenvolvimento de aplicações de potencial utilização diagnóstica ou terapêutica (De Rossi, 2008).

Pelo exposto, justifica-se a necessidade de realização de estudos comparando animais que expressam o gene para a MyD88 (wild-type) e animais transgênicos (knockout), que não apresentam a MyD88, a fim de elucidar a participação dessa molécula na formação e progressão das lesões periapicais. 

Proposição 



\section{Proposição}

Objetivo geral:

O objetivo deste estudo será caracterizar o desenvolvimento de lesões periapicais induzidas experimentalmente em dentes de camundongos knockout para a molécula adaptadora myeloid differentiation primary response gene 88 (MyD88), comparados a animais wild-type (WT).

Objetivos específicos:

- Descrever as características do canal radicular e das regiões apical e periapical e efetuar a contagem do número de células inflamatórias (neutrófilos), em microscopia de luz convencional;

- Mensurar a extensão da área microscópica correspondente às lesões periapicais por microscopia de fluorescência;

- Realizar a histoenzimologia para a marcação e contagem de osteoclastos (TRAP);

- Avaliar a presença e localização de bactérias pela coloração de Brown \& Brenn; e

- Realizar a técnica de imunohistoquímica para a identificação de marcadores da osteoclastogênese (RANK, RANKL e OPG). 

Material e Métodos 



\section{Material e Métodos}

Inicialmente, o presente projeto de pesquisa foi submetido à apreciação pela Comissão de Ética no Uso de Animais da Universidade de São Paulo (USP) - Campus de Ribeirão Preto, tendo sido aprovado (Processo n 11.1.91.53.0).

\section{Animais}

Foram utilizados 30 camundongos wild-type (WT) da linhagem C57BL/6, machos, de 6 a 8 semanas de idade, pesando em média 20 gramas, adquiridos do Biotério Central da Universidade de São Paulo - Campus de Ribeirão Preto e 30 camundongos knockout para a MyD88 (MyD88 KO) da linhagem C57BL/6, fornecidos pelo Biotério de Genética da Faculdade de Medicina de Ribeirão Preto - USP e provenientes do The Jackson Laboratory (Bar Harbor, Maine, EUA). Todos os animais foram mantidos no biotério da Faculdade de Odontologia de Ribeirão Preto - USP, alocados em gaiolas de polipropileno com tampas de aço inoxidável perfurado, de $15 \times 20 \mathrm{~cm}$ (4 a 6 animais por gaiola), forradas com cama de maravalha autoclavada, em temperatura $\left(22 \pm 2^{\circ} \mathrm{C}\right)$ e umidade relativa do ar $(55 \pm 10 \%)$ constantes, em um ciclo de claro-escuro de 12:12 horas, com dieta padrão de laboratório e livre acesso à água autoclavada.

\section{Indução das lesões periapicais}

Para a realização dos procedimentos operatórios, os animais foram anestesiados com cloridrato de quetamina (Ketamina 10\%, Agener União Química Farmacêutica Nacional S/A, Embu-Guaçu, SP) na dosagem de $150 \mathrm{mg} / \mathrm{Kg}$ de peso, e xilazina a $2 \%$ (Dopaser, Laboratórios Calier, SA, Barcelona, Espanha) na dosagem de 7,5mg/Kg de peso, via intramuscular. Em seguida, os animais foram devidamente posicionados em mesa cirúrgica específica para a realização de procedimentos odontológicos, permitindo a manutenção da abertura da boca, para acesso aos molares inferiores (Figura 1). 

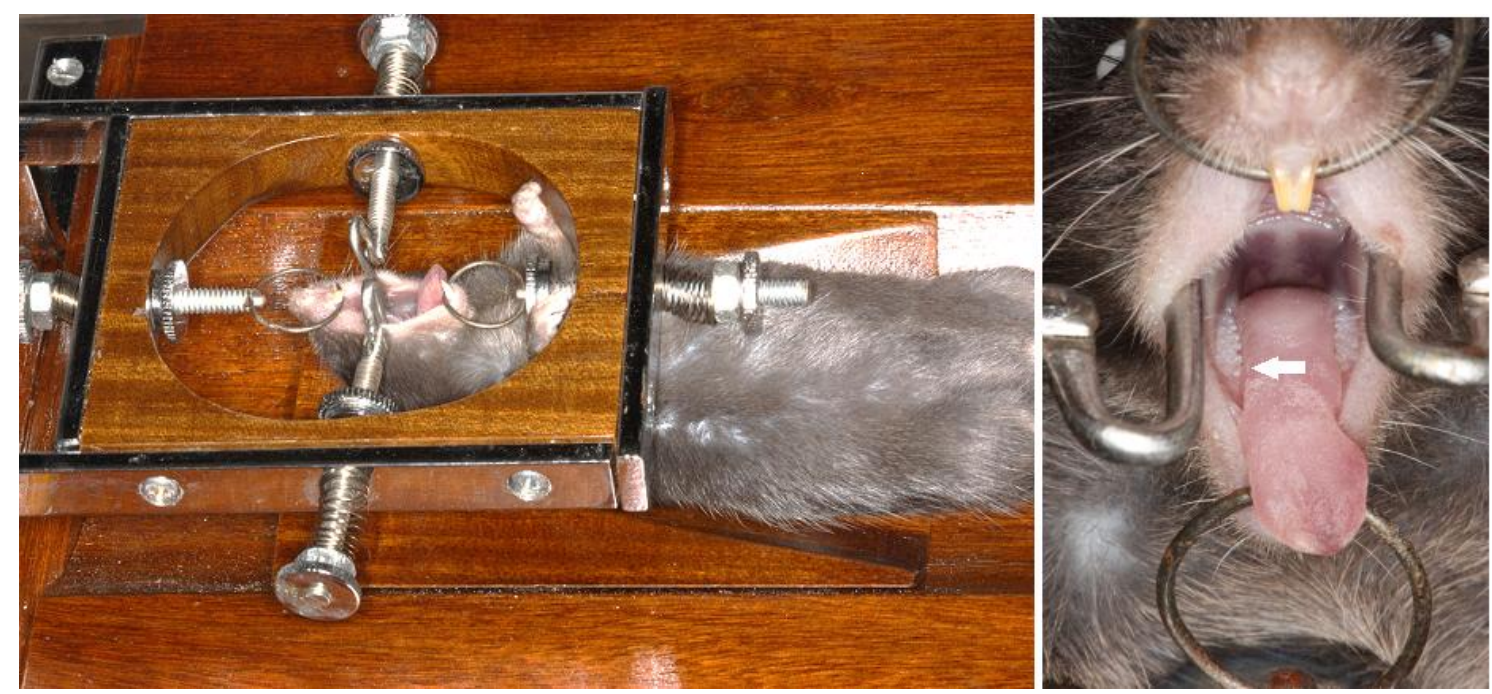

Figura 1. Mesa cirúrgica especificamente confeccionada para a realização de procedimentos odontológicos em dentes de camundongos. A seta indica o molar selecionado para a abertura coronária, exposição pulpar e indução da lesão periapical.

A indução das lesões periapicais foi realizada nos primeiros molares inferiores, totalizando 60 dentes para cada grupo de animais. Inicialmente, a abertura coronária foi realizada pela face oclusal, com broca esférica de aço inoxidável (n० 1/4 - GDK Densell Dental Technology, Buenos Aires, Argentina), montada em motor de baixa rotação e contra-ângulo (Dabi Atlante Equipamentos Odontológicos, Ribeirão Preto, SP). A seguir, os canais radiculares foram localizados com uma lima do tipo K número 08 (Les Fils d'Auguste Maillefer S/A, Suíça) esterilizada e foram deixados expostos ao meio ambiente bucal (Fouad, 1997; Huang et al., 2001, De Rossi et al., 2008; Alshwaimi et al., 2009; Xiong et al., 2010; Wang et al., 2011; Ferreira, 2011; da Silva et al., 2012).

Após os períodos experimentais de 7, 21 e 42 dias, os animais foram aleatoriamente submetidos à eutanásia em câmara de $\mathrm{CO}_{2}$, de acordo com os grupos apresentados na Tabela 1.

Tabela 1. Distribuição dos grupos experimentais

\begin{tabular}{ccc} 
Período & WT & MyD88 KO \\
\hline 7 dias & 10 animais (20 dentes) & 10 animais (20 dentes) \\
\hline 21 dias & 10 animais (20 dentes) & 10 animais (20 dentes) \\
\hline 42 dias & 10 animais (20 dentes) & 10 animais (20 dentes) \\
\hline
\end{tabular}




\section{Processamento histotécnico e avaliação microscópica}

Após a morte dos animais, as mandíbulas foram removidas com tesoura cirúrgica esterilizada, fixadas por imersão em formol tamponado a $10 \%$ por 24 horas à temperatura ambiente e, em seguida, lavadas por, aproximadamente, 4 horas em água corrente. Para descalcificação das peças, foi utilizada solução à base de EDTA a 4,13\% (pH 7,4) (Warshawsky \& Moore, 1967). As peças foram mantidas nesta solução, à temperatura ambiente, trocada semanalmente, até sua completa descalcificação, que ocorreu, aproximadamente, após 30 dias. O grau de descalcificação das estruturas mineralizadas foi testado por meio da penetração de uma agulha nos tecidos, para verificação da sua consistência. Após a descalcificação, as peças foram submetidas ao processamento histotécnico de rotina, sendo lavadas em água corrente por 2 horas, desidratadas em álcool de concentrações crescentes (70\% e 95\% por 30 minutos cada; 2 trocas de $100 \%$ por 20 minutos cada; e 2 trocas de álcool $100 \%$ por 40 minutos cada) e diafanizadas em xilol (2 banhos de 20 minutos e 1 de 40 minutos). Em seguida as peças foram incluídas em parafina, para confecção dos blocos, os quais foram armazenados em congelador. Os blocos contendo os dentes foram cortados longitudinalmente em micrótomo (Leica RM2145; Leica Microsystems GmbH, Wetzlar, Alemanha) no sentido mésio-distal. Cortes semi-seriados de $5 \mu \mathrm{m}$, com intervalos de $15 \mu \mathrm{m}$, foram obtidos em toda a extensão da lesão periapical, exceto na região do forame apical, onde todos os cortes foram coletados sem intervalos. A Figura 2 esquematiza as etapas de indução da lesão periapical e do processamento histotécnico. 


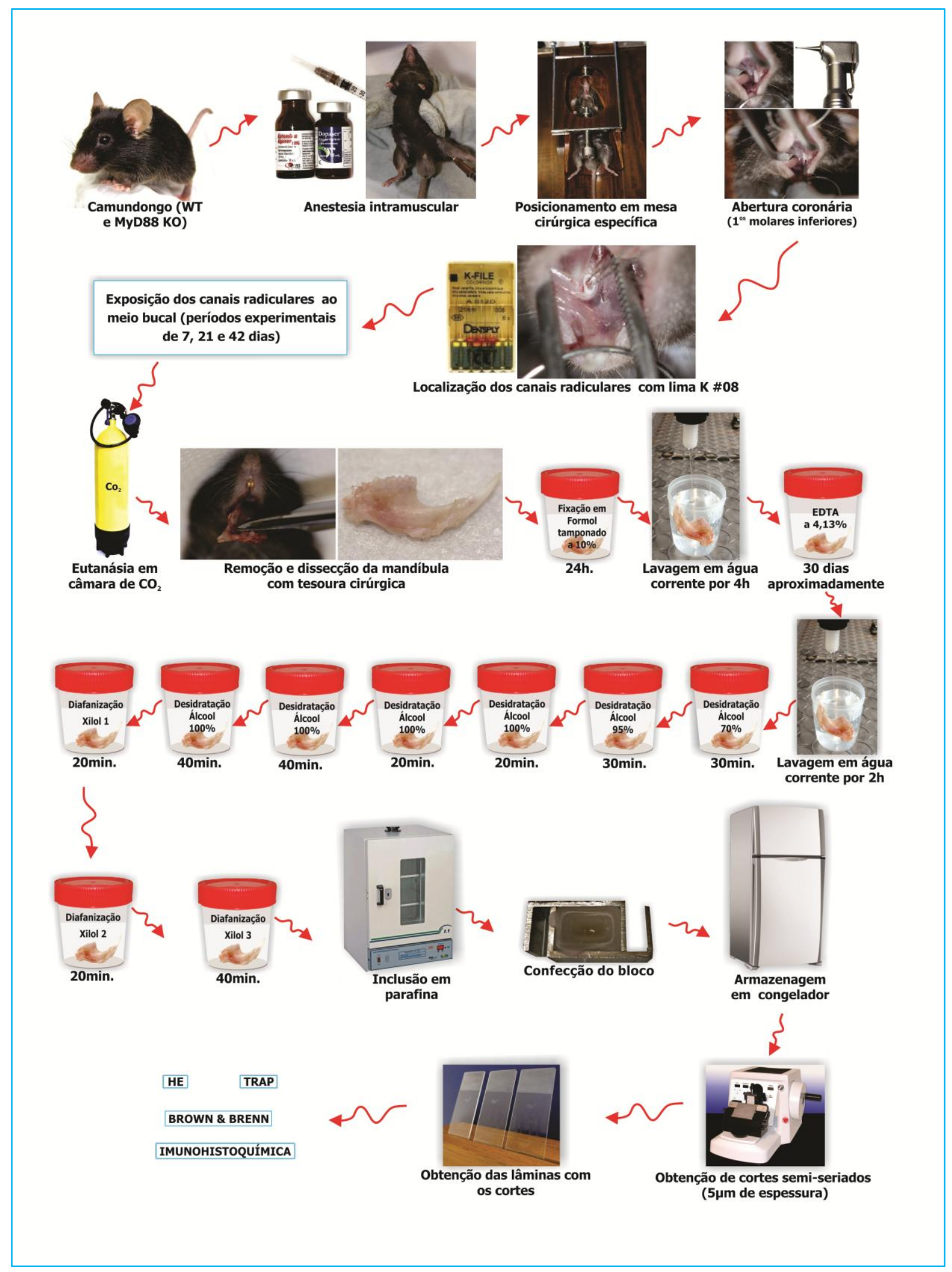

Figura 2. Fluxograma ilustrando as etapas de indução da lesão periapical e do processamento histotécnico. Imagem adaptada de Ferreira (2011). 
Inicialmente, os cortes de cada grupo experimental foram corados com hematoxilina e eosina (HE), como ilustrado na Figura 3, e foram submetidos à análise em microscopia de luz, para descrição do canal radicular e das regiões apical e periapical e para contagem do número de células inflamatórias (neutrófilos). Paralelamente, foi realizada a análise morfométrica da extensão da área das lesões periapicais, em microscopia de fluorescência. Em seguida, espécimes sequenciais foram avaliados por meio de histoenzimologia para a atividade da TRAP, para identificação e contagem de osteoclastos; Brown \& Brenn, para identificar a presença e localização de bactérias; e imunohistoquímica para a identificação de marcadores da osteoclastogênese (RANK, RANKL e OPG). Todas as análises foram realizadas no microscópio Axio Imager.M1 (Carl Zeiss MicroImaging GmbH, Göttingen, Alemanha), com câmera AxioCam MRc5 acoplada (Carl Zeiss MicroImaging GmbH, Göttingen, Alemanha). As análises foram realizadas apenas nas raízes distais dos primeiros molares inferiores, em cortes mostrando simultaneamente os terços coronário, médio e apical do canal radicular, o forame apical e o osso alveolar. Todas as análises foram realizadas por um único avaliador experiente, sem conhecimento prévio do grupo que estava sendo analisado.

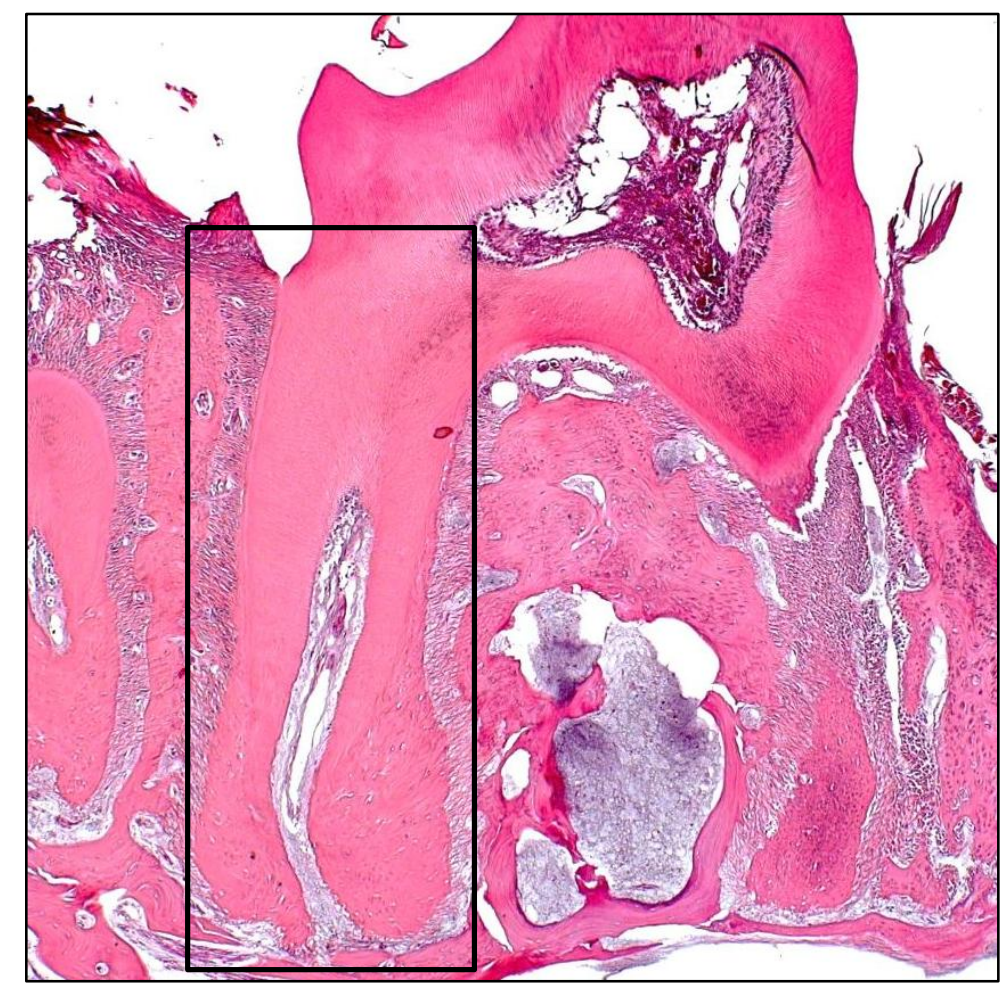

Figura 3. Fotomicrografia representativa da raiz distal de um $1^{\circ}$ molar inferior hígido corado com HE. 


\section{Análise microscópica descritiva das características do canal radicular e das regiões apical e periapical}

A análise descritiva do canal radicular e das regiões apical e periapical foi realizada nos cortes representativos de cada período e de cada grupo experimental, de acordo com os seguintes parâmetros (Silva et al., 2010; da Silva et al., 2012):

- Canal radicular: necrose (total ou parcial);

- Cemento apical: características da superfície (regular ou irregular);

- Ligamento periodontal: extensão (normal ou aumentado), característica do infiltrado celular inflamatório, presença de edema e de fibras colágenas;

- Osso alveolar: ausência/presença de reabsorção e de osteoblastos e osteoclastos.

\section{Morfometria em microscopia de fluorescência}

A avaliação morfométrica da extensão da área das lesões periapicais foi realizada nos espécimes corados com HE utilizando o microscópio Axio Imager.M1, em aumento de 10x, operando no modo fluorescente, conforme descrito por De Rossi et al. (2007). Foi utilizado filtro Alexa Fluor 488 (AF488) com as seguintes características: excitação de G365, refletores FT395 e emissão LP420. Para cada espécime, a extensão (área) da lesão periapical foi delineada e mensurada em $\mu \mathrm{m}^{2}$, empregando o software Axio Vision Rel 4.8. A delimitação da lesão excluiu as estruturas intactas (ligamento periodontal, cemento e osso alveolar), facilmente identificadas pela forte fluorescência verde, e incluiu áreas de reabsorção e infiltrado inflamatório, identificadas pela ausência de fluorescência e aparência escurecida.

\section{Contagem de células inflamatórias (neutrófilos)}

Em seguida, nos mesmos cortes, em microscopia de luz, foi realizada a contagem do número de neutrófilos, com base em suas características morfológicas, presentes na região mediana da lesão adjacente ao forame apical, em uma área de aproximadamente $0,08 \mathrm{~mm}^{2}$, de acordo com De Rossi et al. (2008) e da Silva et al. (2012). Os resultados foram expressos em número de células.

\section{Histoenzimologia para a atividade da fosfatase ácida resistente ao tartarato (TRAP)}

A atividade da TRAP foi utilizada para a marcação e contagem de osteoclastos (Minkin, 1982). Os cortes foram desparafinizados ( 2 banhos de xilol de 5 minutos cada) e 
hidratados (álcool 100\% por 2 vezes de 5 minutos cada; alcoóis 95\%, 70\% e 50\% por 2 minutos cada e água destilada pelo mesmo período). A seguir, as lâminas foram colocadas em solução de álcool/acetona a $50 \%$ durante 1 minuto e os cortes foram secos à temperatura ambiente. Em seguida, a solução contendo $10 \mathrm{~mL}$ de tampão de ácido acético, 0,1 $\mathrm{mL}$ de dimetilformamida, $5 \mathrm{mg}$ de Fast-red e $1 \mathrm{mg}$ de ácido fosfórico naftol AS-BI (kit Fosfatase ácida, leucócitos; Sigma-Aldrich Corporation, Saint Louis, EUA) foi pipetada sobre os cortes, que foram mantidos protegidos da luz em estufa a $37^{\circ} \mathrm{C}$ por, aproximadamente, 40 minutos. Após a incubação, foi realizada a contra-coloração com Fast-green por 1 minuto. A seguir, as lâminas foram montadas e avaliadas no microscópio Axio Imager.M1 sob luz convencional, para contagem do número de células TRAP-positivas presentes nas lacunas de reabsorção, em contato direto com o osso alveolar ao redor da lesão periapical. Os resultados foram expressos em número de células, de acordo com da Silva et al. (2012).

\section{Coloração de Brown \& Brenn Modificada}

Inicialmente, os cortes foram desparafinizados (3 banhos de xilol de 8 minutos cada), hidratados (banhos com alcoóis a 100\%, 95\% e 80\%), lavados em água corrente por, aproximadamente, 3 minutos, e colocados em um recipiente com água destilada. A solução de violeta cristal $1 \%$ tamponada com bicarbonato de sódio a $5 \%$ foi aplicada sobre os cortes por 30 segundos e, em seguida, as lâminas foram lavadas em água destilada. A seguir, as lâminas foram mergulhadas em solução de iodo de Gram por 1 minuto e lavadas em água destilada. Após a remoção do excesso de água destilada com papel absorvente, as lâminas passaram por uma solução de éter-acetona (proporção 1:1) para remoção do excesso de corantes, e, novamente, foram lavadas em água destilada. Em seguida, as lâminas foram colocadas em fucsina básica, durante 1 minuto, lavadas em água destilada, colocadas em ácido pícrico aquoso, por 1 minuto, lavadas e secas com papel absorvente. Posteriormente, as lâminas foram mergulhadas em solução de acetona P.A., para remoção do excesso de corantes, e em solução de acetona-xilol. A seguir, foi realizada a diafanização, a desidratação e montagem das lâminas com lamínula e entellan (Brown e Brenn, 1931; Taylor, 1966).

Essa coloração foi utilizada para avaliar a presença ou ausência de bactérias e sua localização na coroa do dente, no sistema de canais radiculares e nos tecidos periapicais (cemento, ligamento periodontal e osso alveolar) (Chen et al., 1999). Para esta avaliação foram atribuídos escores de 0 a 5 (De Rossi, 2008; da Silva et al., 2012), como descrito a seguir:

- Escore 0: Ausência de bactérias;

- Escore 1: Presença de bactérias na coroa dental; 
- Escore 2: Presença de bactérias no terço cervical do canal radicular;

- Escore 3: Presença de bactérias no terço médio do canal radicular;

- Escore 4: Presença de bactérias no terço apical do canal radicular;

- Escore 5: Presença de bactérias na lesão periapical.

\section{Imunomarcação (Imunohistoquímica)}

As reações foram realizadas utilizando o método do complexo avidina-biotinaperoxidase (método indireto). Os cortes histológicos foram desparafinizados e hidratados de forma rotineira. A recuperação antigênica foi realizada com calor utilizando tampão citrato $(\mathrm{pH}=6,0)$ no forno de microondas (2 vezes de 10 segundos). Após retorno à temperatura ambiente, as lâminas foram lavadas 2 vezes por 5 minutos com PBS e 1 vez com solução PBS/Triton (Sigma-Aldrich Corporation, Saint Louis, EUA) a 0,5\%, também por 5 minutos. 0 bloqueio da peroxidase endógena foi realizado com peróxido de hidrogênio a 3\% por 20 minutos, sob proteção da luz. A seguir, as lâminas foram novamente lavadas com PBS e PBS/Triton conforme descrito anteriormente. O bloqueio das ligações inespecíficas foi realizado com solução de BSA a 1\% (albumina de soro bovino)/PBS por 30 minutos. A seguir, as lâminas foram incubadas overnight em refrigerador com os anticorpos primários diluídos em BSA a 1\%: anti-RANK (polyclonal rabbit antibody H300 sc:9072; Santa Cruz Biotechnology Inc.; diluído 1:700), anti-RANKL (polyclonal goat antibody n-19 sc:7628; Santa Cruz Biotechnology Inc.; diluído 1:400) e anti-OPG (polyclonal goat antibody n-20 sc:8468; Santa Cruz Biotechnology Inc.; diluído 1:700). Após retornarem à temperatura ambiente, as lâminas foram lavadas com PBS e incubadas com anticorpo secundário biotinilado (goat anti-rabbit IgG-B sc-2040 e rabbit anti-goat IgG-B sc-2774; Santa Cruz Biotechnology Inc., diluídos 1:200), por 1 hora à temperatura ambiente. Após nova lavagem, foi colocado o complexo avidina-biotina-peroxidase (ABC kit, Vecstain; Vector Laboratories Inc.) por 30 minutos. A seguir, as lâminas foram novamente lavadas com PBS e PBS/Triton e foi efetuada a revelação da reação com solução de diaminobenzidina (DAB; Sigma-Aldrich Corporation, Saint Louis, EUA) e $\mathrm{H}_{2} \mathrm{O}_{2}$ a $3 \%$ em PBS, por 1 minuto. As lâminas foram contracoradas com Hematoxilina de Harris por 10 segundos, lavadas em água corrente, lavadas em água amoniacal por 30 segundos, lavadas em água corrente, diafanizadas, desidratadas e montadas. A identificação de marcadores da osteoclastogênese (RANK, RANKL e OPG) foi realizada em microscópio Axio Imager.M1 sob luz convencional. Os resultados foram expressos de maneira qualitativa, levando-se em consideração a presença/ausência e a localização das marcações, como descrito por da Silva et al. (2012). 


\section{Análise Estatística}

A comparação da extensão da área das lesões periapicais, do número de células inflamatórias e de osteoclastos entre os períodos do mesmo grupo de animais (WT e MyD88 KO) foi efetuada pelo teste não-paramétrico de Kruskal-Wallis e pós-teste de Dunn. A comparação entre os mesmos períodos nos diferentes grupos de animais (WT e MyD88 KO) foi realizada por meio do teste não-paramétrico de Mann-Whitney. Os dados foram analisados por meio do programa SPSS (Statistical Package Social Sciences) versão 17.0, com nível de significância de 5\%. 

Resultados 



\section{Resultados}

\section{Análise microscópica descritiva das características do canal radicular e das regiões apical e periapical}

Nos animais WT, 7 dias após a indução das lesões periapicais, havia necrose total do tecido pulpar. O ligamento periodontal apresentava-se suavemente aumentado, com presença eventual de células inflamatórias, predominantemente mononucleadas. A superfície cementária estava regular e com ausência de áreas de reabsorção. $O$ osso alveolar apresentava-se normal e com osteoblastos em sua superfície. A mediana da extensão da lesão neste período foi de $60.842,5 \mu^{2}$ (Figura 4 - A e B). No período de 21 dias, o tecido pulpar apresentava-se totalmente necrosado. $O$ cemento radicular apresentava-se com irregularidades na sua superfície. O ligamento periodontal estava aumentado, com extensas áreas de edema e dissociação fibrilar. Havia presença de células inflamatórias, predominantemente mononcleadas, espalhadas por toda a região. O osso alveolar encontrava-se desnudo e com presença de áreas de reabsorção. A mediana da extensão da lesão neste período foi de 74.368,0 $\mu^{2}$ (Figura 4 - E e F). Aos 42 dias, havia necrose total da polpa radicular. $O$ ligamento periodontal estava severamente aumentado, com presença de infiltrado inflamatório denso, predominantemente mononuclear, difuso por toda a região. $\mathrm{O}$ cemento e o osso alveolar apresentavam-se com extensas áreas de reabsorção. A mediana da extensão da lesão neste período foi de 258.088,0 $\mu \mathrm{m}^{2}$ (Figura 4 - I e J).

Com relação aos animais MyD88 KO, a análise descritiva revelou que aos 7 dias, os espécimes também apresentavam necrose total do tecido pulpar. 0 ligamento periodontal estava moderadamente aumentado, com infiltrado inflamatório misto, difuso e com presença considerável de neutrófilos. A superfície cementária apresentava-se regular, enquanto que no osso alveolar havia presença de áreas de reabsorção e ausência de osteoblastos em sua superfície. Além disso, no ligamento periodontal, havia áreas de edema e início de dissociação fibrilar. A mediana da extensão da lesão neste período foi de $123.803,0 \mu \mathrm{m}^{2}$ (Figura 4 - C e D). Aos 21 dias, o tecido pulpar apresentava-se totalmente necrosado. No cemento havia início de áreas de reabsorção, tornando sua superfície ligeiramente irregular. O ligamento periodontal estava aumentado, com áreas de edema e dissociação das fibras colágenas. Havia presença de infiltrado inflamatório misto, com células porlimorfonucleadas e mononucleadas, com presença considerável de neutrófilos, espalhado por toda a região periapical. O osso alveolar encontrava-se desnudo e com áreas de reabsorção. A mediana da extensão da lesão neste período foi de 153.306,0 $\mu \mathrm{m}^{2}$ (Figura 4 - G e H). No período de 42 
dias, havia necrose total da polpa radicular. O ligamento peridontal apresentava-se severamente aumentado, com dissociação fibrilar e edema. Havia presença de um denso infiltrado celular inflamatório misto, difuso por toda a região, com presença abundante de neutrófilos. O osso alveolar encontrava-se distante do ápice radicular, com ausência de osteoblastos em sua superfície. O cemento radicular estava irregular, devido às áreas de reabsorção e, no osso alveolar, havia intensa atividade reabsortiva, com presença marcante de células clásticas. A mediana da extensão da lesão neste período foi de $467.777,0 \mu \mathrm{m}^{2}$ (Figura 4 - $\mathrm{Ke} \mathrm{L}$ ).

Resumidamente, a análise microscópica descritiva do grupo MyD88 KO revelou um infiltrado inflamatório mais intenso, com presença abundante de células porlimorfonucleadas e mononucleadas e com grande destruição tecidual, comparado aos animais WT, que apresentava um predomínio de mononucleares (Figura 5). 

Figura 4. Fotomicrografias dos cortes microscópicos representativos dos animais WT e MyD88 KO, nos períodos experimentais de 7, 21 e 42 dias, corados com hematoxilina e eosina. Em A, C, E, G, I e K, as imagens foram observadas em microscopia de luz convencional para a análise descritiva do canal radicular e das regiões apical e periapical e para contagem do número de neutrófilos, e em $\mathbf{B}$, D, F, H, J e $\mathbf{L}$, as imagens foram analisadas no modo fluorescente para mensuração da área das lesões periapicais, como delimitado nas figuras. (10X) 


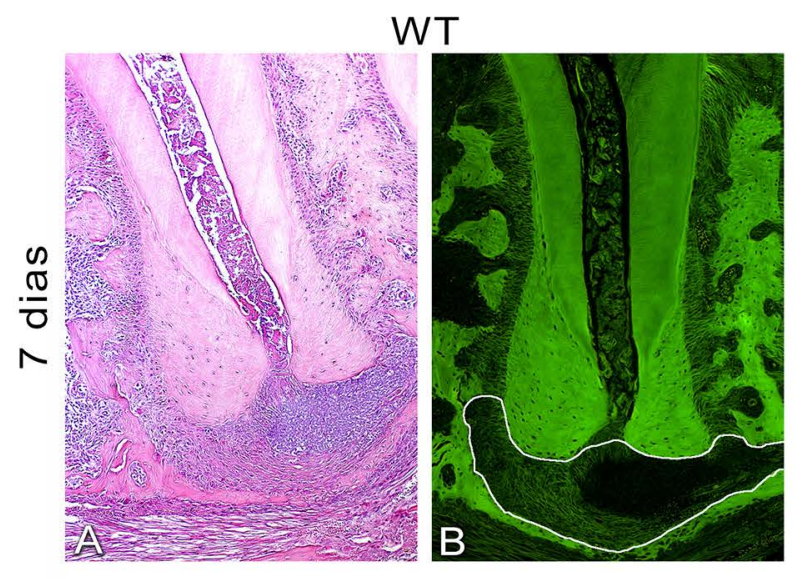

WT
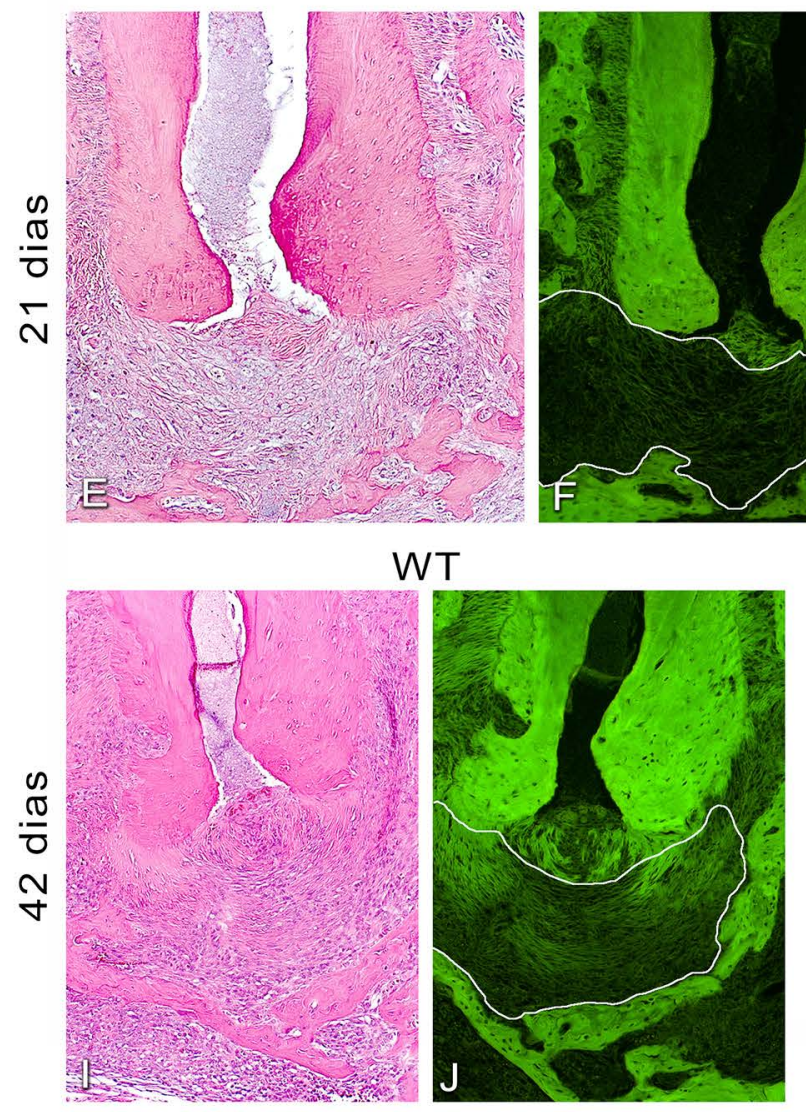

MyD88 KO

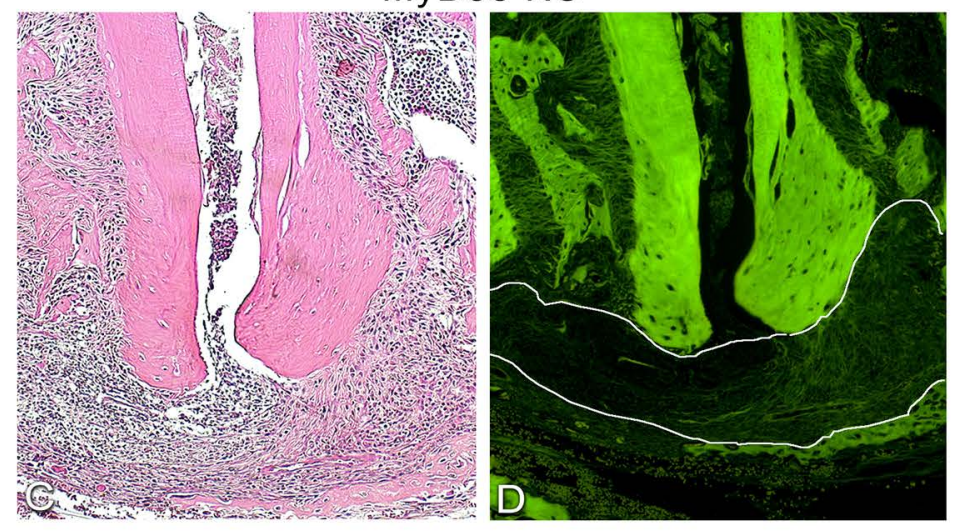

MyD88 KO

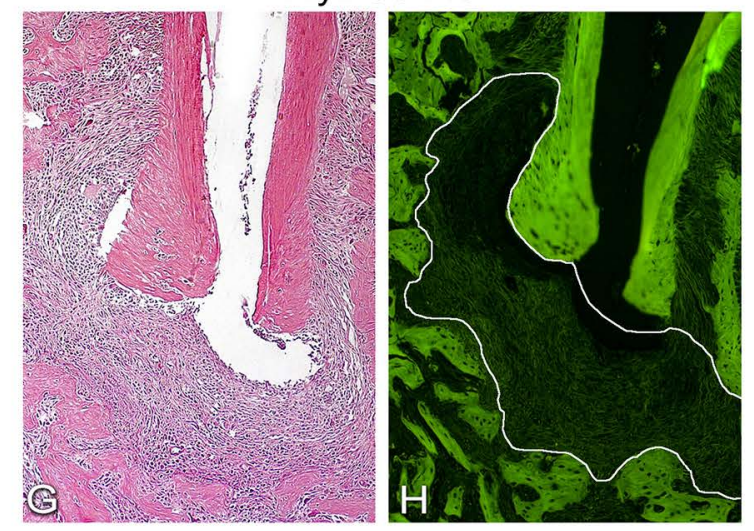

MyD88 KO

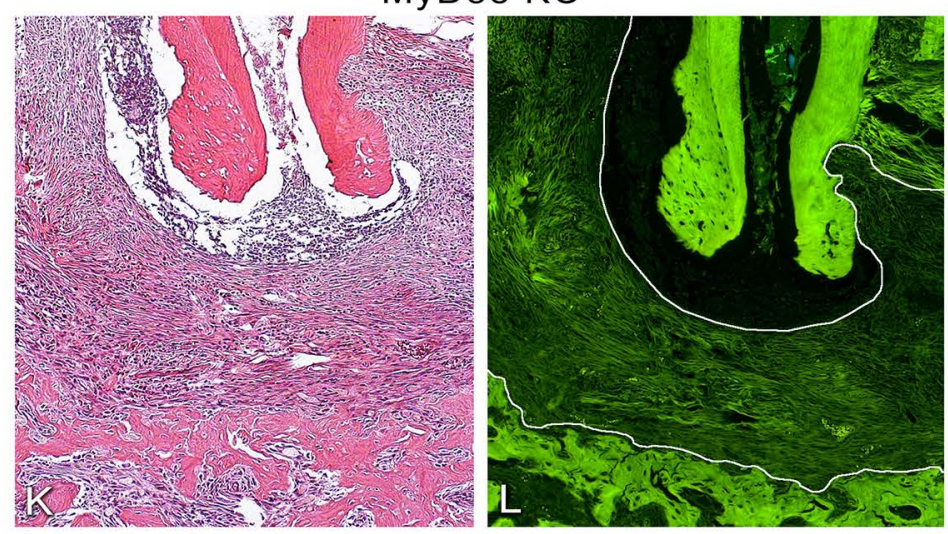




Figura 5. Fotomicrografias representativas dos eventos microscópicos observados durante análise descritiva do canal radicular e das regiões apical e periapical, após indução experimental das lesões periapicais nos animais WT e MyD88 KO, nos diferentes períodos experimentais, em microscopia de luz convencional:

(A) Regiões apical e periapical. Tecido pulpar necrosado (P), ligamento periodontal (LP) severamente aumentado; e osso alveolar ( $O)$ com áreas de reabsorção. (MyD88 KO - 42 dias; 10X)

(B) Detalhe da imagem A (quadrado), onde observa-se superfície cementária (C) com áreas de reabsorção (seta), com dissociação fibrilar e células inflamatórias. (MyD88 KO - 42 dias; 40X)

(C) Detalhe da imagem A, onde observa-se ligamento periodontal (LP) severamente ampliado, com áreas de edema e dissociação fibrilar, infiltrado inflamatório misto e difuso, com presença abundante de neutrófilos. O osso alveolar ( 0 ) encontra-se desnudo com osteoclastos (seta) em sua superfície. (MyD88 KO - 42 dias; 40X)

(D) Detalhe da imagem A, evidenciando ligamento periodontal (LP) aumentado e osso alveolar $(0)$ distante do ápice radicular, com extensa reabsorção. (MyD88 KO - 42 dias; 40X)

(E) Ligamento periodontal (LP) com presença de denso infiltrado inflamatório, predominantemente mononuclear, difuso por toda a região, característico do grupo WT. (WT - 42 dias; 40X)

(F) Ligamento periodontal (LP) com denso infiltrado celular inflamatório misto, difuso por toda a região, evidenciando presença abundante de neutrófilos, característico do grupo MyD88 KO. (MyD88 KO - 42 dias; 40X) 

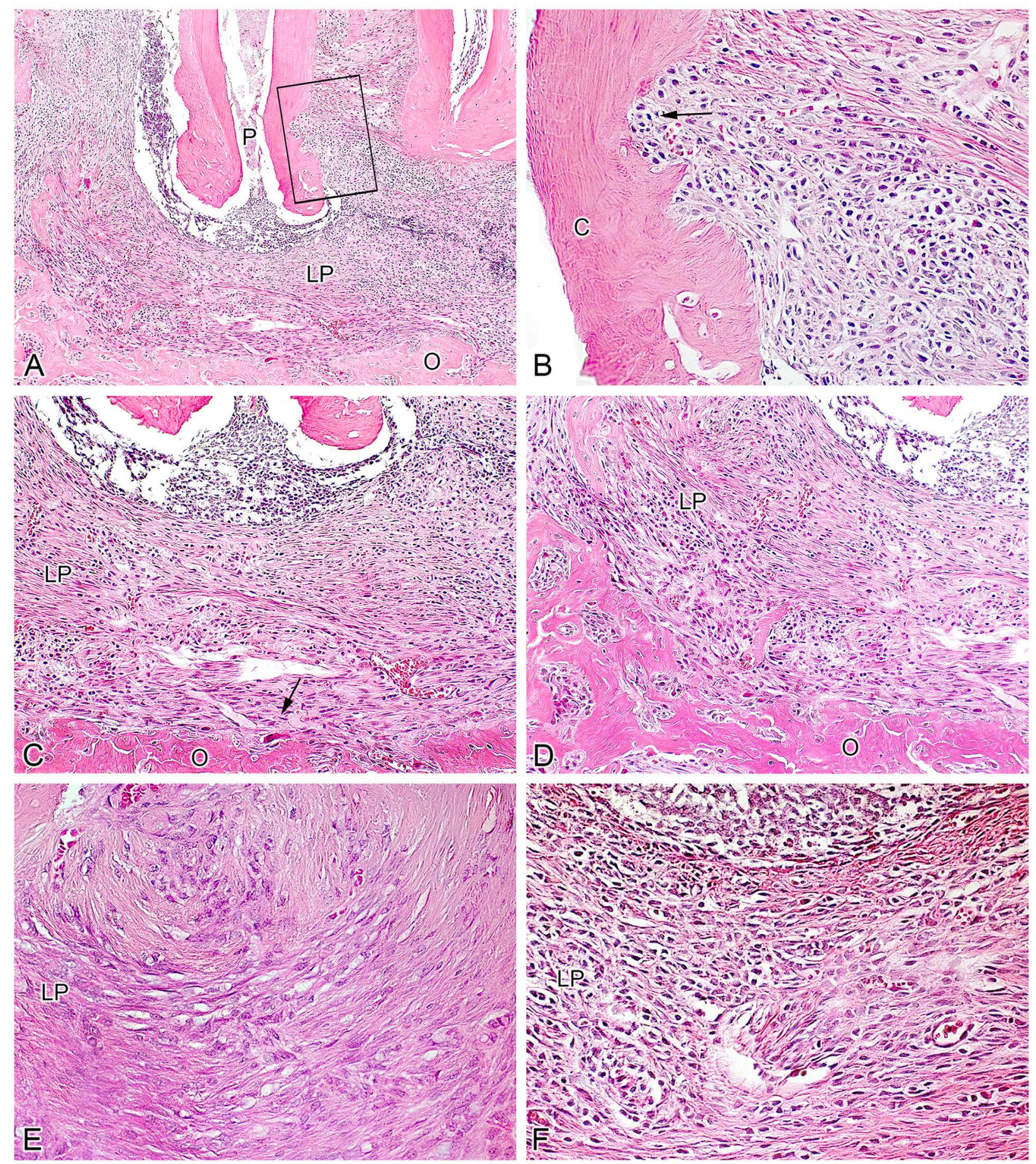



\section{Morfometria em microscopia de fluorescência}

As Figuras 6 e 7 representam os dados obtidos nos diferentes períodos experimentais, com relação à mensuração da extensão da área das lesões periapicais, nos grupos WT e MyD88 KO, respectivamente. No grupo de camundongos WT, observou-se diferença estatisticamente significante entre os períodos $(p<0,001)$ e pelo pós-teste de Dunn foi observado que no período de 42 dias as lesões foram significativamente superiores em comparação aos períodos de $7(p<0,001)$ e 21 dias $(p=0,001)$ (Figura 6). Em relação ao grupo My88 KO ( $p=0,002)$, também foi demonstrado que no período de 42 dias, as medidas foram significativamente superiores às dos períodos de $7(p=0,001)$ e de 21 dias $(p=0,005)$ (Figura 7).

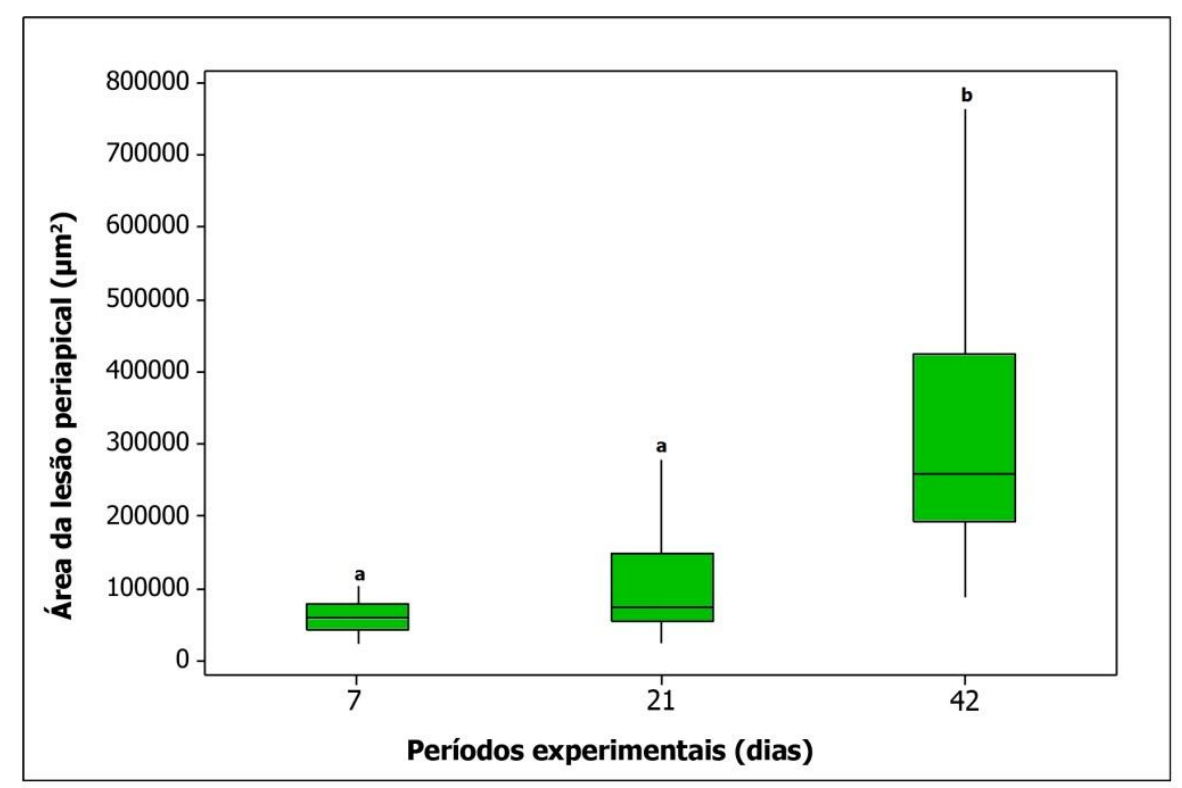

Figura 6. Representação gráfica da comparação dos resultados obtidos após a mensuração da área das lesões periapicais, em microscopia de fluorescência, nos diferentes períodos experimentais (7, 21 e 42 dias) do grupo de animais WT. Letras diferentes indicam diferença estatisticamente significante. 


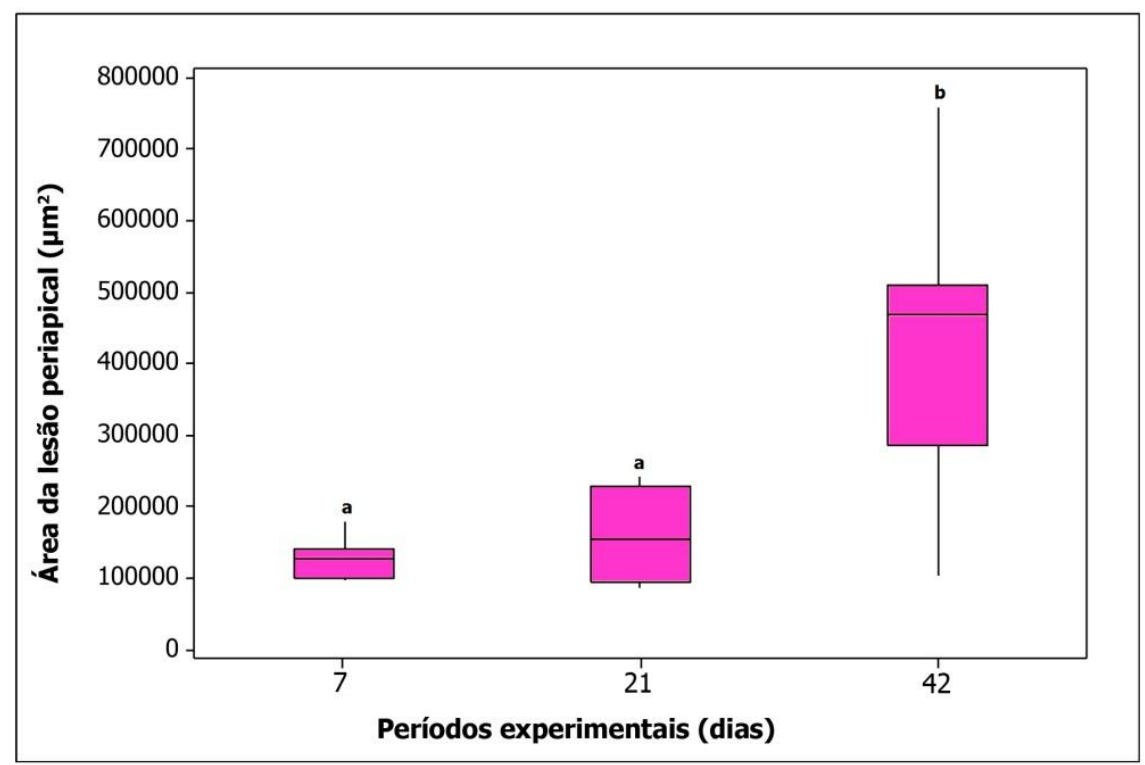

Figura 7. Representação gráfica da comparação dos resultados obtidos após a mensuração da área das lesões periapicais, em microscopia de fluorescência, nos diferentes períodos experimentais (7, 21 e 42 dias) do grupo de animais MyD88 KO. Letras diferentes indicam diferença estatisticamente significante.

A comparação dos períodos de 7, 21 e 42 dias entre os grupos WT e MyD88 KO evidenciou diferença significante nos períodos experimentais de $7(p=0,001)$ e 21 dias $(p=0,05)$, com valores significativamente superiores para o grupo MyD88 KO. Com relação ao período de 42 dias, houve uma tendência numérica de seguir este mesmo comportamento, entretanto não foi possível observar diferença estatisticamente significante $(p=0,09)$.

As figuras 8, 9 e 10 ilustram a comparação da mensuração da área das lesões periapicais, em microscopia de fluorescência, entre os grupos WT e MyD88 KO, nos períodos experimentais de 7, 21 e 42 dias, respectivamente. 


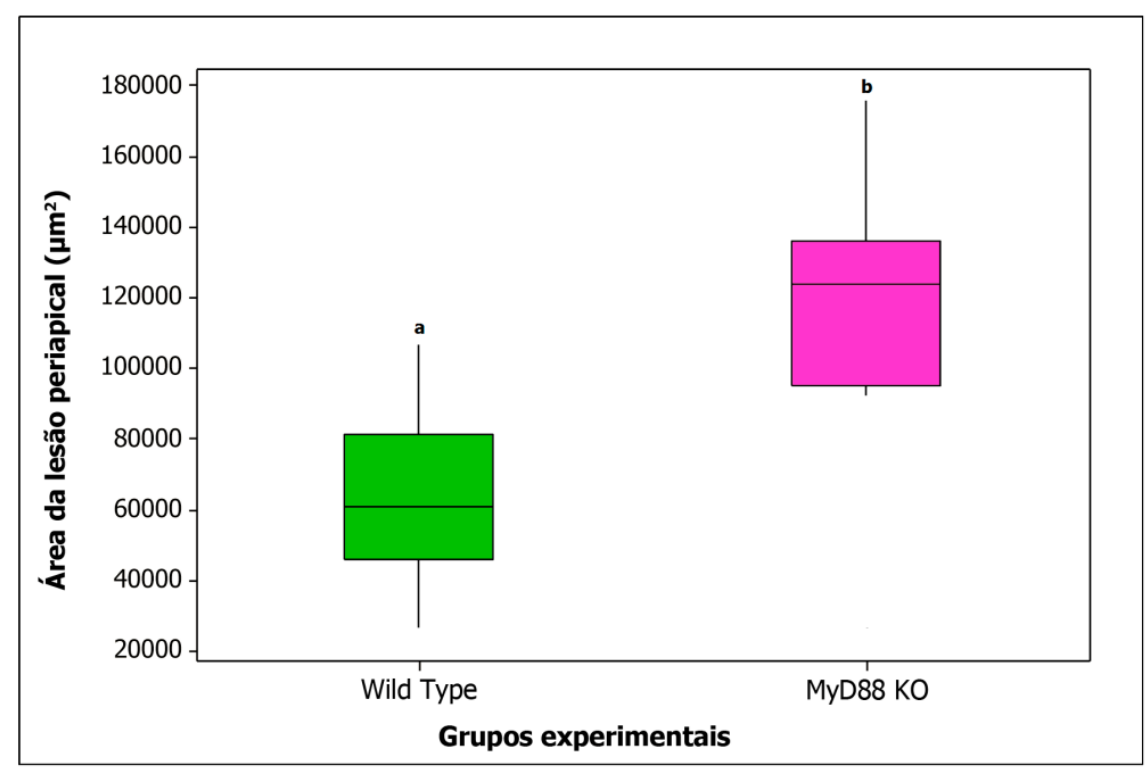

Figura 8. Representação gráfica da comparação dos resultados obtidos após a mensuração da área das lesões periapicais, em microscopia de fluorescência, entre o grupo WT e o grupo MyD88 KO, no período de 7 dias. Letras diferentes indicam diferença estatisticamente significante.

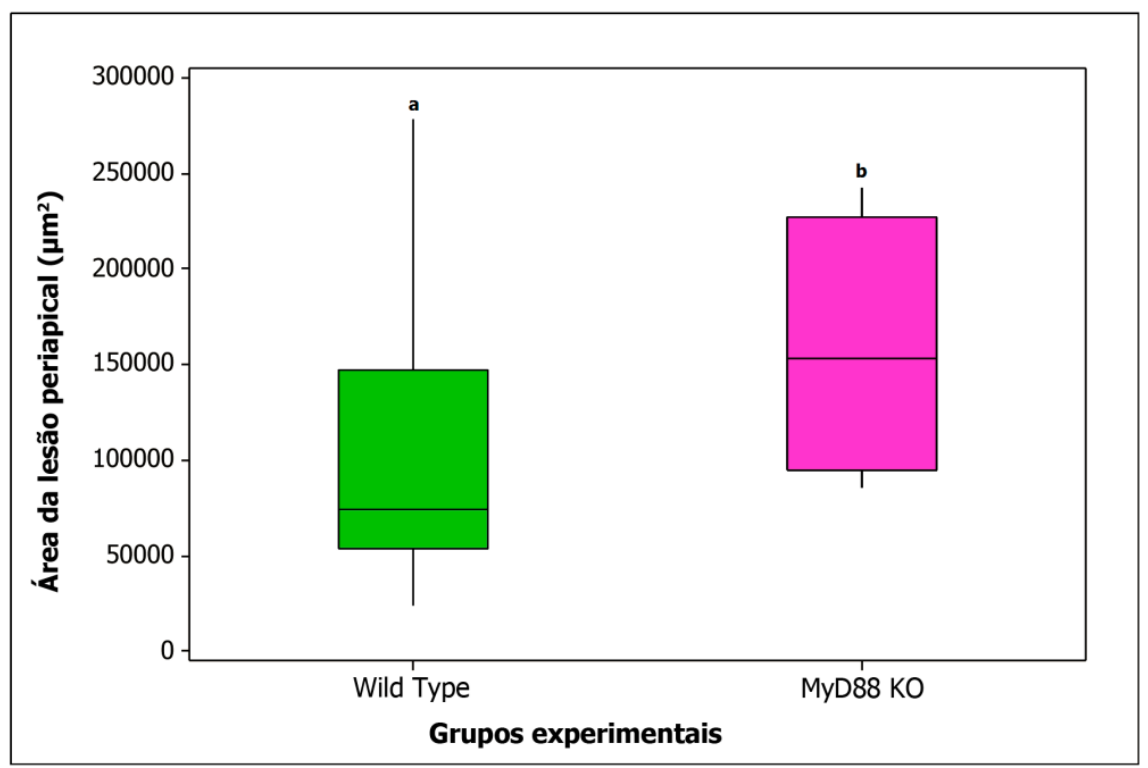

Figura 9. Representação gráfica da comparação dos resultados obtidos após a mensuração da área das lesões periapicais, em microscopia de fluorescência, entre o grupo WT e o grupo MyD88 KO, no período de 21 dias. Letras diferentes indicam diferença estatisticamente significante. 


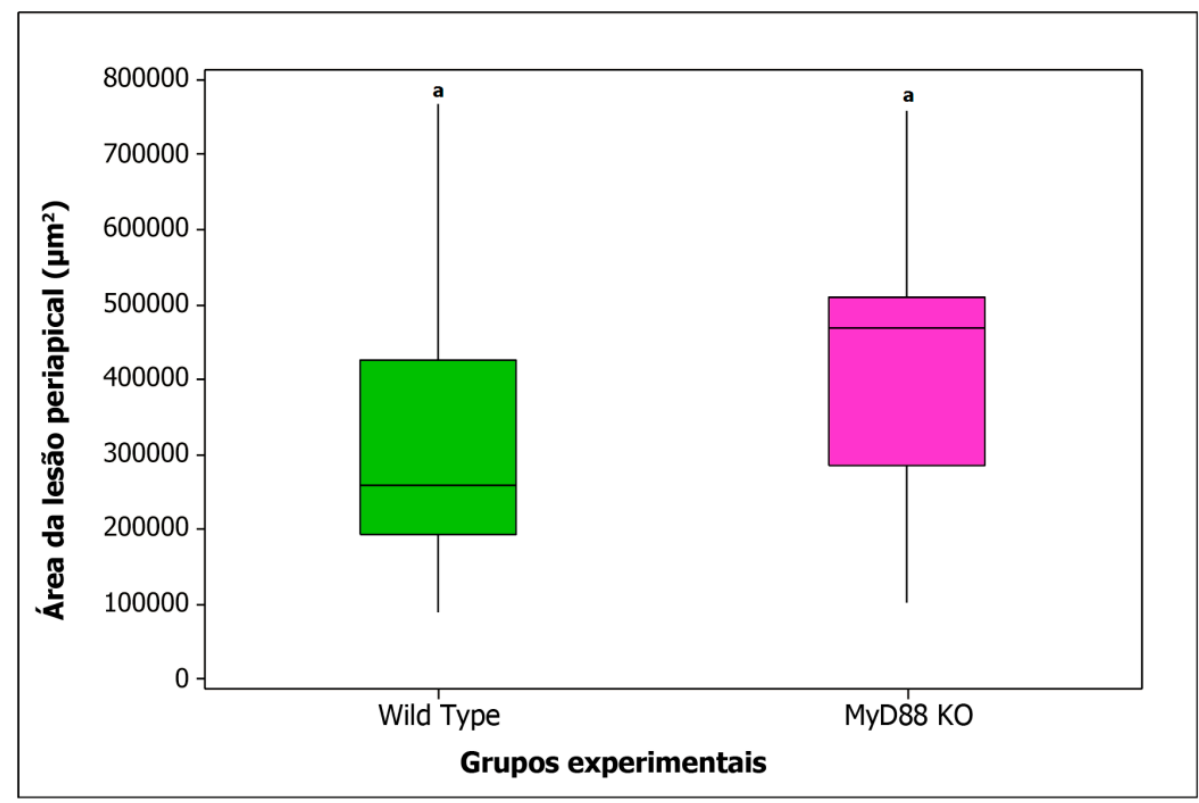

Figura 10. Representação gráfica da comparação dos resultados obtidos após a mensuração da área das lesões periapicais, em microscopia de fluorescência, entre o grupo WT e o grupo MyD88 KO, no período de 42 dias. Letras iguais indicam ausência de diferença estatisticamente significantes.

A Tabela 2 apresenta as medianas e os valores mínimos e máximos da extensão da área das lesões periapicais em microscopia de fluorescência e análise estatística dos resultados, nos períodos experimentais (7, 21 e 42 dias), nos diferentes grupos (WT e MyD88 KO).

Tabela 2. Comparação entre os diferentes períodos experimentais dos animais WT e MyD88 KO e entre os diferentes grupos de animais nos mesmos períodos de avaliação, após mensuração da área das lesões periapicais, em microscopia de fluorescência

\begin{tabular}{ccccc} 
& $\mathbf{7}$ dias & $\mathbf{2 1}$ dias & 42 dias & P* \\
& $\mathbf{M}(\mathbf{M n}-\mathbf{M x})$ & $\mathbf{M}(\mathbf{M n}-\mathbf{M x})$ & $\mathbf{M}(\mathbf{M n}-\mathbf{M x})$ & \\
\cline { 2 - 5 } WT & $60.842,5$ & $74.368,0$ & $258.088,0$ & $<0,001$ \\
\cline { 2 - 5 } & $(26446,0-106925,0)$ & $(23738,0-278760,0)$ & $(87696,0-765935,0)$ & \\
\hline MYD88 & $123.803,0$ & $153.306,0$ & $467.777,0$ & 0,002 \\
\cline { 2 - 5 } KO & $(92083,0-175784,0)$ & $(85444,0-242377,0)$ & $(101560,0-759868,0)$ & \\
\hline p** $^{*}$ & 0,001 & 0,05 & 0,09 & \\
\hline
\end{tabular}

M: mediana; Mn: mínimo; Mx: máximo; $p^{*}$ : Teste de Kruskal-Wallis; $p^{* *}$ : Teste de Mann-Whitney.

Os cortes microscópicos representativos da mensuração das lesões periapicais dos animais WT e MyD88 KO estão ilustrados na Figura 4 (B, D, F, H, J e L). 


\section{Contagem de células inflamatórias (neutrófilos)}

As Figuras 11 e 12 representam os dados obtidos nos diferentes períodos experimentais, com relação à contagem do número de neutrófilos, nos grupos WT e MyD88 KO, respectivamente. No grupo de camundongos WT observou-se diferença estatisticamente significante entre os períodos $(p=0,01)$, sendo que no período de 21 dias o número de neutrófilos foi significativamente superior, com relação aos períodos de $7(p<0,01)$ e de 42 dias $(p=0,03)$ (Figura 11). Com relação ao grupo MyD88 KO, houve diferença apenas entre os períodos de 21 e de 42 dias $(p=0,01)$ (Figura 12).

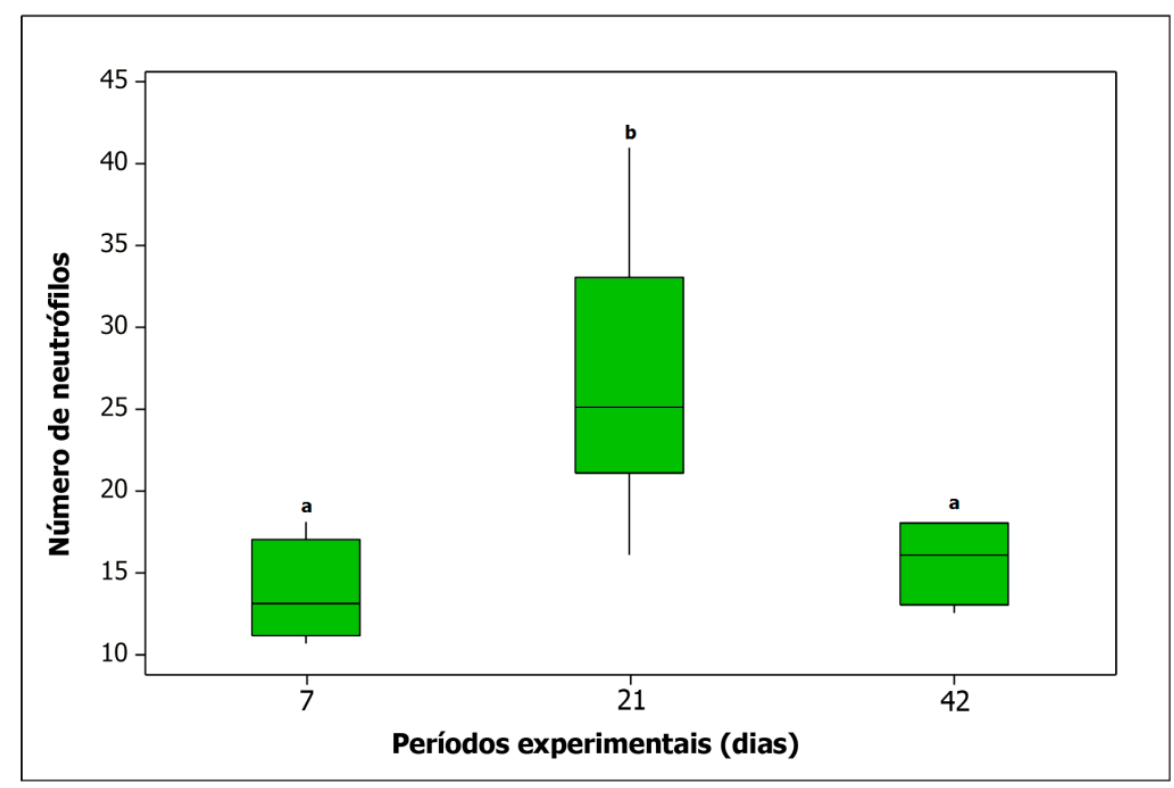

Figura 11. Representação gráfica da comparação dos resultados obtidos após contagem do número de neutrófilos nos diferentes períodos experimentais (7, 21 e 42 dias), no grupo de animais WT. Letras diferentes indicam diferença estatisticamente significante. 


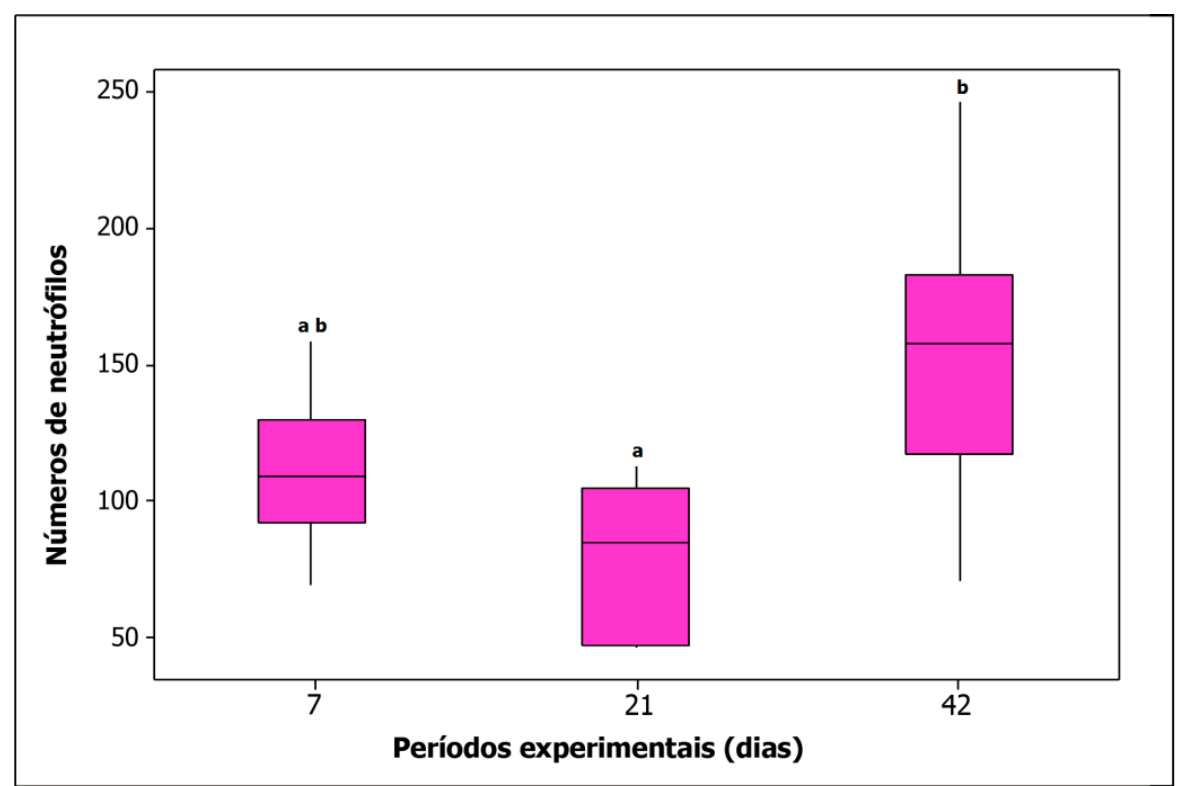

Figura 12. Representação gráfica da comparação dos resultados obtidos após contagem do número de neutrófilos nos diferentes períodos experimentais (7, 21 e 42 dias), no grupo de animais MyD88 KO. Letras diferentes indicam diferença estatisticamente significante.

A comparação dos períodos de 7, 21 e 42 dias entre os grupos WT e MyD88 KO evidenciou diferença significante nos períodos experimentais de $7(p=0,01), 21(p=0,004)$ e 42 dias $(p<0,001)$, com valores significativamente superiores para o grupo MyD88 KO.

As figuras 13, 14 e 15 ilustram a comparação entre a contagem do número de neutrófilos entre os grupos WT e MyD88 KO, nos períodos experimentais de 7, 21 e 42 dias, respectivamente. 


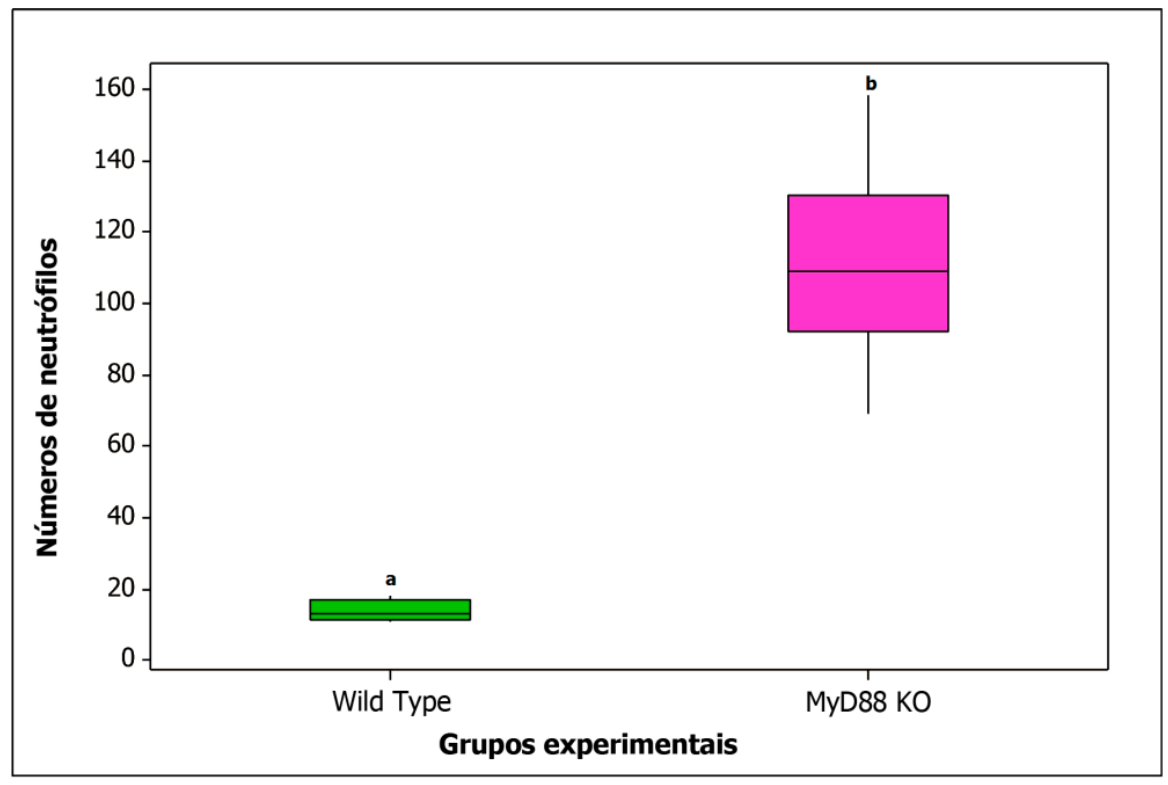

Figura 13. Representação gráfica da comparação dos resultados obtidos após contagem do número de neutrófilos entre o grupo WT e o grupo MyD88 KO, no período de 7 dias. Letras diferentes indicam diferença estatisticamente significante.

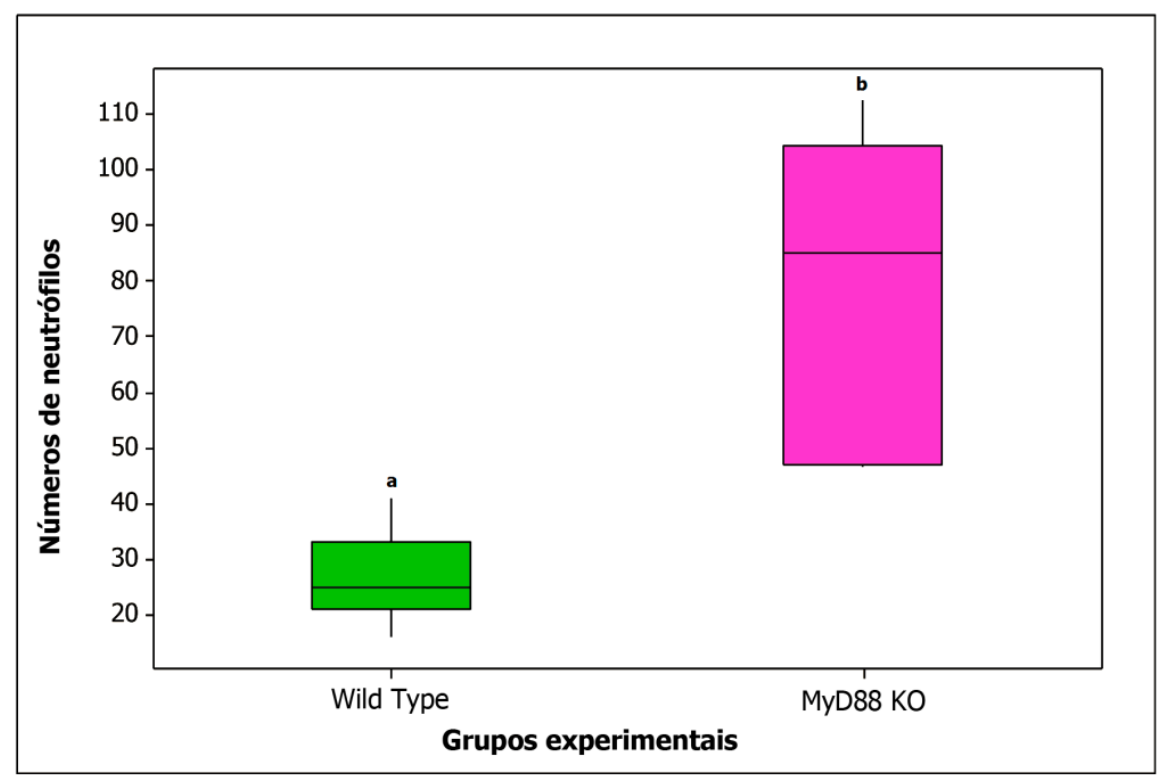

Figura 14. Representação gráfica da comparação dos resultados obtidos após contagem do número de neutrófilos entre o grupo WT e o grupo MyD88 KO, no período de 21 dias. Letras diferentes indicam diferença estatisticamente significante. 


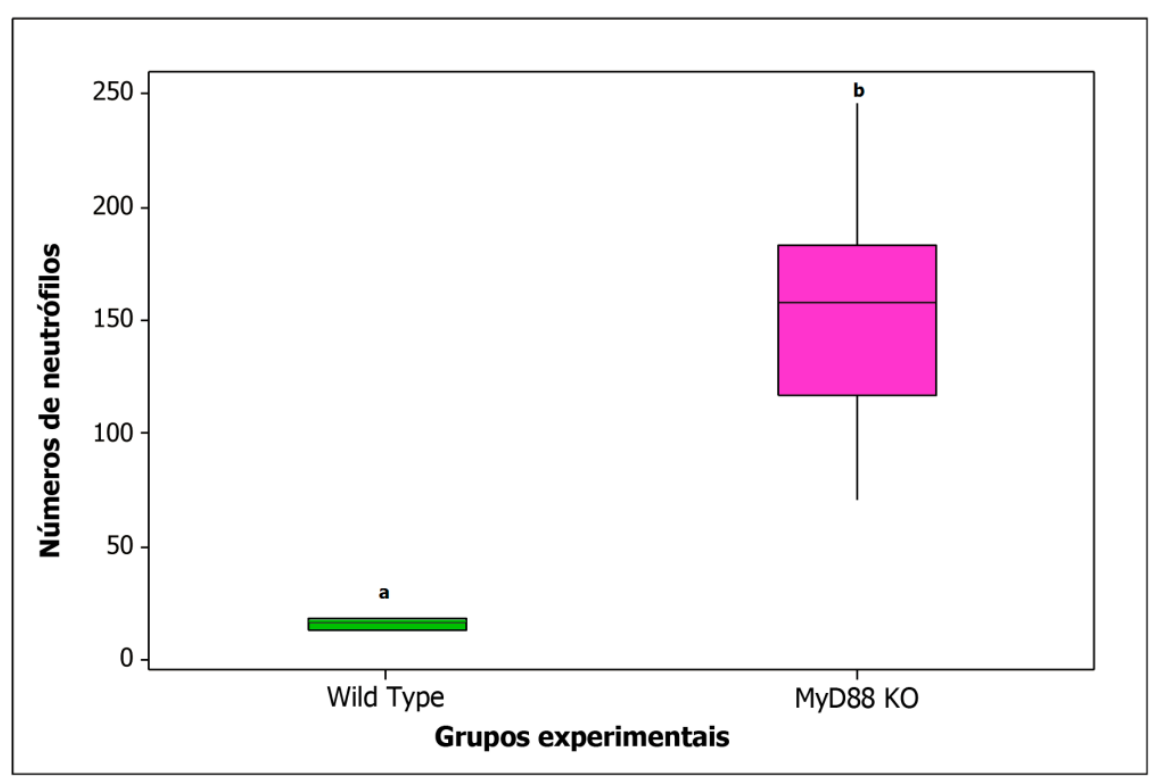

Figura 15. Representação gráfica da comparação dos resultados obtidos após contagem do número de neutrófilos entre o grupo WT e o grupo MyD88 KO, no período de 42 dias. Letras diferentes indicam diferença estatisticamente significante.

A Tabela 3 apresenta as medianas e os valores mínimos e máximos da contagem do número de neutrófilos presentes na região mediana da lesão adjacente ao forame apical e análise estatística dos resultados, nos períodos experimentais (7, 21 e 42 dias), nos diferentes grupos (WT e MyD88 KO).

Tabela 3. Comparação entre os diferentes períodos experimentais dos animais WT e MYD88 KO e entre os diferentes grupos de animais nos mesmos períodos de avaliação após contagem do número de neutrófilos

\begin{tabular}{ccccc} 
& $\begin{array}{c}\mathbf{7} \text { dias } \\
\mathbf{M}(\mathbf{M n}-\mathbf{M x})\end{array}$ & $\begin{array}{c}\mathbf{2 1} \text { dias } \\
\mathbf{M}(\mathbf{M n}-\mathbf{M x})\end{array}$ & $\begin{array}{c}\text { 42 dias } \\
\mathbf{M}(\mathbf{M n}-\mathbf{M x})\end{array}$ & p* \\
\cline { 2 - 5 } WT & 13,0 & 25,0 & 16,0 & 0,01 \\
\cline { 2 - 5 } & $(10,5-18,0)$ & $(16,0-41,0)$ & $(12,5-26,0)$ & \\
\hline \multirow{2}{*}{$\begin{array}{c}\text { MYD88 } \\
\text { KO }\end{array}$} & 109,0 & 85,0 & 158,0 & 0,02 \\
\cline { 2 - 5 } & $(69,0-158,5)$ & $(46,5-112,5)$ & $(70,5-246,0)$ & \\
\end{tabular}

\begin{tabular}{cccc} 
p** & 0,01 & 0,004 & $<, 001$ \\
\hline M: mediana; Mn: mínimo; Mx: máximo; $p^{*}:$ Teste de Kruskal-Wallis; $p^{* *}:$ Teste de Mann-Whitney.
\end{tabular}

Na Figura 5 pode-se observar a presença abundante de neutrófilos na lesão periapical do grupo MyD88 KO (5 - F), em comparação aos animais WT (5 - E). 


\section{Histoenzimologia para a atividade da fosfatase ácida resistente ao tartarato (TRAP)}

As Figuras 16 e 17 representam os dados obtidos nos diferentes períodos experimentais, com relação à contagem do número de osteoclastos, nos grupos WT e MyD88 KO, respectivamente. Nos animais WT, não foi possível detectar diferença estatisticamente significante entre os períodos de 7, 21 e 42 dias ( $p=0,226)$ (Figura 16). Da mesma maneira, com relação ao grupo MyD88 KO, não houve diferença estatística no número de osteoclastos entre os períodos experimentais $(p=0,457)$ (Figura 17).

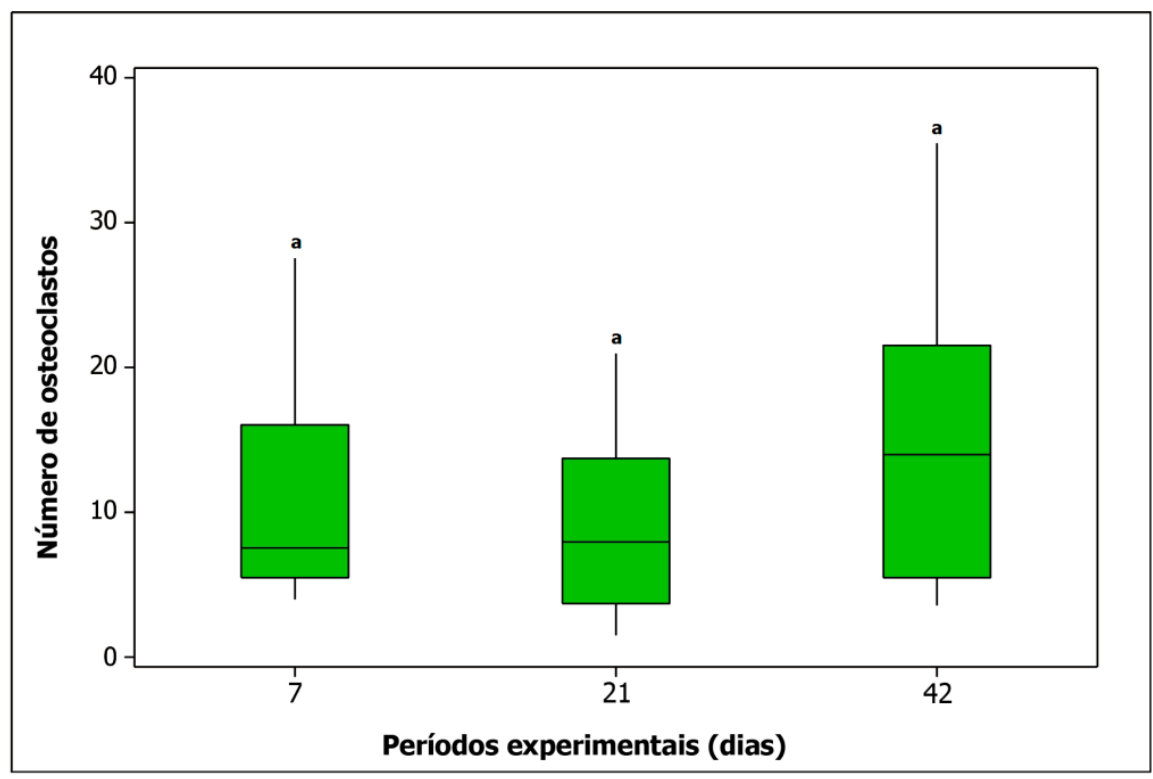

Figura 16. Representação gráfica da comparação dos resultados obtidos após contagem do número de osteoclastos nos diferentes períodos experimentais (7, 21 e 42 dias), no grupo de animais WT. Letras iguais indicam ausência de diferença estatisticamente significante. 


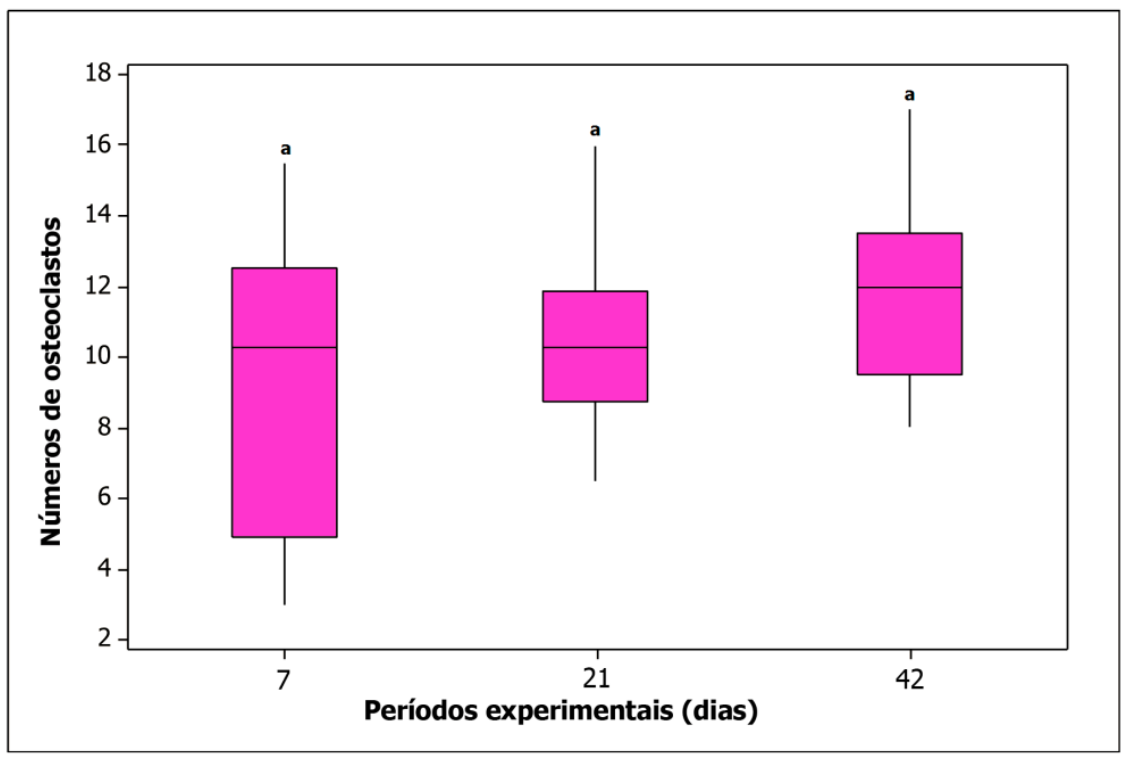

Figura 17. Representação gráfica da comparação dos resultados obtidos após contagem do número de osteoclastos nos diferentes períodos experimentais (7, 21 e 42 dias), no grupo de animais MyD88 KO. Letras iguais indicam ausência de diferença estatisticamente significante.

A comparação dos períodos de 7, 21 e 42 dias entre os grupos WT e MyD88 KO não revelou diferença significante nos períodos experimentais de $7(p=0,884), 21(p=0,506)$ e 42 dias $(p=0,211)$.

As figuras 18, 19 e 20 ilustram a comparação entre a contagem do número de osteoclastos entre os grupos WT e MyD88 KO, nos períodos experimentais de 7, 21 e 42 dias, respectivamente. 


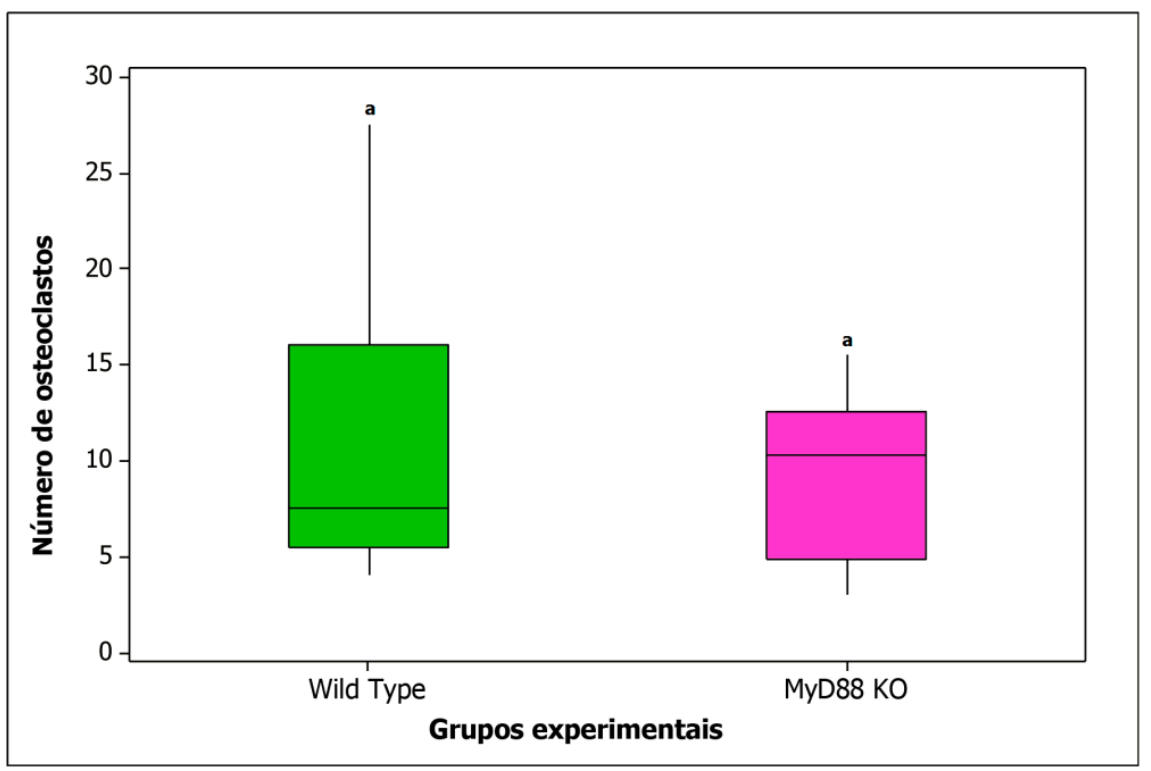

Figura 18. Representação gráfica da comparação dos resultados obtidos após contagem do número de osteoclastos entre o grupo WT e o grupo MyD88 KO, no período de 7 dias. Letras iguais indicam ausência de diferença estatisticamente significante.

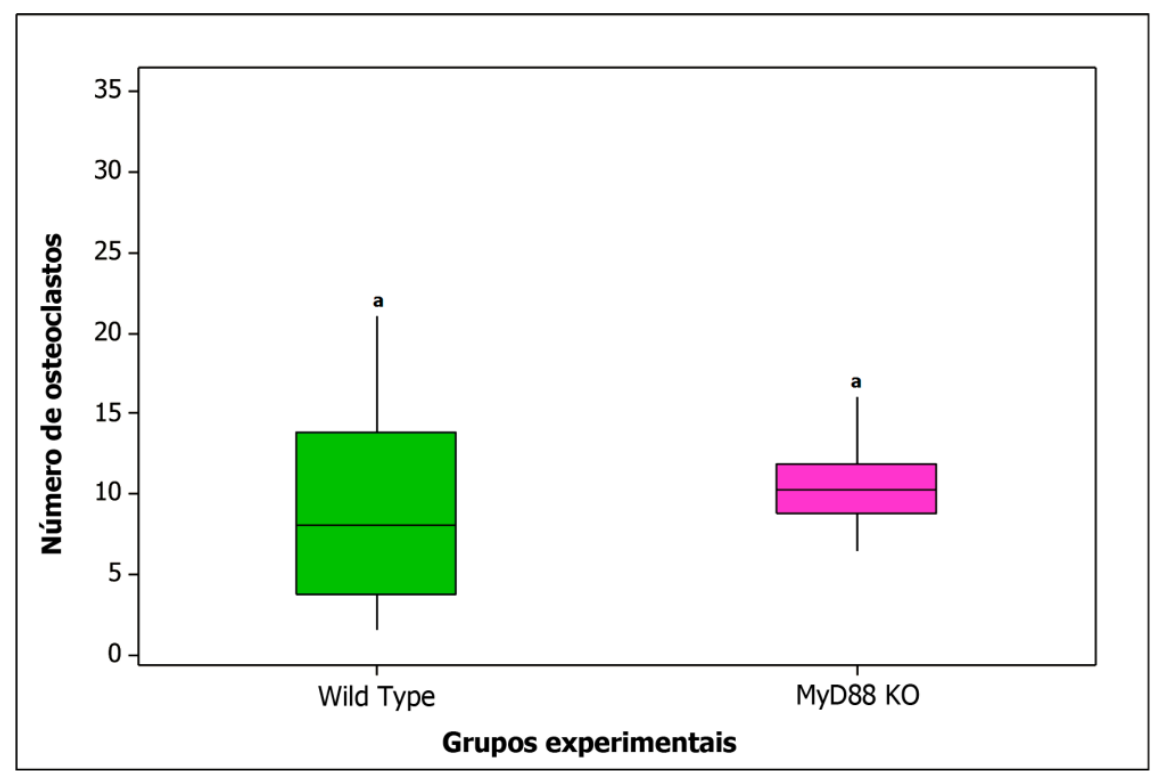

Figura 19. Representação gráfica da comparação dos resultados obtidos após contagem do número de osteoclastos entre o grupo WT e o grupo MyD88 KO, no período de 21 dias. Letras iguais indicam ausência de diferença estatisticamente significante. 


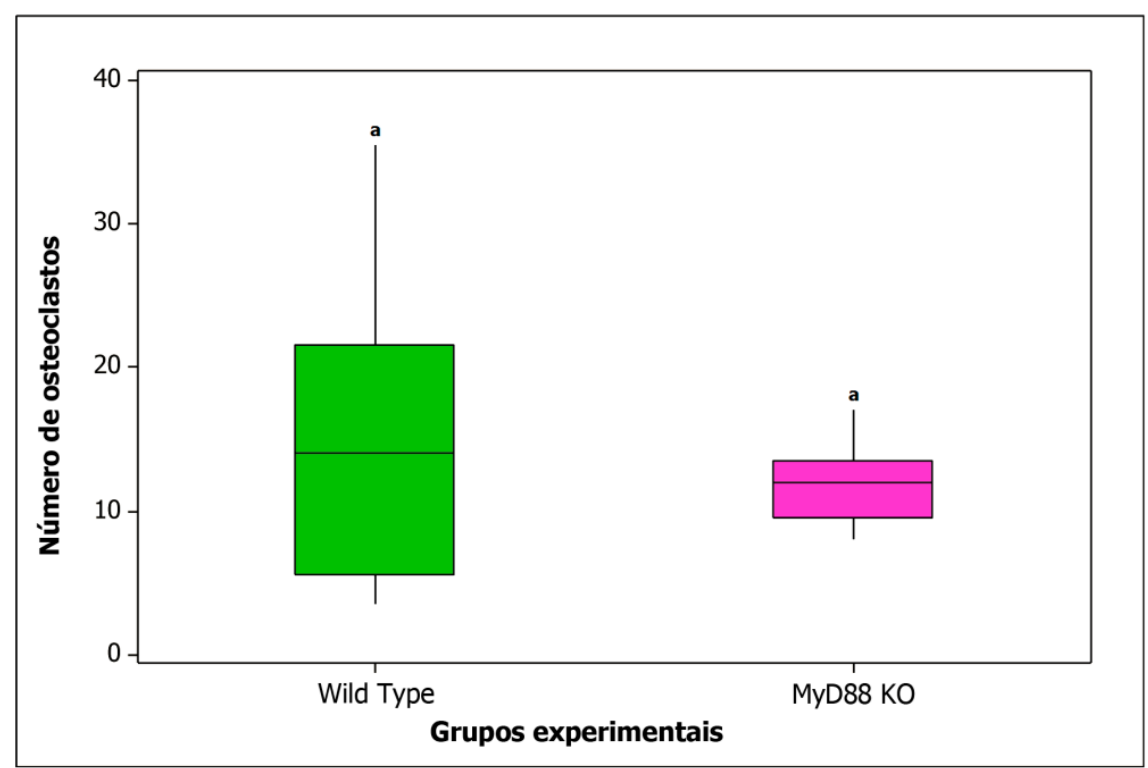

Figura 20. Representação gráfica da comparação dos resultados obtidos após contagem do número de osteoclastos entre o grupo WT e o grupo MyD88 KO, no período de 42 dias. Letras iguais indicam ausência de diferença estatisticamente significante.

A Tabela 4 apresenta as medianas e os valores mínimos e máximos da contagem do número de osteoclastos presentes nas lacunas de reabsorção e em contato direto com o osso alveolar ao redor da lesão periapical e análise estatística dos resultados nos períodos experimentais (7, 21 e 42 dias) nos diferentes grupos (WT e MyD88 KO).

Tabela 4. Comparação entre os diferentes períodos experimentais dos animais WT e MyD88 KO e entre os diferentes grupos de animais nos mesmos períodos de avaliação após contagem do número de osteoclastos

\begin{tabular}{ccccc}
\hline & $\mathbf{7}$ dias & $\mathbf{2 1}$ dias & $\mathbf{4 2}$ dias & : \\
& $\mathbf{M}(\mathbf{M n}-\mathbf{M x})$ & $\mathbf{M}(\mathbf{M n}-\mathbf{M x})$ & $\mathbf{M}(\mathbf{M n}-\mathbf{M x})$ & \\
\cline { 2 - 5 } WT & 7,5 & 8,0 & 14,0 & 0,226 \\
\hline MYD88 & $(4,0-27,5)$ & $(1,5-34,5)$ & $(3,5-35,5)$ & \\
\cline { 2 - 5 } K0 & 10,25 & 10,25 & 12,0 & 0,457 \\
\hline p** & $(3,0-15,5)$ & $(6,5-16,0)$ & $(8,0-17,0)$ & \\
\hline
\end{tabular}

M: mediana; Mn: mínimo; Mx: máximo; $p^{*}$ : Teste de Kruskal-Wallis; $p^{* *}$ : Teste de Mann-Whitney.

Os cortes microscópicos representativos das marcações das células TRAP positivas ao redor da lesão periapical dos grupos WT e MyD88 KO, nos períodos de 7, 21 e 42 dias, estão ilustradas na Figura 21. 

Figura 21. Fotomicrografias dos cortes microscópicos representativos dos animais WT (B, C e D) e MyD88 KO (E, F e G), nos períodos experimentais de 7, 21 e 42 dias, corados por meio da técnica de histoenzimologia para a atividade da fosfatase ácida resistente ao tartarato (TRAP) para identificação e contagem de osteoclastos. Em A observa-se células osteoclásticas presentes nas lacunas de reabsorção, em contato direto com o osso alveolar ao redor da lesão periapical. $(10$ e 40X) 
WT
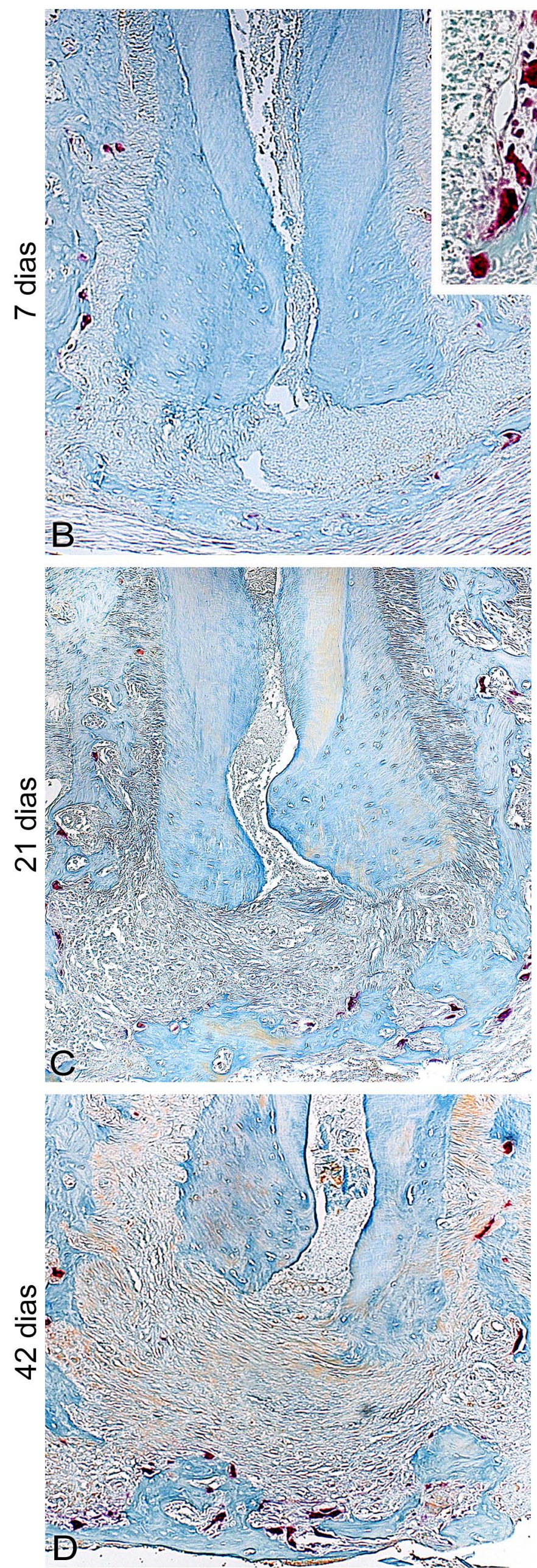

\section{MyD88 KO}
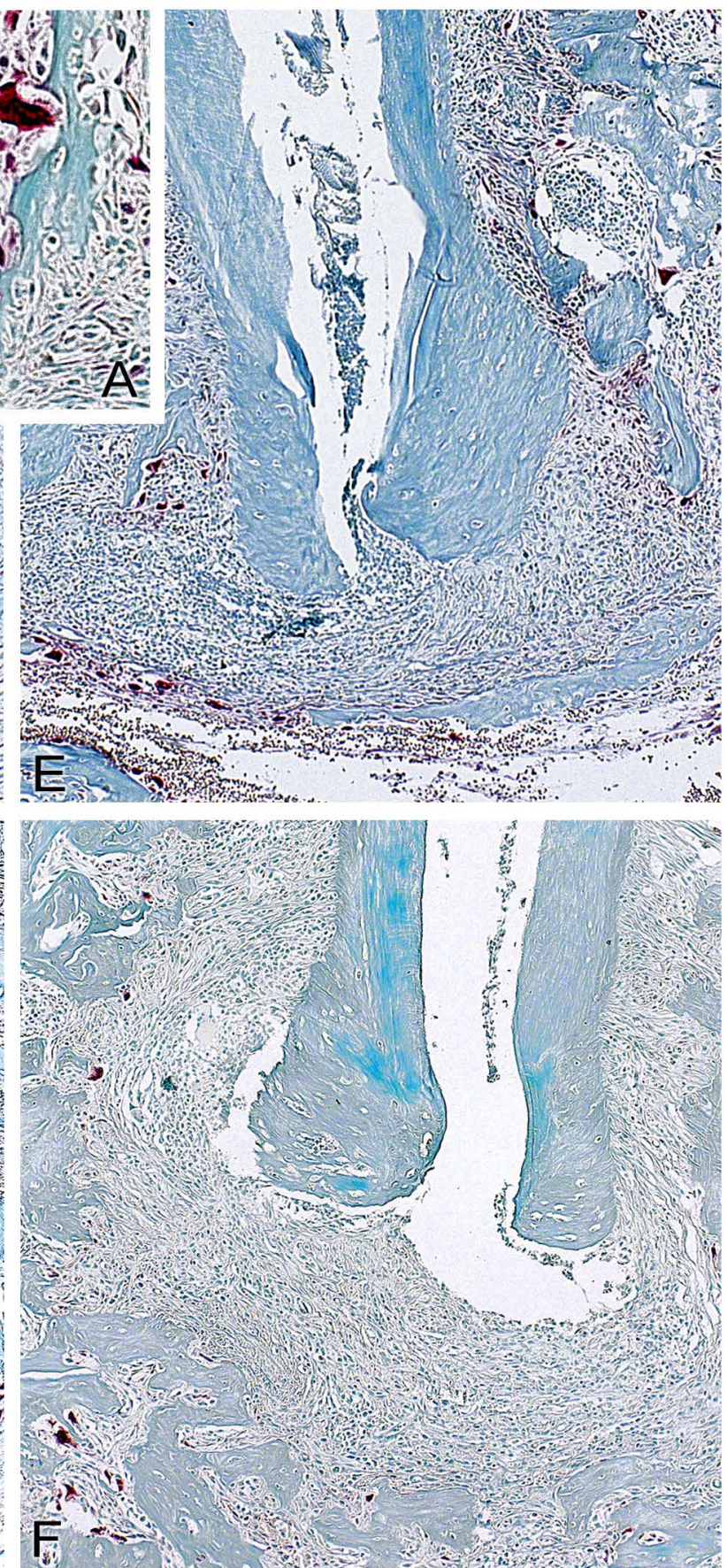



\section{Coloração de Brown \& Brenn Modificada}

Com relação à avaliação da presença e da localização bacteriana no sistema de canais radiculares e nos tecidos periapicais, os espécimes do grupo de animais WT foram classificados como escore 4, aos 7, 21 e 42 dias. Observou-se presença de grande quantidade de bactérias na coroa do dente e no terço cervical do canal radicular, inclusive nos túbulos dentinários e na região inter-radicular. A quantidade de bactérias reduziu progressivamente em direção à região apical, com poucas bactérias nos terços médio e apical, e ausência na lesão periapical. Por outro lado, no grupo MyD88 KO, a infecção microbiana encontrava-se mais intensamente disseminada pelo sistema de canais radiculares, inclusive na região periapical e na lesão, sendo este grupo classificado como escore 5. As bactérias estavam presentes de forma abundante na coroa do dente, nos terços cervical e médio do canal radicular, com profunda penetração nos túbulos dentinários. Além disso, os espécimes apresentaram bactérias na saída do forame apical, nas lacunas cementárias, no biofilme apical e na lesão periapical (Figura 22). 
Figura 22. Fotomicrografias representativas dos cortes microscópicos dos animais MyD88 KO, corados por meio da técnica de Brown \& Brenn Modificada, evidenciando a presença e a localização bacteriana no sistema de canais radiculares e nos tecidos periapicais:

(A) Fotomicrografia panorâmica, demonstrando intensa contaminação bacteriana em toda a extensão do dente. (10X)

(B) Terço coronário do canal radicular, evidenciando presença abundante de micro-organismos. (40X)

(C) Detalhe da imagem B que permite observar túbulos dentinários com intensa presença bacteriana.

(D) Detalhe de imagem A, onde observa-se presença de micro-organismos no terço apical e nas crateras de reabsorção.

(E) Detalhe de imagem A, evidenciando presença de abundante de bactérias nas lacunas cementárias.

(F) Detalhe da imagem A, demonstrando micro-organismos na lesão periapical. 

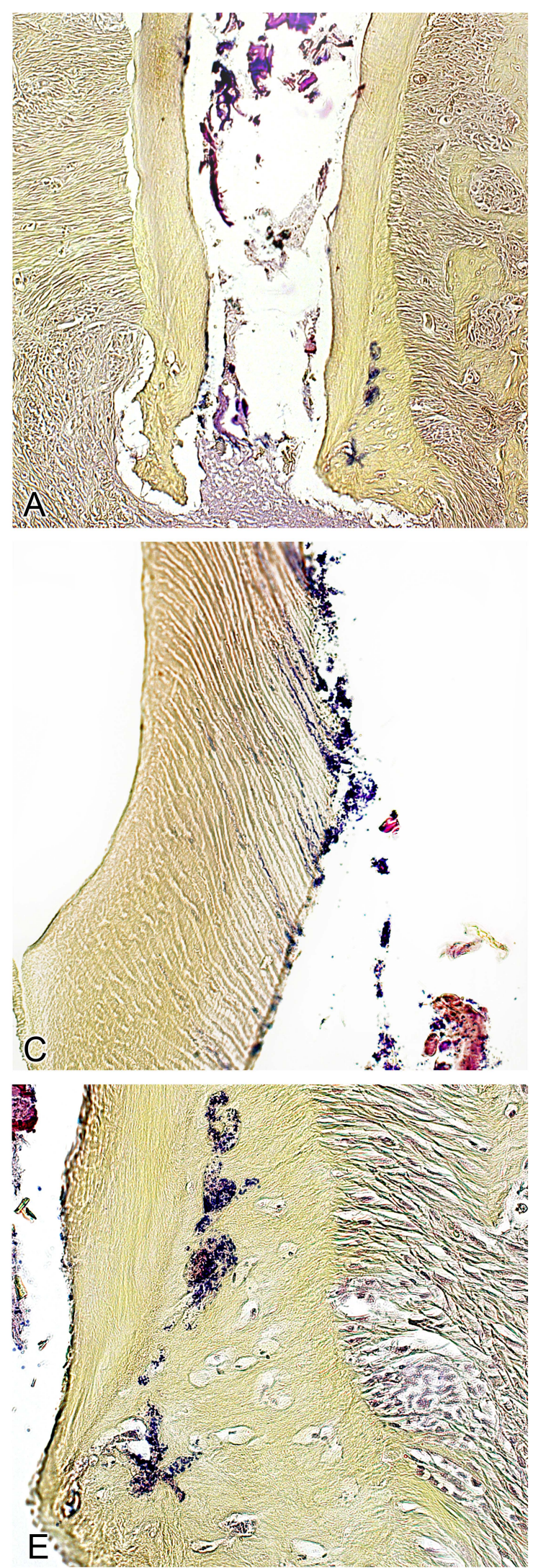
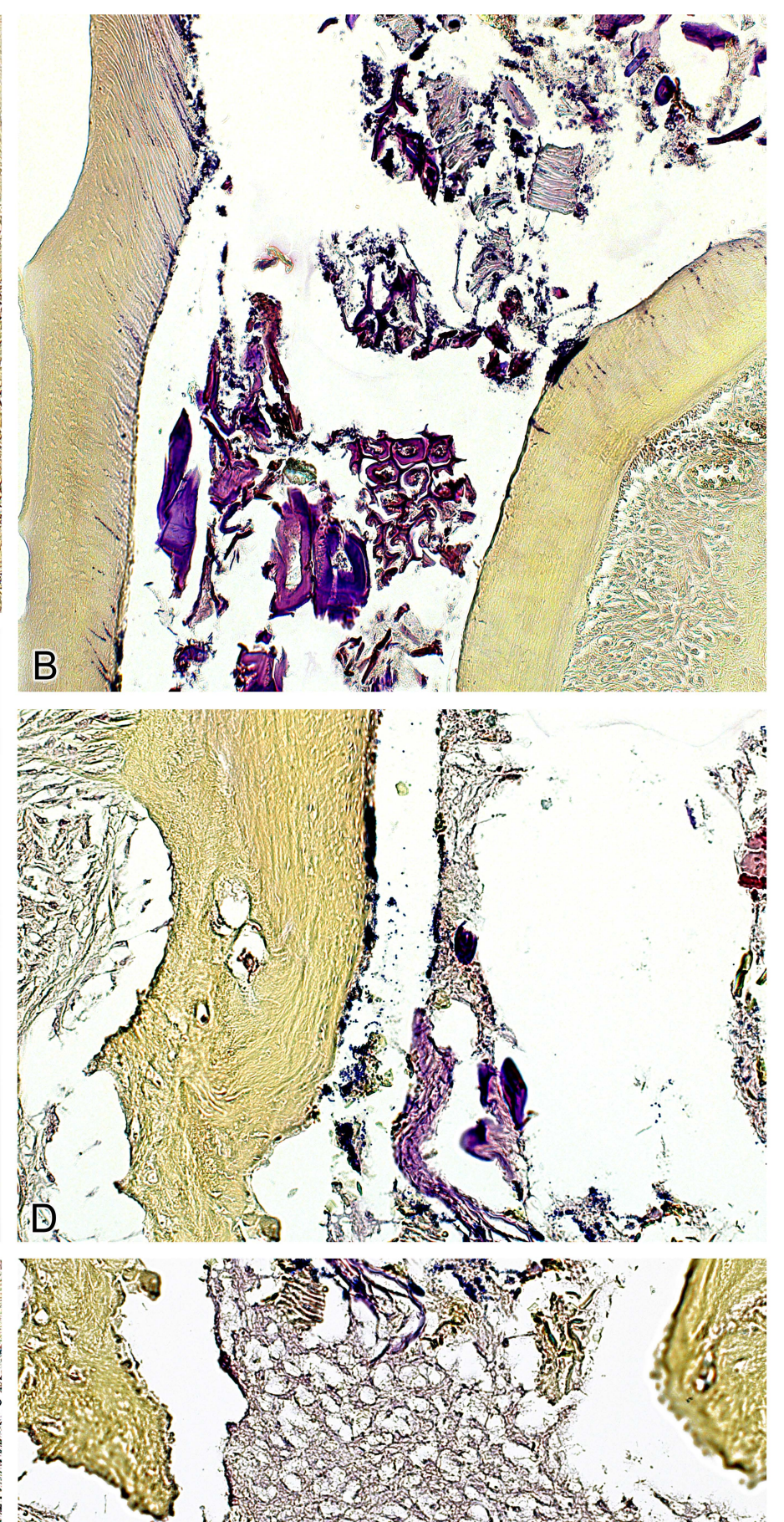

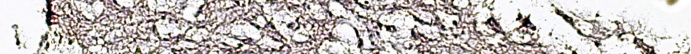

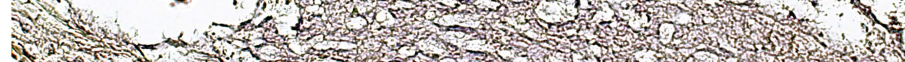

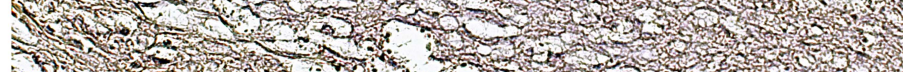

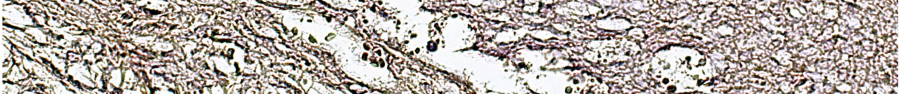

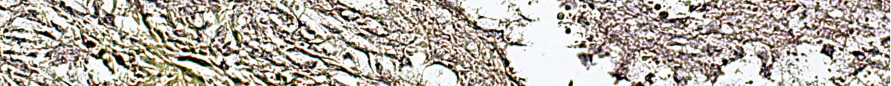

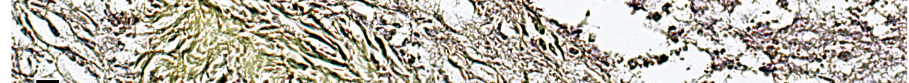

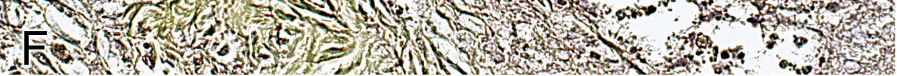





\section{Imunomarcação (Imunohistoquímica)}

Marcações positivas para RANK foram observadas nos espécimes de ambos os grupos em todos os períodos experimentais, localizadas preferencialmente na região do forame apical.

Paralelamente, marcações para RANKL foram observadas nos espécimes tanto no grupo WT quanto no MyD88 KO, em todos os períodos experimentais, localizadas especialmente na região do forame apical e no interior da lesão periapical.

As marcações para OPG foram observadas nos espécimes do grupo WT e do grupo MyD88 KO, principalmente no interior da lesão. Nos espécimes do grupo WT, as marcações também foram observadas nas extremidades da lesão periapical.

As imagens representativas das marcações para RANK, RANKL e OPG estão apresentadas na Figura 23, evidenciando suas localizações. 
Figura 23. Fotomicrografias de cortes microscópicos representativos dos animais WT e MyD88 KO, nos diferentes períodos experimentais, corados por meio da técnica de imunohistoquímica, evidenciando a presença e a localização dos marcadores da osteoclastogênese RANKL, RANK e OPG. (10 e 40X) 

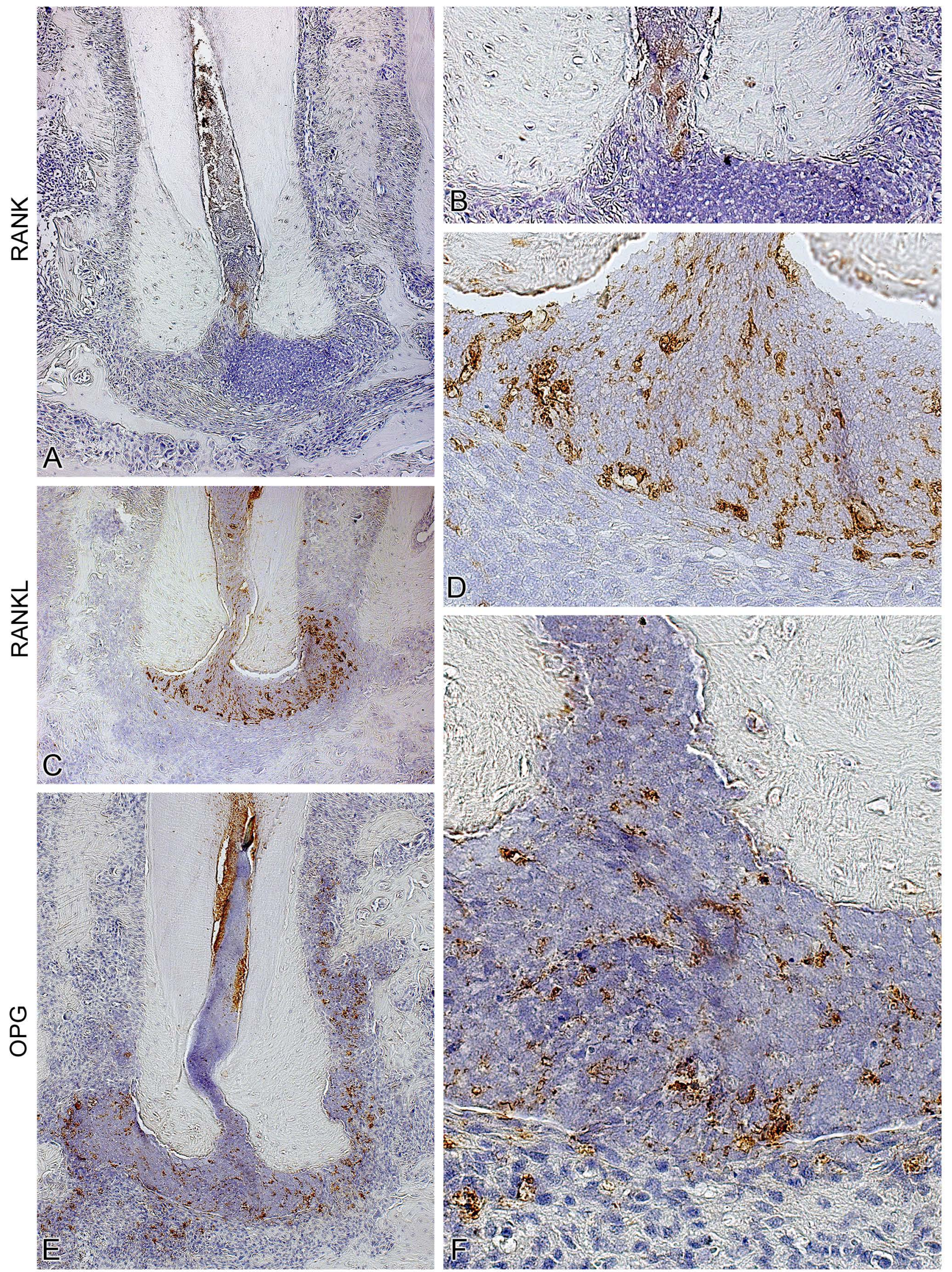

Discussão 



\section{DisCUSSÃO}

A lesão periapical apresenta uma diversidade de células inflamatórias e não inflamatórias que estão envolvidas na regulação desse processo imunoinflamatório. Células da imunidade inata (neutrófilos, macrófagos e células dendríticas), bem como células da imunidade adaptativa (linfócitos T e B e células plasmáticas) estão presentes, em diferentes proporções, nas lesões periapicais. A presença de bactérias e de toxinas provenientes do sistema de canais radiculares contaminado causa, inicialmente, reação inflamatória não específica seguida por produção de anticorpos, ativação do sistema complemento, produção de citocinas e de uma série de mediadores inflamatórios, com o objetivo de limitar a disseminação da infecção e proteger os tecidos periapicais (Desai et al., 2011). Entretanto, a resposta do hospedeiro exerce um papel protetor e ao mesmo tempo crítico na tentativa de controlar o aumento da infecção nas lesões de origem endodôntica. A inflamação e a reabsorção óssea no periápice, em muitos casos, é consequência da interação entre a infecção microbiana e a resposta do hospedeiro (Graves et al., 2011).

A análise dos cortes corados com HE por microscopia de fluorescência, em ambos os grupos, revelou um aumento progressivo no tamanho da lesão periapical a partir do período inicial de 7 dias, até 21 e 42 dias, sendo que, neste último período, as lesões eram severamente mais extensas $(p<0,05)$. Ressalta-se que as lesões periapicais no grupo MyD88 KO eram significantemente maiores que no grupo WT nos períodos de $7(p=0,001)$ e 21 dias $(p=0,05)$, sendo que no período de 42 dias também foi observada essa tendência $(p=0,09)$. Este fato pode ser explicado em parte pela diferença na característica do infiltrado inflamatório, o qual estava mais exacerbado e com presença considerável de neutrófilos e células mononucleadas na ausência da MyD88, evidenciando deficiência no controle da sua cronificação.

No presente estudo, a análise quantitativa do número de neutrófilos na região mediana da lesão, adjacente ao forame apical, confirmou a descrição qualitativa e revelou um número significantemente maior destas células no grupo MyD88 KO, comparado a animais WT, em todos os períodos ( $p=0,01$ em 7 dias; $p=0,004$ em 21 dias e $p<0,001$ em 42 dias). Os neutrófilos constituem o principal elemento celular da fase inicial da inflamação e apresentam uma função essencialmente fagocitária. O citoplasma dos neutrófilos contém muitos lisossomos carregados de enzimas proteolíticas e de outros componentes, os quais têm capacidade de degradar uma variedade de proteínas e eliciar uma severa destruição tecidual (Segal, 2005; Eming et al., 2007). Os neutrófilos têm um tempo de vida muito curto e atuam como parte do infiltrado inflamatório por aproximadamente 3 dias (Reinke e Sorg, 
2012), o que nos faz inferir que, no grupo MyD88 KO, o estímulo agressor bacteriano foi mais intenso e persistente, o que estimulou a migração neutrofílica até os períodos finais do experimento. Paralelamente, é possível sugerir que os eventos moleculares e os mecanismos envolvidos no controle do influxo de neutrófilos para os sítios inflamatórios possam ser mediados pela MyD88.

A ausência de estudos que avaliam o efeito da molécula MyD88 no desenvolvimento de lesões periapicais impossibilita uma comparação direta com os resultados do presente estudo. No entanto, nossos resultados estão de acordo com resultados prévios da área da saúde, que demonstraram que a sinalização via MyD88 é essencial para o controle da infecção, para a organização da resposta inflamatória e imunológica de forma adequada e eficiente (Hughes et al., 2005; LaRosa et al., 2008; Koh et al., 2010; Loures et al., 2011; Hanke et al., 2012). LaRosa et al. (2008) afirmaram que a MyD88 exerce papel importante para a resistência do hospedeiro mediada por células $T$, além da função bem estabelecida desta molécula em vincular imunidade inata e adaptativa por meio do reconhecimento de patógenos mediado por células apresentadoras de antígeno (APCs). A vulnerabilidade aumentada de camundongos MyD88 KO submetidos a desafios microbianos pode ser uma consequência da imunidade celular alterada causada pela ausência de sinalização dependente da MyD88 em células T (LaRosa et a., 2008). Além disso, foi demonstrado que a ausência desta molécula afeta intensamente as respostas imunes do tipo Th1, Th2 e Th17, que são responsáveis pela indução das citocinas IL-12 e IL-18; IL-33, IL-4, IL-5 e IL-10; e TGF- $\beta$, IL-1 $\beta$, IL-6, IL-23 e IL-17, respectivamente (Loures et al., 2011). Embora esses parâmetros não tenham sido avaliados no presente estudo, possivelmente a liberação dessas citocinas pode ter sido alterada no grupo MyD88 KO em função de que, neste grupo, as células mononucleadas eram menos abundantes, em comparação à considerável presença neutrofílica.

Seguindo este contexto, paralelamente às características do infiltrado inflamatório, destaca-se a diferença observada na presença e localização de bactérias entre os grupos, evidenciada pela coloração de Brown e Brenn. Nos animais do grupo MyD88 KO, as bactérias estavam mais severamente disseminadas pelo sistema de canais radiculares, com presença intensa nos terços cervical, médio e apical, inclusive na lesão periapical, indicando um possível prejuízo na resistência do hospedeiro e no combate à infecção na ausência da MyD88 KO, corroborando com as informações prévias.

Os TLRs são principalmente expressos em células apresentadoras de antígenos, como células dentríticas, macrófagos e células B. A ativação dessas células é seguida pela diferenciação de células $\mathrm{T}^{\mathrm{C}} \mathrm{CD} 4^{+}$e $\mathrm{CD}^{+}$e a diferenciação de células $\mathrm{B}$ produtoras de 
anticorpos antígeno-específicos (Kawai and Akira, 2011). De acordo com resultados do presente estudo e com base na literatura, pode-se inferir que o silenciamento da molécula MyD88 pode ter prejudicado a sinalização via TLR nestas células, comprometendo a ativação da resposta imunológica, o que resultou no quadro histopatológico encontrado nas lesões periapicais dos animais MyD88 KO.

Utilizando o mesmo modelo experimental, da Silva et al. (2012) encontraram lesões periapicais mais extensas e com maior número de osteoclastos em animais TLR2 KO. Os autores sugeriram que possivelmente ocorreu a ativação de outras vias de sinalização, bem como uma ativação mais intensa dos outros TLRs, particularmente do TLR4, que reconhece o LPS bacteriano. Por outro lado, Hou et al. (2000) demonstraram que camundongos TLR4 KO desenvolveram lesões periapicais menores e expressão reduzida de citocinas próinflamatórias. Esses resultados podem indicar o grande potencial do LPS em ocasionar efeitos deletérios e exacerbar a destruição óssea periapical, por meio do receptor TLR4.

A MyD88 é utilizada por todos os TLRs, exceto pelo TLR3, e transmite sinais que culminam com a ativação de NF-KB e a indução de mediadores pró-inflamatórios, incluindo TNF-a, IL-6 e a produção de INF do tipo I, a e $\beta$ (Siednienko et al., 2011). Além disso, a MyD88 atua nos receptores para IL-1 (IL-1R, IL-18R e IL-33R) e, como conseqüência, a sinalização celular e a produção de citocinas por esses receptores também encontram-se deficientes na ausência desta molécula adaptadora (Kawai e Akira, 2011; Loures et al., 2011). Sendo assim, a deleção genética da MyD88 no presente estudo promoveu o silenciamento de muitas vias importantes de sinalização, o que provavelmente levou à exacerbação do processo inflamatório, ao aumento da extensão da área da lesão periapical e disfunções na ativação e organização da resposta imunológica. Pelo exposto, verifica-se o importante papel desta molécula durante as respostas inflamatória e imunológica desencadeadas para combater a infecção presente no sistema de canais radiculares e tecidos periapicais, durante a gênese e desenvolvimento da lesão periapical, indicando uma função protetora.

Por outro lado, sabe-se que existe uma via de sinalização independente da MyD88, que é principalmente ativada pelo TLR4, da qual participam as moléculas TRIF ou TICAM-1 e TRAM ou TICAM-2. Nesta via, ocorre o recrutamento de TRAF3 e das proteínas quinases TBK1 e IKKi, as quais catalizam a fosforilação de IRF3, levando à expressão de INF-I. Além disso, o complexo TRAM-TRIF também recruta TRAF6 e TAK1, como ocorre na via MyD88dependente, mediando a ativação tardia de NF-kB (Takeda e Akira, 2004; Kawai e Akira, 2011). Sendo assim, o comportamento diferente da evolução das lesões periapicais nos animais MyD88 KO pode ter ocorrido devido à superativação desta via independente, 
principalmente pelo fato da mesma ser estimulada via TLR4. Esta hipótese suporta a relevância do LPS como principal mediador da gênese e progressão da lesão periapical.

Deve-se ressaltar que os mecanismos e processos que modularam a resposta imunoinflamatória do hospedeiro frente à infecção de origem endodôntica na ausência da molécula adaptadora MyD88 permanecem desconhecidos. Sabe-se que a deleção genética desta molécula resultou em alterações no sistema de defesa, confirmando o seu papel importante. Os resultados encontrados no presente estudo estão de acordo com Graves et al. (2011), que afirmaram que a inibição da resposta imune em lesões de origem endodôntica causa um aumento na suscetibilidade à infecção bacteriana. Além disso, os autores afirmaram que o uso de inibidores específicos de citocinas inflamatórias induz a formação de lesões osteolíticas mais extensas, uma vez que comprometem a capacidade do hospedeiro de se proteger do reservatório de bactérias presente em polpas necrosadas, como observado no presente estudo em camundongos MyD88 KO e no estudo de da Silva et al. (2012), em camundongos TLR2 KO.

Paralelamente, sabe-se que o osso é um tecido dinâmico que sofre constante remodelação ao longo da vida. Em condições de normalidade, é reabsorvido simultaneamente à formação de novo tecido e mantém a sua extensão e grau de mineralização por meio de um balanço entre formação e reabsorção. Em condições patológicas, quando há perda óssea, como nos casos das lesões periapicais crônicas, esse balanço é desestabilizado e a reabsorção se sobrepõe à formação óssea. Um dos achados característicos dessa condição é o acúmulo crescente de osteoclastos nas áreas de reabsorção óssea (Walsh et al., 2006). Em concordância com a literatura (Zhang e Peng, 2005; De Rossi et al., 2008; Xiong et al., 2009; Liu et al., 2010; Xiong et al., 2010; Silva et al., 2011; da Silva et al., 2012), no presente estudo foram observados osteoclastos associados às áreas de reabsorção na região periapical dos dentes de camundongos WT e MyD88 KO, após a histoenzimologia para marcação da atividade da TRAP. Entretanto, não foi possível observar diferenças na quantidade destas células entre ambos os grupos, em nenhum dos períodos experimentais ( $p=0,884$ em 7 dias; $p=0,506$ em 21 dias; e $p=0,211$ em 42 dias).

Sugere-se que a destruição tecidual aumentada observada nos espécimes do grupo MyD88 KO possa ter sido ocasionada também por outros mecanismos imunoinflamatórios, além daqueles que induzem a diferenciação e ativação osteoclástica. Estes mecanismos incluem a expressão de citocinas pró-inflamatórias que podem ter sido exacerbados pela presença de produtos e subprodutos mais agressivos e de outros fatores de virulência nas infecções endodônticas dos animais MyD88 KO. 
Osteoclastos, células multinucleadas e derivadas de precursores hematopoiéticos da linhagem monocítica-macrofágica, são as mais importantes células reabsortivas do corpo humano (Rho et al., 2004; Walsh et al., 2006; David, 2007; Asagiri e Takayanagi, 2007). A diferenciação de osteoclastos é regulada essencialmente por duas moléculas: o fator estimulador de colônias de macrófagos (M-CSF) (Asagiri e Takayanagi, 2007) e o receptor ativador do ligante do NF-кB (RANKL) (Teitelbaum e Ross, 2003; Asagiri e Takayanagi, 2007). Enquanto o M-CSF participa da proliferação e sobrevivência dos precursores de osteoclastos, o RANKL permite a diferenciação desses precursores (David, 2007), além de atuar na atividade e sobrevivência de osteoclastos maduros. O RANKL exerce sua função por meio de sua ligação no receptor RANK, presente nos precursores das células osteoclásticas, assim como nas células maduras. A interação entre RANKL e RANK ativa múltiplas vias intracelulares e fatores de transcrição, o que leva à diferenciação e ativação de osteoclastos (David, 2007; Asagiri e Takayanagi, 2007; Teitelbaum, 2007). Paralelamente, a osteoprotegerina (OPG) é o inibidor natural do RANKL, a qual pode impedir a ligação RANKRANKL (Teitelbaum, 2000; Theill et al., 2002; Alliston and Derynck, 2002; Baud' huin et al., 2007).

Por meio de análise imunohistoquímica no presente estudo, foi encontrada marcação similar para RANK, RANKL e OPG nos animais WT e MyD88 KO, nos períodos de 7, 21 e 42 dias. Desta forma, confirma-se a participação desses mediadores da osteoclastogênese no desenvolvimento da lesão periapical, como já sugerido na literatura (Sabeti et al., 2005; Menezes et al., 2006; Vernal et al., 2006; Kawashima et al., 2007; Menezes et al., 2008; Moraes et al., 2011, da Silva et al., 2012).

Resumidamente, os resultados obtidos no presente estudo permitiram confirmar a hipótese de que camundongos MyD88 KO desenvolvem lesões periapicais mais extensas que animais WT, provavelmente em função do prejuízo no sistema imunológico ocasionado pela ausência da molécula adaptadora MyD88, a qual participa da sinalização dos TLRs. Dessa forma, apesar da ativação das vias independentes, pode-se atribuir um papel protetor à participação dessa molécula nos inúmeros e complexos eventos moleculares envolvidos na resposta do organismo contra as infecções de origem endodôntica.

Deve-se ressaltar que o estudo das funções exercidas pelas moléculas e vias de sinalização responsáveis pelo reconhecimento de patógenos invasores e pelas reações imunoinflamatórias desencadeadas é de fundamental importância, pois possibilita a descoberta de novas estratégias e alvos terapêuticos, conduzindo ao desenvolvimento de medicamentos com a finalidade de modular a resposta do hospedeiro e gerar benefícios aplicáveis clinicamente. 
Estudos adicionais são necessários para elucidar as funções realizadas pela molécula adaptadora MyD88, bem como os mecanismos desencadeados após o seu silenciamento genético, incluindo compensação, estímulo e inibição dos eventos imunoinflamatórios e de reabsorção óssea, que ocorrem após o reconhecimento dos microrganismos e instalação da lesão periapical. 


\section{Conclusão}





\section{ConclusÃo}

Com base nas metodologias e nos resultados obtidos no presente estudo pode-se concluir que na ausência da MyD88, os animais apresentaram lesões periapicais mais extensas, com um infiltrado inflamatório severo e com número significantemente maior de neutrófilos, quando comparados aos animais WT, sugerindo o importante papel desta molécula na resposta imune e inflamatória do organismo no combate à infecção de origem endodôntica. 

Referências 



\section{REFERÊNCIAS}

1. Akira S, Takeda K. Toll-like receptor signalling. Nat Rev Immunol. 2004;4(7):499-511.

2. Akira $S$, Uematsu $S$, Takeuchi O. Pathogen recognition and innate immunity. Cell. 2006;124(4):783-801.

3. Alexopoulou L, Holt AC, Medzhitov R, Flavell RA. Recognition of double-stranded RNA and activation of NF-kappaB by Toll-like receptor 3. Nature. 2001;413(6857):732-8.

4. Aliprantis AO, Yang RB, Mark MR, Suggett S, Devaux B, Radolf JD, Klimpel GR, Godowski P, Zychlinsky A. Cell activation and apoptosis by bacterial lipoproteins through toll-like receptor-2. Science. 1999;285(5428):736-9.

5. Alliston T, Derynck R. Medicine: interfering with bone remodelling. Nature. 2002;416(6882):686-7.

6. Alshwaimi E, Purcell $P$, Kawai T, Sasaki H, Oukka M, Campos-Neto A, Stashenko P. Regulatory T cells in mouse periapical lesions. J Endod. 2009;35(9):1229-33.

7. Armant MA, Fenton MJ. Toll-like receptors: a family of pattern-recognition receptors in mammals. Genome Biol 2002;3(8):30111-6.

8. Asagiri $\mathrm{M}$, Takayanagi $\mathrm{H}$. The molecular understanding of osteoclast differentiation. Bone. 2007;40(2):251-64.

9. Assed S, Ito IY, Leonardo MR, Silva LAB, Lopatin DE. Anaerobic microorganisms in root canals of human teeth with chronic apical periodontitis detected by indirect immunofluorescence. Endod Dent Traumatol 1996;12(2):66-9.

10. Bar-Shavit Z. Taking a toll on the bones: regulation of bone metabolism by innate immune regulators. Autoimmunity. 2008;41(3):195-203.

11. Baud'huin $M$, Lamoureux F, Duplomb L, Rédini $F$, Heymann D. RANKL, RANK, osteoprotegerin: key partners of osteoimmunology and vascular diseases. Cell Mol Life Sci. 2007;64(18):2334-50.

12. Benarafa C, Priebe GP, Remold-O'Donnell E. The neutrophil serine protease inhibitor serpinb1 preserves lung defense functions in Pseudomonas aeruginosa infection. J Exp Med. 2007;204(8):1901-9.

13. Beutler BA. TLRs and innate immunity. Blood. 2009;113(7):1399-407.

14. Beutler B, Hoebe $K$, Du $X$, Ulevitch RJ. How we detect microbes and respond to them: the Toll-like receptors and their transducers. J Leukoc Biol 2003; 74(4):479-85.

15. Brown JH, Brenn L. A method for the differential staining of Gram-positive and Gramnegative bacteria in tissue sections. Bull. Johns Hopkins Hosp. 1931;48:69-73. 
16. Burgner D, Harnden A. Kawasaki disease: what is the epidemiology telling us about the etiology? Int J Infect Dis. 2005;9(4):185-94.

17. Chen $C P$, Hertzberg $M$, Jiang $Y$, Graves DT. Interleukin-1 and tumor necrosis factor receptor signaling is not required for bacteria-induced osteoclastogenesis and bone loss but is essential for protecting the host from a mixed anaerobic infection. Am J Pathol. 1999; 155:2145-52.

18. Cogulu D, Uzel A, Oncag O, Eronat C. PCR-based identification of selected pathogens associated with endodontic infections in deciduous and permanent teeth. Oral Surg Oral Med Oral Pathol Oral Radiol Endod. 2008;106(3):443-9.

19. Da Silva RAB, Ferreira PDF, De Rossi A, Nelson-Filho P, Silva LAB. Toll-like receptor2 knockout mice showed increased periapical lesion size and osteoclast number. J Endod 2012;38(6):803-13.

20. David JP. Osteoimmunology: a view from the bone. Adv Immunol. 2007;95:149-65.

21. De Rossi A, Rocha LB, Rossi MA. Application of fluorescence microscopy on hematoxylin and eosin-stained sections of healthy and diseased teeth and supporting structures. J Oral Pathol Med. 2007;36(6):377-81.

22. De Rossi A, Rocha LB, Rossi MA. Interferon-gamma, interleukin-10, Intercellular adhesion molecule-1, and chemokine receptor 5, but not interleukin-4, attenuate the development of periapical lesions. J Endod. 2008;34(1):31-8.

23. De Rossi, A. Interferon-gama, interleucina-10, molécula de adesão celular-1 e receptor de quimiocinas 5 desempenham papel protetor enquanto interleucina-4 não altera 0 desenvolvimento da lesão periapical experimentalmente induzida em camundongos. 2008. 102 f. Tese (Doutorado) - Faculdade de Medicina de Ribeirão Preto, Universidade de São Paulo, Ribeirão Preto, Brasil.

24. Desai SV, Love RM, Rich AM, Seymour GJ. Toll-like receptor 2 expression in refractory periapical lesions. Int Endod J. 2011;44(10):907-16.

25. Doyle SL, O'Neill LA. Toll-like receptors: from the discovery of NFkappaB to new insights into transcriptional regulations in innate immunity. Biochem Pharmacol. 2006;72(9):1102-13.

26. Dziarski R, Gupta D. Role of MD-2 in TLR2- and TLR4-mediated recognition of Gramnegative and Gram-positive bacteria and activation of chemokine genes. J Endotoxin Res. 2000;6(5):401-5.

27. Eming SA, Krieg T, Davidson JM. Inflammation in wound repair: molecular and cellular mechanisms. J Invest Dermatol. 2007;127(3):514-25.

28. Fabricius $L$, Dahlén $G$, Öhman $A E$, Möller AJR. Predominant indigenous oral bacteria isolated from infected root canals after varied times of closure. Scand J Dent Res $1982 ; 90(2): 134-44$. 
29. Ferreira PDF. Ausência do receptor Toll-like 2 ocasionou a formação de lesões periapicais mais extensas e com maior número de osteoclastos em camundongos. 2011. Dissertação de Mestrado - Faculdade de Odontologia de Ribeirão Preto, Universidade de São Paulo, Ribeirão Preto, Brasil.

30. Fouad AF. IL-1 alpha and TNF-alpha expression in early periapical lesions of normal and immunodeficient mice. J Dent Res. 1997;76(9):1548-54.

31. Fornarino S, Laval G, Barreiro LB, Manry J, Vasseur E, Quintana-Murci L. Evolution of the TIR-domain-containing adaptors in humans: swinging between constraint and adaptation. Mol Biol Evol. 2011;28(11):3087-97.

32. Forthal DN, Landucci G, Bream J, Jacobson LP, Phan TB, Montoya B. FcgammaRIIa genotype predicts progression of HIV infection. J Immunol. 2007;179(11):7916-23.

33. Gomes BPFA, Pinheiro ET, Gade-Neto CR, Sousa EL, Ferraz CC, Zaia AA, Teixeira FB, Souza-Filho FJ. Microbiological examination of infected dental root canals. Oral Microbiol Immunol 2004;19(2):71-6.

34. Gomes BP, Endo MS, Martinho FC. Comparison of endotoxin levels found in primary and secondary endodontic infections. J Endod. 2012;38(8):1082-6.

35. Gomes MT, Campos PC, de Almeida LA, Oliveira FS, Costa MM, Marim FM, Pereira GS, Oliveira SC. The role of innate immune signals in immunity to Brucella abortus. Front Cell Infect Microbiol. 2012;2:130.

36. of osteoimmunology and the host response in en dodontic and periodontal lesions. J Oral Microbiol. 2011;17;3. doi: 10.3402/jom.v3i0.5304.

37. Haimovich B, Calvano J, Haimovich AD, Calvano SE, Coyle SM, Lowry SF. In vivo endotoxin synchronizes and suppresses clock gene expression in human peripheral blood leukocytes. Crit Care Med. 2010 Mar;38(3):751-8.

38. Hanke ML, Angle A, Kielian T. MyD88-dependent signaling influences fibrosis and alternative macrophage activation during Staphylococcus aureus biofilm infection. PLoS One. 2012;7(8):e42476.

39. Hayashi F, Means TK, Luster AD. Toll-like receptors stimulate human neutrophil function. Blood. 2003;102(7):2660-9.

40. Hayashi F, Smith KD, Ozinsky A, Hawn TR, Yi EC, Goodlett DR, Eng JK, Akira S, Underhill DM, Aderem A. The innate immune response to bacterial flagellin is mediated by Toll-like receptor 5. Nature. 2001;410(6832):1099-103.

41. Hedayat M, Takeda K, Rezaei N. Prophylactic and therapeutic implications of toll-like receptor ligands. Med Res Rev. 2012;32(2):294-325.

42. Heil F, Hemmi H, Hochrein H, Ampenberger F, Kirschning C, Akira S, Lipford G, Wagner $\mathrm{H}$, Bauer S. Species-specific recognition of single-stranded RNA via toll-like receptor 7 and 8. Science. 2004;303(5663):1526-9. 
43. Helewski KJ, Kowalczyk-Ziomek GI, Konecki J. Neutrophils' contribution to ischaemia and reperfusion injury in liver. Wiad Lek. 2007;60(1-2):47-52.

44. Hemmi H, Takeuchi O, Kawai T, Kaisho T, Sato S, Sanjo H, Matsumoto M, Hoshino K, Wagner $\mathrm{H}$, Takeda $\mathrm{K}$, Akira S. A Toll-like receptor recognizes bacterial DNA. Nature. 2000;408(6813):740-5.

45. Hetherington $\mathrm{CJ}$, Kingsley PD, Crocicchio F, Zhang P, Rabin MS, Palis J, Zhang D. Characterization of Human Endotoxin Lipopolysaccharide Receptor CD14 Expression in Transgenic Mice. J Immunol. 1999;162(1):503-9.

46. Hirao K, Yumoto H, Takahashi K, Mukai K, Nakanishi T, Matsuo T. Roles of TLR2, TLR4, NOD2, and NOD1 in pulp fibroblasts. J Dent Res. 2009;88(8):762-7.

47. Hoshino K, Takeuchi O, Kawai T, Sanjo H, Ogawa T, Takeda Y, Takeda K, Akira S. Cutting edge: Toll-like receptor 4 (TLR4)-deficient mice are hyporesponsive to lipopolysaccharide: evidence for TLR4 as the Lps gene product. J Immunol. 1999;162(7):3749-52.

48. Hou L, Sasaki H, Stashenko P. Toll-like receptor 4-deficient mice have reduced bone destruction following mixed anaerobic infection. Infect Immun. 2000;68(8):4681-7.

49. Huang GT, Do M, Wingard M, Park JS, Chugal N. Effect of interleukin-6 deficiency on the formation of periapical lesions after pulp exposure in mice. Oral Surg Oral Med Oral Pathol Oral Radiol Endod. 2001;92(1):83-8.

50. Hughes MA, Green CS, Lowchyj L, Lee GM, Grippe VK, Smith MF Jr, Huang LY, Harvill ET, Merkel TJ. MyD88-dependent signaling contributes to protection following Bacillus anthracis spore challenge of mice: implications for Toll-like receptor signaling. Infect Immun. 2005;73(11):7535-40.

51. Ito IY, Junior FM, Paula-Silva FW, Da Silva LA, Leonardo MR, Nelson-Filho P. Microbial culture and checkerboard DNA-DNA hybridization assessment of bacteria in root canals of primary teeth pre- and post-endodontic therapy with a calcium hydroxide/chlorhexidine paste. Int J Paediatr Dent. 2011;21(5):353-60.

52. Jiang J, Zuo J, Chen SH, Holliday LS. Calcium hydroxide reduces lipopolysaccharidestimulated osteoclast formation. Oral Surg Oral Med Oral Pathol Oral Radiol Endod. 2003;95(3):348-54.

53. Kandaswamy D, Venkateshbabu N. Root canal irrigants. J Conserv Dent 2010;13(4):256-64.

54. Kawai T, Adachi O, Ogawa T, Takeda K, Akira S. Unresponsiveness of MyD88-deficient mice to endotoxin. Immunity. 1999;11(1):115-22.

55. Kawai T, Akira S. TLR signaling. Cell Death Differ. 2006;13(5):816-25.

56. Kawai T, Akira S. The roles of TLRs, RLRs and NLRs in pathogen recognition. Int Immunol. 2009;21(4):317-37. 
57. Kawai T, Akira S. Toll-like receptors and their crosstalk with other innate receptors in infection and immunity. Immunity. 2011;34(5):637-50.

58. Kawashima N, Suzuki N, Yang G, Ohi C, Okuhara S, Nakano-Kawanishi H, Suda H. Kinetics of RANKL, RANK and OPG expressions in experimentally induced rat periapical lesions. Oral Surg Oral Med Oral Pathol Oral Radiol Endod. 2007;103(5):707-11.

59. Kerekes K, Tronstad L. Long-term results of endodontic treatment performed with a standardized technique. J Endod. 1979;5(3):83-90.

60. Kirschning $\mathrm{CJ}$, Wesche $\mathrm{H}$, Merrill Ayres $\mathrm{T}$, Rothe M. Human toll-like receptor 2 confers responsiveness to bacterial lipopolysaccharide. J Exp Med. 1998;188(11):2091-7.

61. Kobe $B$, Kajava AV. The leucine-rich repeat as a protein recognition motif. Curr Opin Struct Biol. 2001;11(6):725-32.

62. Koh YS, Koo JE, Biswas A, Kobayashi KS. MyD88-dependent signaling contributes to host defense against ehrlichial infection. PLoS One. 2010;5(7):e11758.

63. Komai-Koma M, Jones L, Ogg GS, Xu D, Liew FY. TLR2 is expressed on activated T cells as a costimulatory receptor. Proc Natl Acad Sci U S A. 2004;101(9):3029-34.

64. LaRosa DF, Stumhofer JS, Gelman AE, Rahman AH, Taylor DK, Hunter CA, Turka LA. T cell expression of MyD88 is required for resistance to Toxoplasma gondii. Proc Natl Acad Sci U S A. 2008;105(10):3855-60.

65. Lemaitre B, Reichhart JM, Hoffmann JA. Drosophila host defense: differential induction of antimicrobial peptide genes after infection by various classes of microorganisms. Proc Natl Acad Sci U S A. 1997;94(26):14614-9.

66. Leonardo MR. Endodontia: tratamento de canais radiculares: princípios técnicos e biológicos. Artes Medicas: São Paulo; 2005.

67. Leonardo MR, Leonardo RT. Tratamento de canais radiculares: Avanços tecnológicos de uma endodontia minimamente invasiva e reparadora. São Paulo: Artes Médicas; 2012.

68. Leonardo MR, Rossi MA, Silva LA, Ito IY, Bonifácio KC. EM evaluation of bacterial biofilm and microorganisms on the apical external root surface of human teeth. J Endod. 2002;28(12):815-8.

69. Leonardo MR, Rossi MA, Bonifácio KC, da Silva LA, Assed S. Scanning electron microscopy of the apical structure of human teeth. Ultrastruct Pathol. 2007;31(4):3215.

70. Lin LM, Skribner JE, Gaengler P. Factors associated with endodontic treatment failures. J Endod. 1992;18(12):625-7.

71. Liu H, Komai-Koma M, Xu D, Liew FY. Toll-like receptor 2 signaling modulates the functions of $\mathrm{CD} 4+\mathrm{CD} 25+$ regulatory $T$ cells. Proc Natl Acad Sci $U$ S A. 2006;103(18):7048-53. 
72. Liu S, Cheng Y, Xu W, Bian Z. Protective effects of follicle-stimulating hormone inhibitor on alveolar bone loss resulting from experimental periapical lesions in ovariectomized rats. J Endod. 2010;36(4):658-63.

73. Loures FV, Pina A, Felonato M, Feriotti C, de Araújo EF, Calich VL. MyD88 signaling is required for efficient innate and adaptive immune responses to Paracoccidioides brasiliensis infection. Infect Immun. 2011;79(6):2470-80.

74. Lye E, Mirtsos C, Suzuki N, Suzuki S, Yeh WC. The role of interleukin 1 receptorassociated kinase-4 (IRAK-4) kinase activity in IRAK-4-mediated signaling. J Biol Chem. 2004;279(39):40653-8.

75. McCurdy JD, Olynych TJ, Maher LH, Marshall JS. Cutting edge: distinct Toll-like receptor 2 activators selectively induce different classes of mediator production from human mast cells. J Immunol. 2003;170(4):1625-9.

76. Mc Gee JOD, Isaacson PG, Wright NA. Oxford textbook of pathology. Principles of pathology. Oxford: University Press, 1992. p.895.

77. Medzhitov R, Preston-Hurlburt $\mathrm{P}$, Janeway CA Jr. A human homologue of the Drosophila Toll protein signals activation of adaptive immunity. Nature. 1997;388(6640):394-7.

78. Medzhitov R. Toll-like receptors and innate immunity. Nat Rev Immunol. 2001;1(2):135-45.

79. Menezes R, Bramante CM, da Silva Paiva KB, Letra A, Carneiro E, Fernando Zambuzzi W, Granjeiro JM. Receptor activator NFkappaB-ligand and osteoprotegerin protein expression in human periapical cysts and granulomas. Oral Surg Oral Med Oral Pathol Oral Radiol Endod. 2006;102(3):404-9.

80. Menezes R, Garlet TP, Letra A, Bramante CM, Campanelli AP, Figueira Rde C, Sogayar MC, Granjeiro JM, Garlet GP. Differential patterns of receptor activator of nuclear factor kappa B ligand/osteoprotegerin expression in human periapical granulomas: possible association with progressive or stable nature of the lesions. J Endod. 2008;34(8):9328.

81. Miggin SM, O'Neill LA. New insights into the regulation of TLR signaling. J Leukoc Biol. 2006;80(2):220-6.

82. Minkin C. Bone acid phosphatase: tartrate-resistant acid phosphatase as a marker of osteoclast function. Calcif Tissue Int. 1982;34:285-90.

83. Miyake K. Endotoxin recognition molecules, Toll-like receptor 4-MD-2. Seminars in Immunology. 2004;16(1):11-6.

84. Mohammadi Z. Endotoxin in Endontic Infections: A Rewiew. J Calif Dent Assoc. 2011;39(3):153-61.

85. Moraes M, Lucena HF, Azevedo PR, Queiroz LM, Costa AD. Comparative immunohistochemical expression of RANK, RANKL and OPG in radicular and dentigerous cysts. Arch Oral Biol. 2011;56(11):1256-63. 
86. Nair PN, Sjögren U, Krey G, Kahnberg KE, Sundqvist G. Intraradicular bacteria and fungi in root-filled, asymptomatic human teeth with therapy-resistant periapical lesions: a long-term light and electron microscopic follow-up study. J Endod. 1990;16(12):5808.

87. Nelson-Filho P, Leonardo MR, Silva LA, Assed S. Radiographic evaluation of the effect of endotoxin (LPS) plus calcium hydroxide on apical and periapical tissues of dogs. J Endod. 2002;28(10):694-6.

88. Nilsen N, Nonstad U, Khan N, Knetter CF, Akira S, Sundan A, Espevik T, Lien E. Lipopolysaccharide and double-stranded RNA up-regulate toll-like receptor 2 independently of myeloid differentiation factor 88. J Biol Chem. 2004;279(38):3972735.

89. O'Neill LA, Bowie AG. The family of five: TIR-domain-containing adaptors in Toll-like receptor signalling. Nat Rev Immunol. 2007;7(5):353-64.

90. Orstavik D. Time-course and risk analyses of the development and healing of chronic apical periodontitis in man. Int Endod J. 1996;29(3):150-5.

91. Poltorak A, He X, Smirnova I, Liu MY, Van Huffel C, Du X, Birdwell D, Alejos E, Silva M, Galanos C, Freudenberg M, Ricciardi-Castagnoli P, Layton B, Beutler B. Defective LPS signaling in $\mathrm{C} 3 \mathrm{H} / \mathrm{He}$ and $\mathrm{C} 57 \mathrm{BL} / 10 \mathrm{ScCr}$ mice: mutations in Tlr4 gene. Science. 1998;282(5396):2085-8.

92. Rashid T, Ebringer A. Rheumatoid arthritis is linked to Proteus--the evidence. Clin Rheumatol. 2007;26(7):1036-43.

93. Regan JD, Fleury AA. Irrigants in non-surgical endodontic treatment. J Ir Dent Assoc. 2006;52(2):84-92.

94. Reinke JM, Sorg H. Wound repair and regeneration. Eur Surg Res. 2012;49(1):35-43.

95. Rho J, Takami M, Choi Y. Osteoimmunology: interactions of the immune and skeletal systems. Mol Cells. 2004;17(1):1-9.

96. Rietschel ET, Brade H. Bacterial endotoxins. Scientific American. 1992;267(2):26-33.

97. Rôças IN, Siqueira JF Jr. Identification of bacteria enduring endodontic treatment procedures by a combined reverse transcriptase-polymerase chain reaction and reverse-capture checkerboard approach. J Endod. 2010. Jan;36(1):45-52.

98. Rocha CT, Rossi MA, Leonardo MR, Rocha LB, Nelson-Filho P, Silva LA. Biofilm on the apical region of roots in primary teeth with vital and necrotic pulps with or without radiographically evident apical pathosis. Int Endod J. 2008;41(8):664-9.

99. Ruviere DB, Leonardo MR, Silva LA, Ito IY, Nelson-Filho P. Assessment of the microbiota in root canals of human primary teeth by checkerboard DNA-DNA hybridization. J Dent Child. 2007; 74(2):118-23.

100. Sabeti M, Simon J, Kermani V, Valles Y, Rostein I. Detection of receptor activator of NF-kappa beta ligand in apical periodontitis. J Endod. 2005;31(1):17-8. 
101. Sakamoto M, Siqueira JF Jr, Rôças IN, Benno Y. Molecular analysis of the root canal microbiota associated with endodontic treatment failures. Oral Microbiol Immunol. 2008;23(4):275-81.

102. Schwandner $R$, Dziarski $R$, Wesche $H$, Rothe $M$, Kirschning $C J$. Peptidoglycan- and lipoteichoic acid-induced cell activation is mediated by toll-like receptor 2. J Biol Chem. 1999;274(25):17406-9.

103. Segal AW. How neutrophils kill microbes. Annu Rev Immunol. 2005;23:197-223.

104. Seltzer S, Farber PA. Microbiologic factors in endodontology. Oral Surg Oral Med Oral Pathol 1994;78(5):634-45.

105. Siednienko J, Gajanayake T, Fitzgerald KA, Moynagh P, Miggin SM. Absence of MyD88 results in enhanced TLR3-dependent phosphorylation of IRF3 and increased IFN- $\beta$ and RANTES production. J Immunol. 2011;186(4):2514-22.

106. Silva LA, Leonardo MR, Oliveira DS, Silva RA, Queiroz AM, Hernández PG, Nelson-Filho $P$. Histopathological evaluation of root canal filling materials for primary teeth. Braz Dent J. 2010;21(1):38-45.

107. Silva LA, Nelson-Filho $P$, Leonardo MR, Rossi MA, Pansani CA. Effect of calcium hydroxide on bacterial endotoxin in vivo. J Endod. 2002;28(2):94-8.

108. Silva LA, Silva RA, Branco LG, Navarro VP, Nelson-Filho P. Quantitative radiographic evaluation of periapical bone resorption in dog's teeth contaminated with bacterial endotoxin (LPS) associated or not with calcium hydroxide. Braz Dent J. 2008;19(4):296-300.

109. Silva MJ, Sousa LM, Lara VP, Cardoso FP, Júnior GM, Totola AH, Caliari MV, Romero $\mathrm{OB}$, Silva GA, Ribeiro-Sobrinho AP, Vieira LQ. The role of iNOS and PHOX in periapical bone resorption. J Dent Res. 2011;90(4):495-500.

110. Siqueira JF Jr, Rôças IN. Polymerase chain reaction-based analysis of microorganisms associated with failed endodontic treatment. Oral Surg Oral Med Oral Pathol Oral Radiol Endod. 2004;97(1):85-94.

111. Sjögren U, Figdor D, Persson S, Sundqvist G. Influence of infection at the time of root filling on the outcome of endodontic treatment of teeth with apical periodontitis. Int Endod J. 1997;30(5):297-306.

112. Stashenko P. Role of immune cytokines in the pathogenesis of periapical lesions. Endod Dent Traumatol. 1990;6(3):89-96.

113. Stashenko P, Dewhirst FE, Peros WJ, Kent RL, Ago JM. Synergistic interactions between interleukin 1, tumor necrosis factor, and lymphotoxin in bone resorption. J Immunol. 1987;138(5):1464-8.

114. Stashenko $\mathrm{P}, \mathrm{Yu} \mathrm{SM}$, Wang $\mathrm{CY}$. Kinetics of immune cell and bone resorptive responses to endodontic infections. J Endod. 1992;18(9):422-6. 
115. Takeda K, Akira S. Microbial recognition by Toll-like receptors. J Dermatol Sci. 2004;34(2):73-82.

116. Takeda K, Akira S. Toll-like receptors in innate immunity. Int Immunol. 2005;17(1):114.

117. Takeuchi O, Takeda K, Hoshino K, Adachi O, Ogawa T, Akira S. Cellular responses to bacterial cell wall components are mediated through MyD88-dependent signaling cascades. Int Immunol 2000;12(1):113-7.

118. Takeuchi O, Kawai T, Mühlradt PF, Morr M, Radolf JD, Zychlinsky A, Takeda K, Akira S. Discrimination of bacterial lipoproteins by Toll-like receptor 6 . Int Immunol. 2001;13(7):933-40.

119. Takeuchi O, Sato S, Horiuchi T, Hoshino K, Takeda K, Dong Z, Modlin RL, Akira S. Cutting edge: role of Toll-like receptor 1 in mediating immune response to microbial lipoproteins. J Immunol. 2002;169(1):10-4.

120. Taylor RD. Modification of the Brown and Brenn Gram stain for the differential staining of gram-positive and gram-negative bacteria in tissue sections. Am J Clin Pathol. 1966; $46: 472-6$.

121. Teitelbaum SL, Ross FP. Genetic regulation of osteoclast development and function. Nat Rev Genet. 2003;4(8):638-49.

122. Teitelbaum SL. Bone resorption by osteoclasts. Science. 2000;289(5484):1504-8.

123. Teitelbaum SL. Osteoclasts: what do they do and how do they do it? Am J Pathol. 2007; 170(2):427-35.

124. Theill LE, Boyle WJ, Penninger JM. RANK-L and RANK: T cells, bone loss, and mammalian evolution. Annu Rev Immunol. 2002;20:795-823.

125. Tronstad L. Recent development in endodontic research. Scand J Dent Res. $1992 ; 100(1): 52-9$.

126. Underhill DM, Ozinsky A, Smith KD, Aderem A. Toll-like receptor-2 mediates mycobacteria-induced proinflammatory signaling in macrophages. Proc Natl Acad Sci U S A. 1999;96(25):14459-63.

127. Underhill DM, Ozinsky A. Toll-like receptors: key mediators of microbe detection. Curr Opin Immunol. 2002;14(1):103-10.

128. Van Bodegom D, May L, Meij HJ, Westendorp RG. Regulation of human life histories: the role of the inflammatory host response. Ann N Y Acad Sci. 2007;1100:84-97.

129. Vasilevsky S, Chattopadhyay G, Colino J, Yeh TJ, Chen Q, Sen G, Snapper CM. B and CD4+ T-cell expression of TLR2 is critical for optimal induction of a T-cell-dependent humoral immune response to intact Streptococcus pneumoniae. Eur J Immunol. 2008;38(12):3316-26. 
130. Vernal R, Dezerega A, Dutzan N, Chaparro A, León R, Chandía S, Silva A, Gamonal J. RANKL in human periapical granuloma: possible involvement in periapical bone destruction. Oral Dis. 2006;12(3):283-9.

131. Walsh MC, Kim N, Kadono Y, Rho J, Lee SY, Lorenzo J, Choi Y. Osteoimmunology: interplay between the immune system and bone metabolism. Annu Rev Immunol. 2006;24:33-63.

132. Wang $L$, Zhang $R$, Xiong $H$, Peng $B$. The involvement of platelet-derived growth factor$A$ in the course of apical periodontitis. Int Endod J. 2011;44(1):65-71.

133. Warshawsky $\mathrm{H}$, Moore $\mathrm{G}$. A technique for the fixation and decalcification of rat incisors for electron microscopy. J Histochem Cytochem. 1967;15(9):542-9.

134. Xiong $\mathrm{H}$, Wei $\mathrm{L}$, Hu $\mathrm{Y}$, Zhang $\mathrm{C}$, Peng B. Effect of alendronate on alveolar bone resorption and angiogenesis in rats with experimental periapical lesions. Int Endod $\mathrm{J}$. 2010;43(6):485-91.

135. Xiong $H$, Wei $L$, Peng B. Immunohistochemical localization of $\mathrm{IL}-17$ in induced rat periapical lesions. J Endod. 2009;35(2):216-20.

136. Yarovinsky F, Zhang D, Andersen JF, Bannenberg GL, Serhan CN, Hayden MS, Hieny S, Sutterwala FS, Flavell RA, Ghosh S, Sher A. TLR11 activation of dendritic cells by a protozoan profilin-like protein. Science. 2005;308(5728):1626-9.

137. Zhang X, Peng B. Immunolocalization of receptor activator of NF kappa B ligand in rat periapical lesions. J Endod. 2005;31(8):574-7. 
Apêndice 



\section{APÊNDICE}

MyD88 knockout mice develop enlarged periapical lesions with increased numbers of neutrophils

Raquel Assed Bezerra da Silva, DDS, MSc, $\mathrm{PhD}^{1}$; Paulo Nelson-Filho, DDS, MSc, $\mathrm{PhD}^{1}$, Marília Pacífico Lucisano, DDS, MSc${ }^{1}$; Andiara De Rossi, DDS, MSc, PhD ${ }^{1}$; Alexandra Mussolino de Queiroz, DDS, MSc, $\mathrm{PhD}^{1}$; Lea Assed Bezerra da Silva, DDS, MSc, PhD

${ }^{\mathbf{1}}$ Department of Pediatric Dentistry, School of Dentistry of Ribeirão Preto, University of São Paulo, Ribeirão Preto, SP, Brazil

Key words: periapical lesion, MyD88 molecule, toll-like receptors, knockout mice.

\section{Acknowledgement}

"The authors deny any conflicts of interest. We affirm that we have no financial affiliation (e.g., employment, direct payment, stock holdings, retainers, consultantships, patent licensing arrangements or honoraria), or involvement with any commercial organization with direct financial interest in the subject or materials discussed in this manuscript, nor have any such arrangements existed in the past three years."

\section{Address Correspondence and Reprint Requests to:}

Profa. Dra. Raquel Assed Bezerra da Silva, Departamento de Clínica Infantil, Faculdade de Odontologia de Ribeirão Preto, USP, Av. do Café, s/n, Monte Alegre, 14040-904 Ribeirão Preto, SP, Brasil. Tel: +55-16-3602-4786. Fax: +55-16-3633-0999. E-mail: raquel@forp.usp.br 


\begin{abstract}
Introduction: The aim of the present study was to characterize the formation and progression of experimentally induced periapical lesions in teeth of myeloid differentiation primary response gene 88 knockout (MyD88 KO) mice compared with wild-type (WT) mice. Methods: Periapical lesions were induced in the mandibular first molars of $30 \mathrm{WT}$ and $30 \mathrm{MyD} 88 \mathrm{KO}$ mice. After 7, 21 and 42 days, the animals were euthanized and the mandibles were subjected to histotechnical processing. Histological sections were stained with hematoxylin and eosin (HE); TRAP histoenzymology, Brown \& Brenn staining, and immunohistochemistry (RANK, RANKL, OPG). Data were subjected to statistical analysis by the nonparametric Mann-Whitney and Kruskal-Wallis tests and the Dunn posttest, using the SPSS software, version $17.0(\alpha=0.05)$. Results: Regarding the periapical lesion size, the MyD88 KO group presented significantly higher values than the WT group in the periods of 7 $(\mathrm{p}=0.001)$ and 21 days $(\mathrm{p}=0.05)$. A larger number of neutrophils in the MyD88 KO group were observed ( $\mathrm{p}=0.01$ at 7 days, $\mathrm{p}=0.004$ at 21 days and $\mathrm{p}<0.001$ at 42 days). Regarding the number of osteoclasts, no statistically significant difference was observed between the groups at any of the experimental periods ( $\mathrm{p}=0.884$ at 7 days, $\mathrm{p}=0.506$ at 21 days and $\mathrm{p}=0.211$ at 42 days). Conclusions: In the absence of MyD88, the animals showed larger periapical lesions, with a severe inflammatory infiltrate and a significantly larger number of neutrophils, suggesting the important role of this molecule during the immune and inflammatory response against infections of endodontic origin.
\end{abstract}

Key words: periapical lesion, MyD88 molecule, toll-like receptors, knockout mice. 


\section{Introduction}

The activation of the host immunoinflammatory response to infection occurs via Pattern Recognition Receptors (PRRs), which are expressed in different cell compartments and which recognize intracellular and extracellular pathogens. PRRs identify Pathogen-Associated Molecular Patterns (PAMPs), which are structurally conserved antigenic moieties that are found both within the pathogens' surface and structure (1). Toll-Like receptors (TLRs) stand out among PRRs (2, 3), participating in the early recognition of various pathogens and immune response activation (1).

TLRs consist of an extracellular N-terminal domain, which is involved in microorganism recognition, signal transduction and receptor dimerization (4), and an intracellular C-terminal domain, which mediates protein-protein interactions between TLRs and signal transducers (5). Intracellular pathways are activated through Toll/IL-1 receptor (TIR) domain interactions with proteins or adapter molecules that are recruited to the site, among which myeloid differentiation primary response gene 88 (MyD88) stands out (6).

MyD88 participates in the activation of all of the TLRs (except TLR3) and triggers the activation of protein kinases and transcription factors that stimulate the expression of genes that are involved in the inflammatory response (7). The MyD88 signaling pathway promotes the recruitment of IL-1R-associated kinase-4 (IRAK-4) and facilitates the phosphorylation of IRAK-1. Once activated, IRAK-1 associates with TNFR-associated factor 6 (TRAF6), triggering the activation of two different signaling pathways (8). The first pathway triggers the activation of activator protein-1 (AP-1) transcription factors through mitogen-activated protein kinases (MAPK) activation. The second pathway activates the transforming growth factor $\beta$-activated kinase 1/TAK1-binding protein (TAK1/TAB) complex, which enhances IкB kinase (IKK) complex activity. This effect induces the phosphorylation and subsequent degradation of inhibitor of $\kappa \mathrm{B}(\mathrm{I} \kappa \mathrm{B})$, causing nuclear translocation of the transcription factor nuclear factor kappa-light-chain-enhancer of activated B cells (NF- $\kappa \mathrm{B})$ and its binding to DNA target regions.

Studies have evaluated the effect of MyD88-dependent signaling in immune system activation and performance in response to infection with different pathogens $(6,7,9-13)$. Although the precise 
contribution of this molecule is not entirely understood, the results tend to indicate that MyD88 plays a key role in controlling infection, the immediate activation of the innate immune system, cytokine production and adaptive immune response activation in late stages (11).

Teeth with pulp necrosis and chronic periapical lesions are known to typify an infectious and immunoinflammatory process, being characterized by a mixed and complex microbiota throughout the root canal system, with a predominance of strictly anaerobic, particularly Gram-negative, microorganisms (14-17). Gram-negative microorganisms contain endotoxins in their cell wall, which stimulate the release of a large number of pro-inflammatory cytokines or bioactive chemical mediators, including Interleukin-1 (IL-1), IL-5, IL-6, IL-8, tumor necrosis factor- $\alpha$ (TNF- $\alpha$ ), TNF- $\beta$ (lymphotoxins), interferon-alpha (IF- $\alpha$ ), and prostaglandins (18-20). These endotoxins cause an inflammatory reaction and periapical bone resorption $(5,21-24)$.

TLRs are highly expressed in multiple cell types that are associated with endodontic infections. The activation of these receptors causes the stimulation of multiple pro-inflammatory cytokines, including IL-1, TNF- $\alpha$, and IL-6. These cytokines are involved in the increased production of receptor activator of nuclear factor-kappa B ligand (RANKL), which regulates osteoclastogenesis and bone resorption $(2,25)$.

Recently, a study that was conducted in our laboratory evaluated the formation and progress of experimentally induced periapical lesions in TLR2 knockout mice. The lack of this receptor was shown to cause the formation of more extensive periapical lesions, with a higher number of osteoclasts than was observed in wild-type (WT) mice. These results indicated a key role of TLR2 during the immunoinflammatory response that is triggered to fight infection of the root canal system and periapical tissue. It was suggested that TLR2 silencing, which is strongly related to the recognition of Gram-positive pathogens and their by-products, caused a more intense activation of other TLRs, particularly TLR4, the activity of which may have exacerbated the deleterious effects of bacterial lipopolysaccharides (LPS) (26). Conversely, TLR4 knockout mice were reported to exhibit reduced alveolar bone destruction, which was directly correlated with the lower expression of bone resorptioninducing cytokines, IL-1 $\alpha$ and IL-1 $\beta$ and IL-12 (27). 
Although the role of adapter molecule MyD88 in controlling infection and immune system activation has been examined, its function/involvement in the development and progression of periapical lesions has not been investigated. For these reasons, the aim of the current study was to describe the formation and progression of experimentally induced periapical lesions in the teeth of MyD88 knockout mice compared to WT mice. This analysis was performed with conventional light microscopy, fluorescence microscopy, tartrate-resistant acid phosphatase (TRAP) histoenzymology, Brown \& Brenn staining and immunohistochemistry.

\section{Materials and Methods}

The current research project was initially submitted and approved by the Ethics Committee on Animal Use of the University of São Paulo (Comissão de Ética no Uso de Animais da Universidade de São Paulo, USP) - Ribeirão Preto Campus (Case no. 11.1.91.53.0). We used 30 male WT C57BL/6 mice between 6 and 8 weeks of age. The mice weighed an average of 20 grams and were purchased from the Central Animal Facility of the University of São Paulo (Biotério Central da Universidade de São Paulo) - Ribeirão Preto Campus. We also examined 30 C57BL/6 MyD88 knockout mice (MyD88 KO), which were provided by the Genetics Animal Facility of the School of Medicine of Ribeirão Preto (Biotério de Genética da Faculdade de Medicina de Ribeirão Preto) - USP and from The Jackson Laboratory, Bar Harbor, Maine. All of the animals were maintained in the animal facility of the School of Dentistry of Ribeirão Preto (Faculdade de Odontologia de Ribeirão Preto) - USP and received routine care.

\section{The induction of periapical lesions}

The animals were anesthetized intramuscularly with ketamine (10\% ketamine, Agener União Química Farmacêutica Nacional ([Agener National Pharmaceutical Chemical Union] S/A, EmbuGuaçu, São Paulo [SP]) at a dose of $150 \mathrm{mg} / \mathrm{Kg}$ body weight, and 2\% xylazine (Dopaser, Laboratórios Calier [Calier Laboratories], SA, Barcelona, Spain) at a dose of $7.5 \mathrm{mg} / \mathrm{Kg}$ body weight to perform the surgical procedures. 
The induction of periapical lesions was performed on the mandibular first molars, totaling 60 teeth for each group of animals. Initially, the crown opening was performed via the occlusal surface using a stainless steel round bur (no. 1/4 - GDK Densell Dental Technology, Buenos Aires, Argentina) that was mounted on a low-speed handpiece. The root canals were located using a sterilized endodontic number 08 K-file (Les Fils d'Auguste Maillefer S/A, Switzerland) and were exposed to the oral environment to induce periapical lesions. Following periods of 7, 21 and 42 days, the animals were randomly submitted to euthanasia in a $\mathrm{CO}_{2}$ chamber.

\section{Histotechnical processing and microscopic evaluation}

Following euthanasia, the mandibles were removed, fixed, decalcified and submitted to routine histological processing (26). Semi-serial $5 \mu \mathrm{m}$-thick sections were longitudinally cut throughout the length of the periapical lesion.

Sections that were representative of each experimental group were stained with hematoxylin and eosin (H\&E) and submitted to light microscopy analysis to observe the features of the root canal and the periapical and apical regions and to count the number of inflammatory cells (neutrophils). We performed a parallel morphometric analysis of the area of the periapical lesions using fluorescence microscopy. Subsequently, sequential specimens were evaluated by (i) TRAP activity histoenzymology to identify and count the osteoclasts; (ii) Brown \& Brenn staining to identify the presence and location of bacteria; and (iii) immunohistochemistry to identify osteoclastogenesis markers (Receptor Activator of Nuclear Factor $\kappa$ B [RANK], RANKL, and Osteoprotegerin [OPG]).

All of the analyses were performed using an Axio Imager.M1 microscope (Carl Zeiss MicroImaging GmbH, Göttingen, Germany) that was coupled to an AxioCam MRc5 camera (Carl Zeiss MicroImaging GmbH, Göttingen, Germany). The analyses were only performed in the distal roots of mandibular first molars using sections simultaneously showing the coronary, the middle and the apical thirds of the root canal, the apical foramen and the alveolar bone. All of the analyses were performed by a single experienced assessor, without prior knowledge of the group under analysis. 
Descriptive microscopic analysis of the characteristics of the root canal and the apical and periapical regions

The descriptive analysis of the root canal and the periapical and apical regions was performed on sections that were representative of each period and each experimental group, according to the following parameters (26): root canal: necrosis (total or partial); apical cementum: surface characteristics (regular or irregular); periodontal ligament: size (normal or increased), the characteristics of the inflammatory cell infiltrate and the presence of edema and collagen fibers; alveolar bone: the absence/presence of resorption, osteoclasts and osteoblasts.

\section{Fluorescence microscopy morphometrics}

The morphometric assessment of the area of the periapical lesions was performed on the H\&E-stained specimens using an Axio Imager.M1 microscope at $10 \mathrm{X}$ magnification, operating in fluorescence mode, as described by De Rossi et al. (28) and da Silva et al. (26). The delimitation of the lesion excluded the intact structures (i.e., the periodontal ligament, the cementum and the alveolar bone), which were easily identified by strong green fluorescence, and included areas of resorption and inflammatory infiltrate, which were identified by the lack of fluorescence and a darkened appearance.

\section{Inflammatory cell count (neutrophils)}

The neutrophil count was subsequently performed for the same representative sections using light microscopy and was based on their morphological characteristics (i.e., darkly stained cells with multilobed, horseshoe-shaped nuclei). The neutrophils were counted in the middle region of the lesion, adjacent to the apical foramen, in an area of approximately $0.08 \mathrm{~mm}^{2}$, according to De Rossi et al. (29) and da Silva et al. (26). The results are expressed as the number of cells.

\section{Tartrate-resistant acid phosphatase (TRAP) activity histoenzymology}

TRAP activity was used for osteoclast staining and counting as described by da Silva et al. (26). The results are expressed as cell number, according to da Silva et al. (26). 


\section{Brown \& Brenn modified staining}

Brown \& Brenn (30) staining was used to assess the presence of absence of bacteria and their location in the tooth's crown, root canal system and periapical tissues (cementum, periodontal ligament and alveolar bone) (31). Scores from 0 to 5 were assigned for this assessment $(26,29)$ using the following system: 0 , the absence of bacteria; 1 , the presence of bacteria in the tooth's crown; 2 , the presence of bacteria in the cervical third of the root canal; 3 , the presence of bacteria in the middle third of the root canal; 4 , the presence of bacteria in the apical third of the root canal; and 5, the presence of bacteria in the periapical lesion.

\section{Immunostaining (Immunohistochemistry)}

The reactions were performed using the avidin-biotin-peroxidase complex method (indirect method), as described by da Silva et al. (26). The primary antibodies that were used were anti-RANK (polyclonal rabbit antibody H300 sc:9072; Santa Cruz Biotechnology Inc.; diluted 1:700), antiRANKL (polyclonal goat antibody n-19 sc:7628; Santa Cruz Biotechnology Inc.; diluted 1:400) and anti-OPG (polyclonal goat antibody n-20 sc:8468; Santa Cruz Biotechnology Inc.; diluted 1:700). The slides were incubated with biotinylated secondary antibody (goat anti-rabbit IgG-B sc-2040 and rabbit anti-goat IgG-B sc-2774; Santa Cruz Biotechnology Inc., diluted 1:200). The identification of osteoclastogenesis markers was performed using an Axio Imager.M1 microscope under conventional light. The results are expressed qualitatively, considering the presence/absence and location of markers, as described by da Silva et al. (26).

\section{Statistical analysis}

The comparison of the areas of the periapical lesions, the number of osteoclasts and the number of inflammatory cells between periods within the same group of animals (WT and MyD88 KO) was performed using the nonparametric Kruskal-Wallis test and Dunn's post-test. The comparisons for samples following the same period of time between different groups of animals (WT and KO MyD88) were performed using the nonparametric Mann-Whitney test. The data were 
analyzed using the Statistical Package for the Social Sciences (SPSS) software version 17.0, at a 5\% significance level.

\section{Results}

Descriptive microscopic analysis of the characteristics of the root canal and both the apical and periapical regions

WT animals exhibited total necrosis of the pulp tissue 7 days following periapical lesion induction. The periodontal ligament was slightly enlarged, with the occasional presence of inflammatory cells, which were predominantly mononuclear. The cementum surface was regular, without resorption areas. The alveolar bone was normal, with osteoblasts on their surface. The median lesion size in this period was $60,842.5 \mu \mathrm{m}^{2}$ (Figure 1 - A and B). At the 21-day time point, the pulp tissue was completely necrotic, and the root cementum exhibited surface irregularities. The periodontal ligament was enlarged, with extensive edema and areas of fibrillar dissociation. Predominantly mononuclear inflammatory cells were scattered throughout the region. The alveolar bone was observed to be bare and to exhibit areas of resorption. The median lesion size at this time was $74,368.0 \mu \mathrm{m}^{2}$ (Figure $1-\mathrm{E}$ and $\mathrm{F}$ ). The pulp roots exhibited total necrosis at day 42 . The periodontal ligament was severely enlarged, exhibiting dense inflammatory infiltrate, predominantly mononuclear, diffusely throughout the region. The cementum and alveolar bone exhibited extensive resorption areas. The median lesion size at this time was $258,088.0 \mu \mathrm{m}^{2}$ (Figure $1-\mathrm{I}$ and $\mathrm{J}$ ).

With respect to MyD88 KO animals, the specimens also exhibited total necrosis of the pulp tissue at day 7 as determined by the descriptive analyses. The periodontal ligament was moderately enlarged, exhibiting mixed and diffuse inflammatory infiltrate, with the considerable presence of neutrophils. The surface cementum was regular, whereas the alveolar bone exhibited resorption areas and no osteoblasts on its surface. Moreover, the periodontal ligament exhibited areas of edema onset and fibrillar dissociation. The median lesion size at this time was $123,803.0 \mu \mathrm{m}^{2}$ (Figure 1 - C and D). At day 21, the pulp tissue was completely necrotic. The cementum exhibited early resorption areas, 
making its surface slightly irregular. The periodontal ligament was enlarged, with areas of edema and the dissociation of collagen fibers. There was mixed inflammatory infiltrate with mononuclear and polymorphonuclear cells spread throughout the periapical region, with the considerable presence of neutrophils. The alveolar bone was observed to be bare, with areas of resorption. The median lesion size at this time was $153,306.0 \mu \mathrm{m}^{2}$ (Figure $1-\mathrm{G}$ and $\mathrm{H}$ ). At 42 days, the radicular pulp exhibited total necrosis. The periodontal ligament was severely enlarged, with fibrillar dissociation and edema. A dense mixed inflammatory cell infiltrate was observed diffusely across the region, with the presence of abundant neutrophils. The alveolar bone was observed far from the root apex, without osteoblasts on its surface. The root cementum was irregular due to resorption areas, and there was intense resorption activity in the alveolar bone, with a strong presence of clastic cells. The median lesion size at this time was $467,777.0 \mu \mathrm{m}^{2}$ (Figure $1-\mathrm{K}$ and $\mathrm{L}$ ).

Briefly, the descriptive microscopic analysis showed a more intense inflammatory infiltrate, with the abundant presence of mononuclear and polymorphonuclear cells and extensive tissue destruction, in the MyD88 KO group compared to the WT mice, which predominantly showed mononuclear cells (Figure 2- E and F). Figure 2 presents microscopic events observed during the descriptive analysis of the root canal system and apical and periapical regions.

\section{Fluorescence microscopy morphometrics}

A statistically significant difference between the time points was observed in the WT mice group, and Dunn's post-test indicated that the lesions were significantly larger at the 42-day time point than at the 7- $(\mathrm{p}<0.001)$ and 21-day $(\mathrm{p}=0.001)$ time points. With respect to the My88 KO group, measures were also observed to be significantly higher at the 42-day time point than at the 7- $(\mathrm{p}=$ $0.001)$ and 21-day $(\mathrm{p}=0.005)$ time points.

The comparison of the 7-, 21- and 42-day time points between the MyD88 KO (Figure 1 - D, $\mathrm{H}$ and $\mathrm{L}$ ) and WT (Figure $1-\mathrm{B}, \mathrm{F}$ and $\mathrm{J}$ ) groups revealed a significant difference in the experimental 7- $(\mathrm{p}=0.001)$ and 21-day $(\mathrm{p}=0.05)$ time point, with significantly higher values for the MyD88 KO 
group. With respect to the 42-day time point, there was a numerical trend towards the same behavior, but no statistically significant difference was observed $(\mathrm{p}=0.09)$.

Table 1 outlines the median, minimum and maximum values of periapical lesion area based on fluorescence microscopy analysis and the statistical analysis of the results. The results are given for all of the experimental periods (7, 21 and 42 days) and for the different groups (WT and MyD88 KO).

\section{Inflammatory cell count (neutrophils)}

A statistically significant difference was observed in the WT mice between the periods of evaluation $(\mathrm{p}=0.01)$. The number of neutrophils that were observed at the 21 -day time point was significantly higher than at the $7-(\mathrm{p}<0.01)$ and 42 -day $(\mathrm{p}=0.03)$ time points. With respect to the MyD88 KO group, the values observed at the 42-day time point were significantly higher than for the 21-day $(\mathrm{p}=0.01)$ time point, whereas no significant difference was observed between the other periods.

The comparison of the 7-, 21- and 42-day time points between the MyD88 KO and WT groups revealed a significant difference at the 7- $(\mathrm{p}=0.01), 21-(\mathrm{p}=0.004)$ and 42-day $(\mathrm{p}<0.001)$ time points, with significantly higher values for the MyD88 KO group.

Table 2 outlines the median, minimum and maximum values of the neutrophil counts that were found in the middle region of the lesion, adjacent to the apical foramen, and the statistical analysis of the results. The results are given for each of the experimental periods (7, 21 and 42 days) and for the different groups (WT and MyD88 KO).

\section{Histoenzymology of tartrate-resistant acid phosphatase (TRAP) activity}

For both of the groups, (i.e., WT and MyD88 KO), no significant difference in osteoclast count was observed between the 7-, 21- and 42-day time points ( $\mathrm{p}=0.226$ and 0.457 , respectively). The comparison of the 7-, 21- and 42-day time points between the WT and MyD88 KO groups also revealed no significant difference for the experimental 7-day $(\mathrm{p}=0.884), 21-(\mathrm{p}=0.506)$ or 42-day $(\mathrm{p}$ 
$=0.211)$ time points. TRAP staining-positive cells surrounding the periapical lesions of the WT and MyD88 KO groups are illustrated in Figure 3.

Table 3 outlines the medians, minimum and maximum values of the osteoclast count in the resorption lacunae and in direct contact with the alveolar bone surrounding the periapical lesions. The statistical results are given for the experimental periods (7,21 and 42 days) and for the different groups (WT and MyD88 KO).

\section{Modified Brown \& Brenn staining}

With respect to the assessment of bacterial presence and location in the root canal system and periapical tissues, specimens from the group of WT animals were rated with a score of 4 at days 7, 21 and 42. The presence of a large amount of bacteria was noted in the tooth crown and the cervical third of the root canal, including the dentinal tubules and the interradicular region. The amount of bacteria progressively decreased towards the apical region, with small number of bacteria in the middle and apical thirds and no bacteria detected in the periapical lesions. Conversely, in the MyD88 KO group, microbial infection was more strongly spread throughout the root canal system, including the periapical region and the lesion; this group was rated with a score of 5. Bacteria were found abundantly in the tooth crown and the cervical and middle thirds of the root canal, with deep penetration in the dentinal tubules. The specimens exhibited bacteria in the apical third, the foramen exit, the cement lacunae and the periapical lesion (Figure 4).

\section{Immunostaining (Immunohistochemistry)}

RANK-positive staining was noted in specimens from both of the groups, generally in the apical foramen region. RANKL staining was noted in specimens in both the MyD88 KO and WT groups at 7, 21 and 42 days, primarily in the apical foramen region and within the periapical lesion. OPG staining was noted in specimens from animals of the WT and MyD88 KO groups, especially within the lesion, at all of the experimental periods. Staining was also noted in the specimens from the 
WT group at the ends of the periapical lesion. Photomicrographs that are representative of RANK, RANKL and OPG staining are shown in Figure 5, indicating their locations.

\section{Discussion}

The results found in the current study confirmed the hypothesis that MyD88 KO mice would develop more extensive periapical lesions than WT animals, most likely due to the damage to the immune system caused by the lack of the adapter molecule MyD88, which participates in TLR signaling. A progressive increase in periapical lesion size was noted from the beginning of the experiment to the end, and MyD88 KO animals developed markedly larger lesions by the 7- and 21day time points. This observation was correlated with differences in the characteristics of inflammatory infiltrate, which was further exacerbated and showed a considerable presence of neutrophils and mononuclear cells in MyD88 KO animals, with deficient control of its chronification.

In the current study, the quantitative analysis of neutrophil number in the middle region of the lesion, adjacent to the apical foramen, confirmed the qualitative description and revealed a significantly higher number of these cells in the MyD88 KO group than in WT animals at all of the time points. Neutrophils have a very brief life span and act within the inflammatory infiltrate for approximately 3 days (32), indicating that the bacterial aggressor stimulus was more intense and persistent in the MyD88 KO group, stimulating neutrophil migration until the final time point of the experiment. Moreover, it is possible that molecular events and the mechanisms that are involved in the control of neutrophil influx to inflammatory sites are mediated by MyD88.

The lack of studies evaluating the effect of the molecule MyD88 on the development of periapical lesions precludes a direct comparison with our results. However, the current study is consistent with previous results, which demonstrated that the MyD88 signaling pathway is essential for infection control and for the adequate and efficient organization of the inflammatory and immune response $(6,10,11)$. 
In this context, the noted difference in bacterial presence and location between groups, as shown by Brown and Brenn staining, stands out. Bacteria were more severely disseminated throughout the root canal system in the MyD88 KO group, being abundantly found in the cervical, middle and apical thirds, including the periapical lesion, indicating a loss of host resistance and infection fighting ability in MyD88 KO mice, which is consistent with previous studies.

TLRs are primarily expressed in antigen-presenting cells, including dendritic cells, macrophages and $\mathrm{B}$ cells. The activation of these cells is followed by $\mathrm{CD}^{+}$and $\mathrm{CD} 8^{+} \mathrm{T}$ cell and antigen-specific antibody-producing B cell differentiation (33). According to the results of the current study and based on the literature, in can be inferred that the silencing of the molecule MyD88 impaired the TLR signaling pathway in these cells and compromised the activation of the immune response, resulting in the histopathological condition that was observed in the periapical lesions of MyD88 KO animals.

Using the same experimental model, da Silva et al. (26) reported more extensive periapical lesions with a higher osteoclast number in TLR2 KO animals. It was suggested that the activation of other signaling pathways and a stronger activation of other TLRs, particularly TLR4, which recognizes bacterial LPS, may have occurred. Conversely, Hou et al. (27) reported that TLR4 KO mice developed smaller periapical lesions with reduced expression of pro-inflammatory cytokines. These results may indicate the great potential of LPS to cause deleterious effects and to exacerbate periapical bone destruction via the TLR4 receptor.

MyD88 is used by all of the TLRs, except TLR3, and transduces signals that culminate in NF$\kappa \mathrm{B}$ activation, the induction of pro-inflammatory mediators, including TNF- $\alpha$ and IL- 6 , and the production of IFN types I, $\alpha$ and $\beta$ (34). Furthermore, MyD88 activates IL-1 (IL-1R, IL-18R and IL33R) receptors and, consequently, the intracellular signaling and cytokine production that is induced by these receptors are also down-regulated in the absence of this adapter molecule $(6,33)$. Thus, the genetic deletion of MyD88 in the current study promoted the silencing of many key signaling pathways, which most likely exacerbated the inflammatory process, increased the area of the periapical lesions and resulted in the dysfunctional activation and organization of the immune 
response. Therefore, this molecule plays a key role during inflammatory and immune responses that are triggered to fight infections in the root canal system and the periapical tissue during the genesis and the development of periapical lesions, indicating a protective function.

It should be noted that the mechanisms and processes that modulate the immunoinflammatory host response against endodontic infections in the absence of MyD88 remain unknown. It is known that the genetic deletion of this molecule results in changes in the defense system, demonstrating its key role. The results that are reported in the present study are in agreement with Graves et al. (35), who reported that the inhibition of an immune response component in endodontic lesions causes a reduction in resistance to bacterial infection and the formation of more extensive osteolytic lesions.

In agreement with the literature, $(26,29,36-38)$, osteoclasts were observed to be associated with the resorption areas in the periapical regions of WT and MyD88 KO mouse teeth in the current study. However, differences in the number of these cells were not observed between the groups following any of the experimental periods. This result suggests that the increased tissue destruction that was observed in specimens in the MyD88 KO group may have also been caused by other immunoinflammatory mechanisms in addition to those inducing osteoclast differentiation and activation. These mechanisms include the expression of pro-inflammatory cytokines, which may have been increased by the presence of more aggressive products, by-products and other virulent factors in the endodontic infections of MyD88 KO animals.

Based on immunohistochemical analysis, similar levels of RANK, RANKL and OPG staining were observed in WT and MyD88 KO animals at the 7-, 21- and 42-day time points. Therefore, the involvement of these osteoclastogenesis mediators in periapical lesion development is confirmed, as previously described $(26,39-41)$.

Importantly, this is the first study to evaluate the effects of the adapter molecule MyD88 on endodontic infections and the development of periapical lesions, precluding direct comparison of the current results with those of previous studies. Further studies are required to elucidate the functions that are performed by this molecule and the mechanisms that are triggered upon its genetic silencing. Such mechanisms include compensation, stimulation and inhibition of immunoinflammatory events 
and bone resorption following the recognition of microorganisms and periapical lesion onset. According to the present methodologies and results, it can be concluded that MyD88 KO animals developed more extensive periapical lesions, with a severe inflammatory infiltrate and significantly greater numbers of neutrophils than WT animals, suggesting the key role of this molecule in the immune and inflammatory response of the body to an infection of endodontic origin.

\section{Acknowledgments}

We thank Marco Antonio dos Santos and Nilza Letícia Magalhães, laboratory technicians of Department of Pediatric Dentistry, School of Dentistry of Ribeirão Preto, University of São Paulo, Ribeirão Preto, SP, Brazil, for the histotechnical processing carried out in this work.

\section{References}

1. Hedayat M, Takeda K, Rezaei N. Prophylactic and therapeutic implications of toll-like receptor ligands. Med Res Rev 2012;32:294-325.

2. Hirao K, Yumoto H, Takahashi K, Mukai K, Nakanishi T, Matsuo T. Roles of TLR2, TLR4, NOD2, and NOD1 in pulp fibroblasts. J Dent Res 2009;88:762-7.

3. Kawai T, Akira S. The roles of TLRs, RLRs and NLRs in pathogen recognition. Int Immunol 2009;21:317-37.

4. Kobe B, Kajava AV. The leucine-rich repeat as a protein recognition motif. Curr Opin Struct Biol $2001 ; 11: 725-32$

5. Jiang J, Zuo J, Chen SH, Holliday LS. Calcium hydroxide reduces lipopolysaccharide-stimulated osteoclast formation. Oral Surg Oral Med Oral Pathol Oral Radiol Endod 2003;95:348-54. 
6. Loures FV, Pina A, Felonato M, Feriotti C, de Araújo EF, Calich VL. MyD88 signaling is required for efficient innate and adaptive immune responses to Paracoccidioides brasiliensis infection. Infect Immun 2011;79:2470-80.

7. Gomes MT, Campos PC, de Almeida LA, Oliveira FS, Costa MM, Marim FM, et al. The role of innate immune signals in immunity to Brucella abortus. Front Cell Infect Microbiol 2012;2:130.

8. Takeda K, Akira S. Microbial recognition by Toll-like receptors. J Dermatol Sci 2004;34:73-82.

9. Hughes MA, Green CS, Lowchyj L, Lee GM, Grippe VK, Smith MF Jr, et al. MyD88-dependent signaling contributes to protection following Bacillus anthracis spore challenge of mice: implications for Toll-like receptor signaling. Infect Immun 2005;73:7535-40.

10. LaRosa DF, Stumhofer JS, Gelman AE, Rahman AH, Taylor DK, Hunter CA, et al. T cell expression of MyD88 is required for resistance to Toxoplasma gondii. Proc Natl Acad Sci USA 2008;105:3855-60.

11. Koh YS, Koo JE, Biswas A, Kobayashi KS. MyD88-dependent signaling contributes to host defense against ehrlichial infection. PLoS One 2010;5:e11758.

12. Ishibashi D, Atarashi R, Nishida N. Protective role of MyD88-independent innate immune responses against prion infection. Prion 2012;6:443-6.

13. Hanke ML, Angle A, Kielian T. MyD88-dependent signaling influences fibrosis and alternative macrophage activation during Staphylococcus aureus biofilm infection. PLoS One 2012;7:e42476.

14. Siqueira JF Jr, Rôças IN. Polymerase chain reaction-based analysis of microorganisms associated with failed endodontic treatment. Oral Surg Oral Med Oral Pathol Oral Radiol Endod 2004;97:85-94. 
15. Rocha CT, Rossi MA, Leonardo MR, Rocha LB, Nelson-Filho P, Silva LA. Biofilm on the apical region of roots in primary teeth with vital and necrotic pulps with or without radiographically evident apical pathosis. Int Endod J 2008;41:664-9.

16. Cogulu D, Uzel A, Oncag O, Eronat C. PCR-based identification of selected pathogens associated with endodontic infections in deciduous and permanent teeth. Oral Surg Oral Med Oral Pathol Oral Radiol Endod 2008;106:443-9.

17. Mohammadi Z. Endotoxin in endontic infections: a review. J Calif Dent Assoc 2011;39:153-61.

18. Tronstad L. Recent development in endodontic research. Scand J Dent Res 1992;100:52-9.

19. Stashenko P, Yu SM, Wang CY. Kinetics of immune cell and bone resorptive responses to endodontic infections. J Endod 1992;18:422-6.

20. Hetherington CJ, Kingsley PD, Crocicchio F, Zhang P, Rabin MS, Palis J, et al. Characterization of human endotoxin lipopolysaccharide receptor CD14 expression in transgenic mice. J Immunol 1999;162:503-9.

21. Stashenko P. Role of immune cytokines in the pathogenesis of periapical lesions. Endod Dent Traumatol 1990;6:89-96.

22. Nelson-Filho P, Leonardo MR, Silva LA, Assed S. Radiographic evaluation of the effect of endotoxin (LPS) plus calcium hydroxide on apical and periapical tissues of dogs. $\mathrm{J}$ Endod 2002;28:694-6.

23. Silva LA, Nelson-Filho P, Leonardo MR, Rossi MA, Pansani CA. Effect of calcium hydroxide on bacterial endotoxin in vivo. J Endod 2002;28:94-8. 
24. Silva LA, Silva RA, Branco LG, Navarro VP, Nelson-Filho P. Quantitative radiographic evaluation of periapical bone resorption in dog's teeth contaminated with bacterial endotoxin (LPS) associated or not with calcium hydroxide. Braz Dent J 2008;19:296-300.

25. Bar-Shavit Z. Taking a toll on the bones: regulation of bone metabolism by innate immune regulators. Autoimmunity 2008;41:195-203.

26. Da Silva RAB, Ferreira PDF, De Rossi A, Nelson-Filho P, Silva LAB. Toll-like receptor2 knockout mice showed increased periapical lesion size and osteoclast number. J Endod 2012;38:80313.

27. Hou L, Sasaki H, Stashenko P. Toll-like receptor 4-deficient mice have reduced bone destruction following mixed anaerobic infection. Infect Immun 2000;68:4681-7.

28. De Rossi A, Rocha LB, Rossi MA. Application of fluorescence microscopy on hematoxylin and eosin-stained sections of healthy and diseased teeth and supporting structures. J Oral Pathol Med 2007;36:377-81.

29. De Rossi A, Rocha LB, Rossi MA. Interferon-gamma, interleukin-10, Intercellular adhesion molecule-1, and chemokine receptor 5, but not interleukin-4, attenuate the development of periapical lesions. J Endod 2008;34:31-8.

30. Brown JH, Brenn L. A method for the differential staining of Gram-positive and Gram-negative bacteria in tissue sections. Bull Johns Hopkins Hosp 1931;48:69-73.

31. Chen CP, Hertzberg M, Jiang Y, Graves DT. Interleukin-1 and tumor necrosis factor receptor signaling is not required for bacteria-induced osteoclastogenesis and bone loss but is essential for protecting the host from a mixed anaerobic infection. Am J Pathol 1999;155:2145-52.

32. Reinke JM, Sorg H. Wound repair and regeneration. Eur Surg Res 2012;49:35-43. 
33. Kawai T, Akira S. Toll-like receptors and their crosstalk with other innate receptors in infection and immunity. Immunity 2011;34:637-50.

34. Siednienko J, Gajanayake T, Fitzgerald KA, Moynagh P, Miggin SM. Absence of MyD88 results in enhanced TLR3-dependent phosphorylation of IRF3 and increased IFN- $\beta$ and RANTES production. J Immunol 2011;186:2514-22.

35. Graves DT, Oates T, Garlet GP. Review of osteoimmunology and the host response in en dodontic and periodontal lesions. J Oral Microbiol 2011;17;3.

36. Liu S, Cheng Y, Xu W, Bian Z. Protective effects of follicle-stimulating hormone inhibitor on alveolar bone loss resulting from experimental periapical lesions in ovariectomized rats. $\mathrm{J}$ Endod 2010;36:658-63

37. Xiong H, Wei L, Hu Y, Zhang C, Peng B. Effect of alendronate on alveolar bone resorption and angiogenesis in rats with experimental periapical lesions. Int Endod J 2010;43:485-91.

38. Silva MJ, Sousa LM, Lara VP, Cardoso FP, Júnior GM, Totola AH, et al. The role of iNOS and PHOX in periapical bone resorption. J Dent Res 2011;90:495-500.

39. Vernal R, Dezerega A, Dutzan N, Chaparro A, León R, Chandía S, et al. RANKL in human periapical granuloma: possible involvement in periapical bone destruction. Oral Dis 2006;12:283-9.

40. Menezes R, Garlet TP, Letra A, Bramante CM, Campanelli AP, Figueira Rde C, et al. Differential patterns of receptor activator of nuclear factor kappa B ligand/osteoprotegerin expression in human periapical granulomas: possible association with progressive or stable nature of the lesions. J Endod $2008 ; 34: 932-8$ 
41. Moraes M, Lucena HF, Azevedo PR, Queiroz LM, Costa AD. Comparative immunohistochemical expression of RANK, RANKL and OPG in radicular and dentigerous cysts. Arch Oral Biol 2011;56:1256-63.

\section{Figure Legends}

Figure 1. Photomicrographs of representative HE-stained microscopic sections of WT and MyD88 KO animals at 7-, 21- and 42-day experimental periods. In A, C, E, G, I and K, the sections were observed under conventional light microscopy for a descriptive analysis of the root canal system and apical and periapical regions, and for measurement of neutrophil counts. In B, D, F, H, J and L, the images were obtained by the fluorescence technique for measuring the size of periapical lesions (10X).

Figure 2. Photomicrographs obtained under conventional light microscopy representative of the microscopic events observed during the descriptive analysis of the root canal system and apical and periapical regions after experimental induction of periapical lesions in the WT and MyD88 KO animals, at the different experimental periods: (A) Apical and periapical regions. Necrotic pulp tissue (NP), severely increased width of the periodontal ligament (PL) space and bone alveolar (B) with resorption areas (MyD88 KO - 42 days; 10X). (B) Detail of image A (square) showing the cemental surface (C) with resorption areas (arrow), fibrilar dissociation and inflammatory cells (MyD88 KO 42 days; 40X). (C) Detail of image A revealing a severely increased width of the periodontal ligament (PL) space, with areas of edema and fibrilar dissociation, mixed and diffuse inflammatory infiltrate, and large number of neutrophils. The alveolar bone (B) appears denuded and exhibits osteoclasts (arrow) on its surface (MyD88 KO - 42 days; 40X). (D) Detail of image A showing increased width of the periodontal ligament PL) space and alveolar bone (B) distant from the root apex and severely resorbed (MyD88 KO - 42 days; 40X).

Figure 3. Photomicrographs of representative microscopic sections of WT animals (A, B, C and D) and MyD88 KO animals (E, F and G) at 7-, 21- and 42-day experimental periods, stained with the 
tartrate resistant acid phosphatase (TRAP) histoenzymology technique for identification and counting of osteoclasts. Image A shows osteoclastic cells present in the resorption lacunae in direct contact with the alveolar bone surrounding the periapical lesion (10 and 40X).

Figure 4. Photomicrographs of representative microscopic sections of MyD88 KO animals sainted with the modified Brown \& Brenn technique showing the presence and location of bacteria in the root canal system and periapical tissues: (A) Panoramic photomicrograph revealing intense bacterial contamination in all tooth extension $(10 \mathrm{X})$. (B) Coronal root canal third with a large number of microorganisms (40X). (C) Detail of image B in which dentinal tubules with intense presence of bacteria can be seen. (D) Detail of image A in which microorganisms can be seen in the apical third and resorption craters. (E) Detail of image A showing a large number of bacteria in the cemental lacunae. (F) Detail of image A showing microorganisms in the periapical lesion.

Figure 5. Photomicrographs representative of microscopic sections of WT and MyD88 KO animals subjected the immunohistochemical staining technique for detection of the osteoclastogenesis markers RANK, RANKL and OPG, at the different experimental periods. 


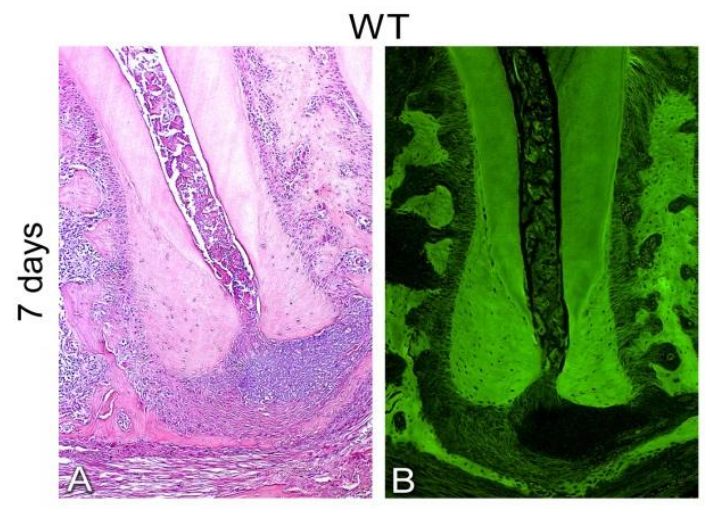

WT

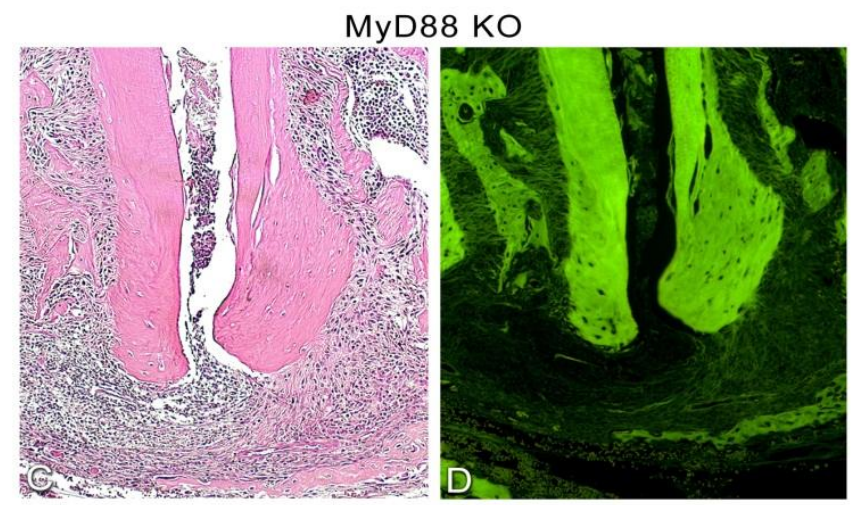

MyD88 KO

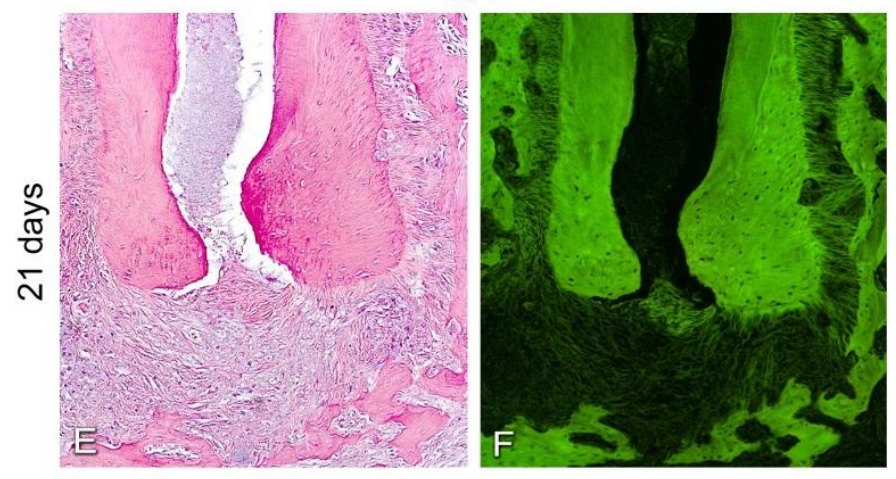

WT

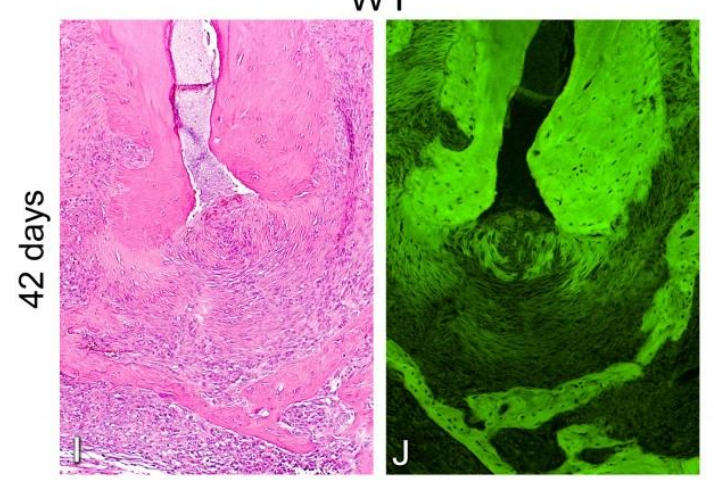

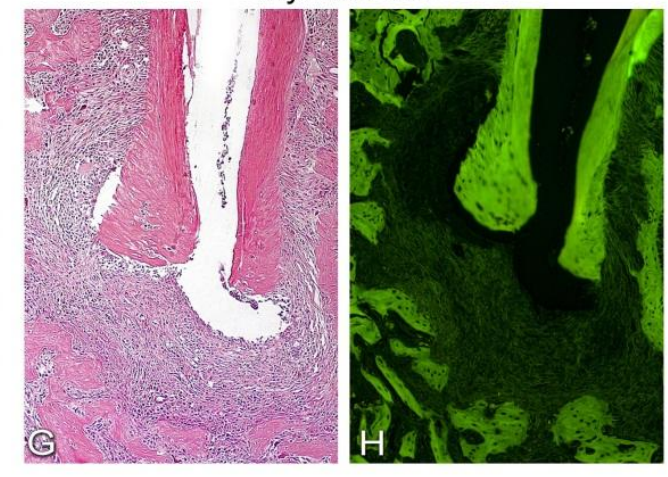

MyD88 KO

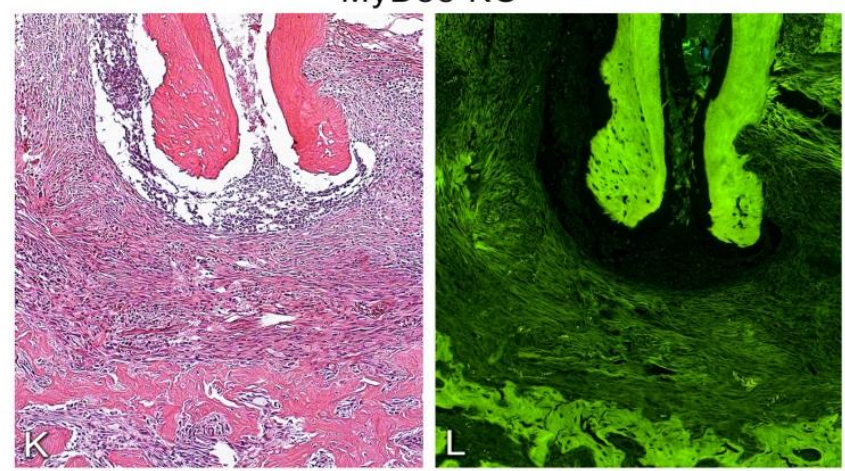



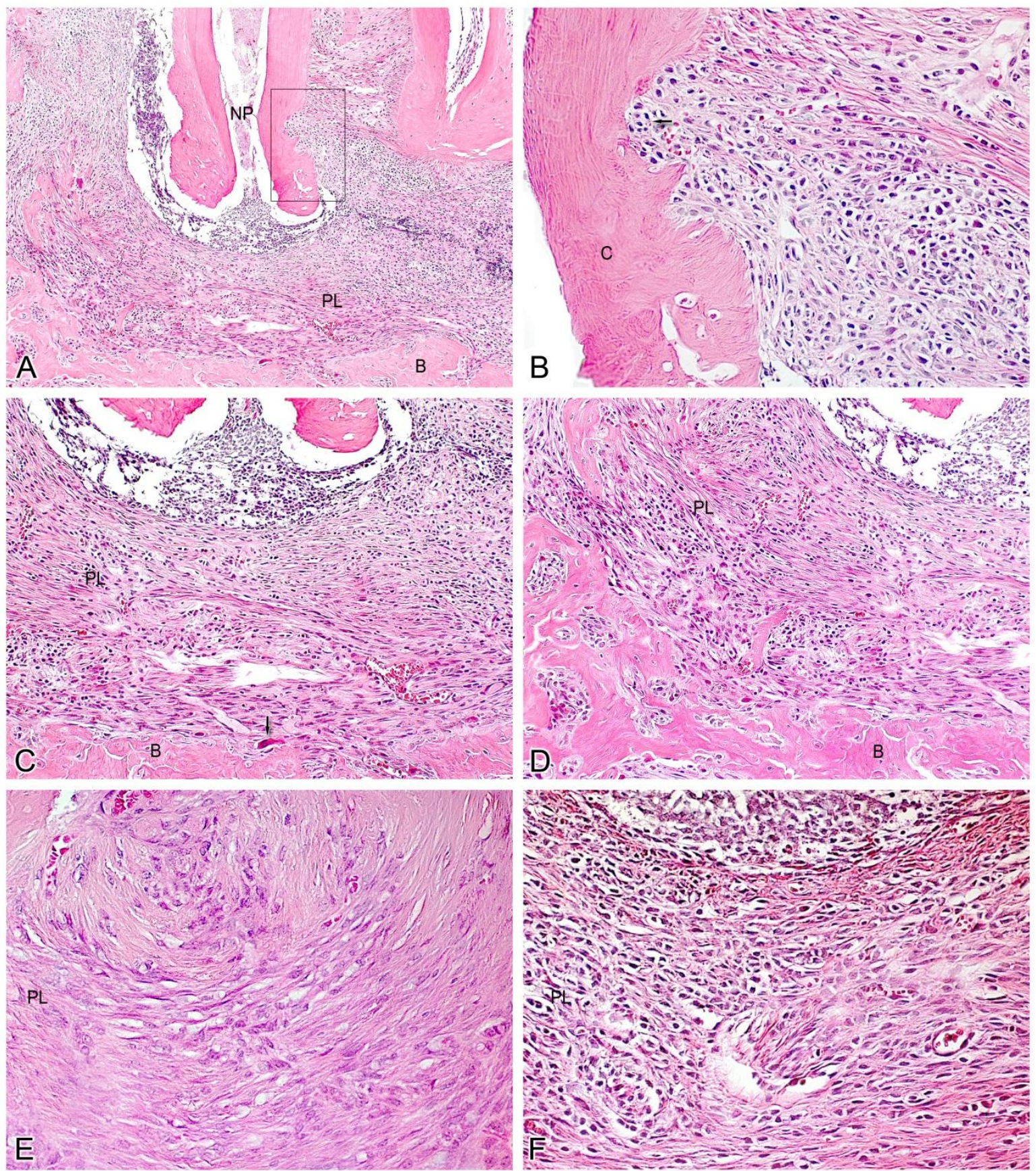


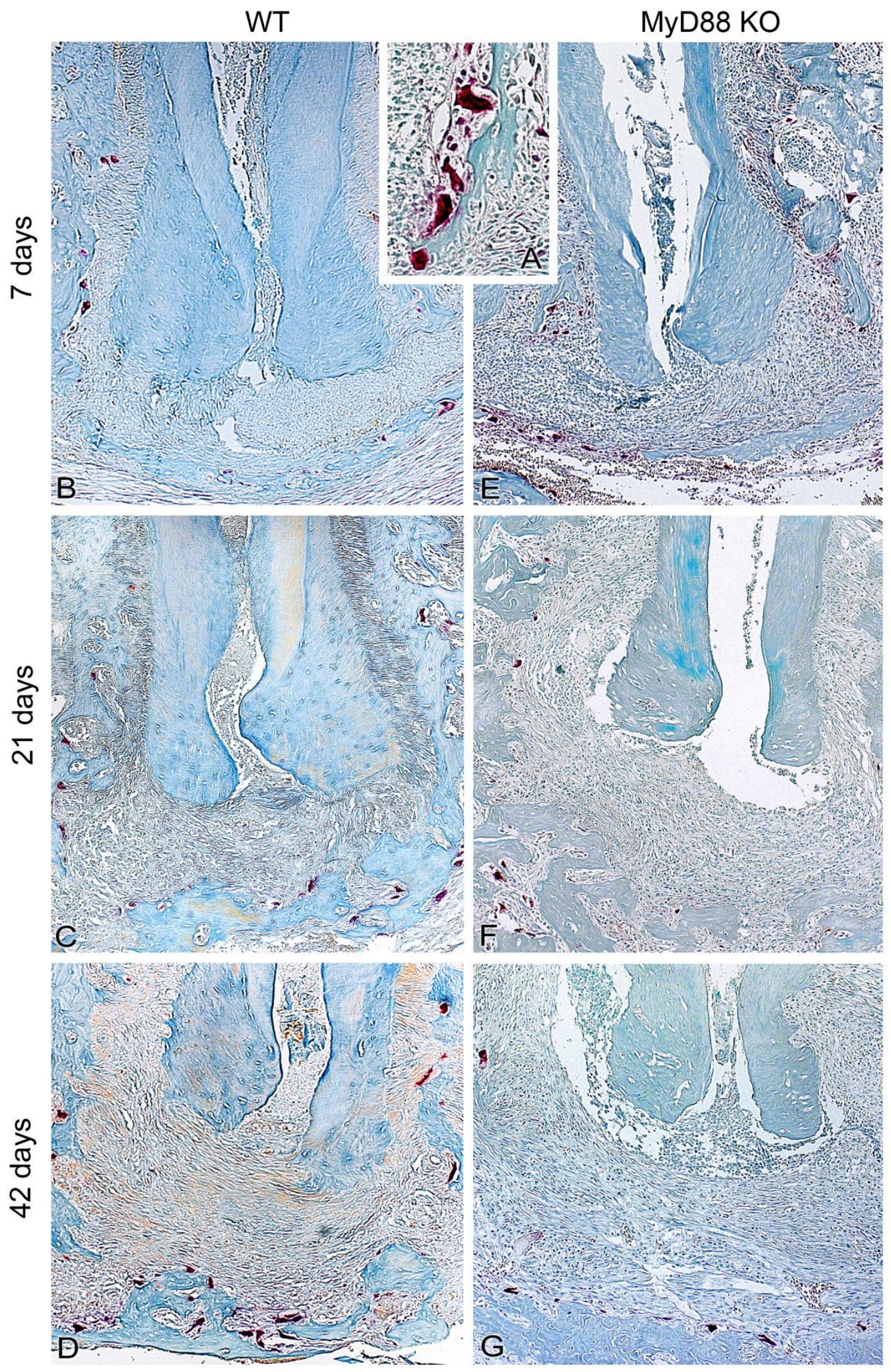



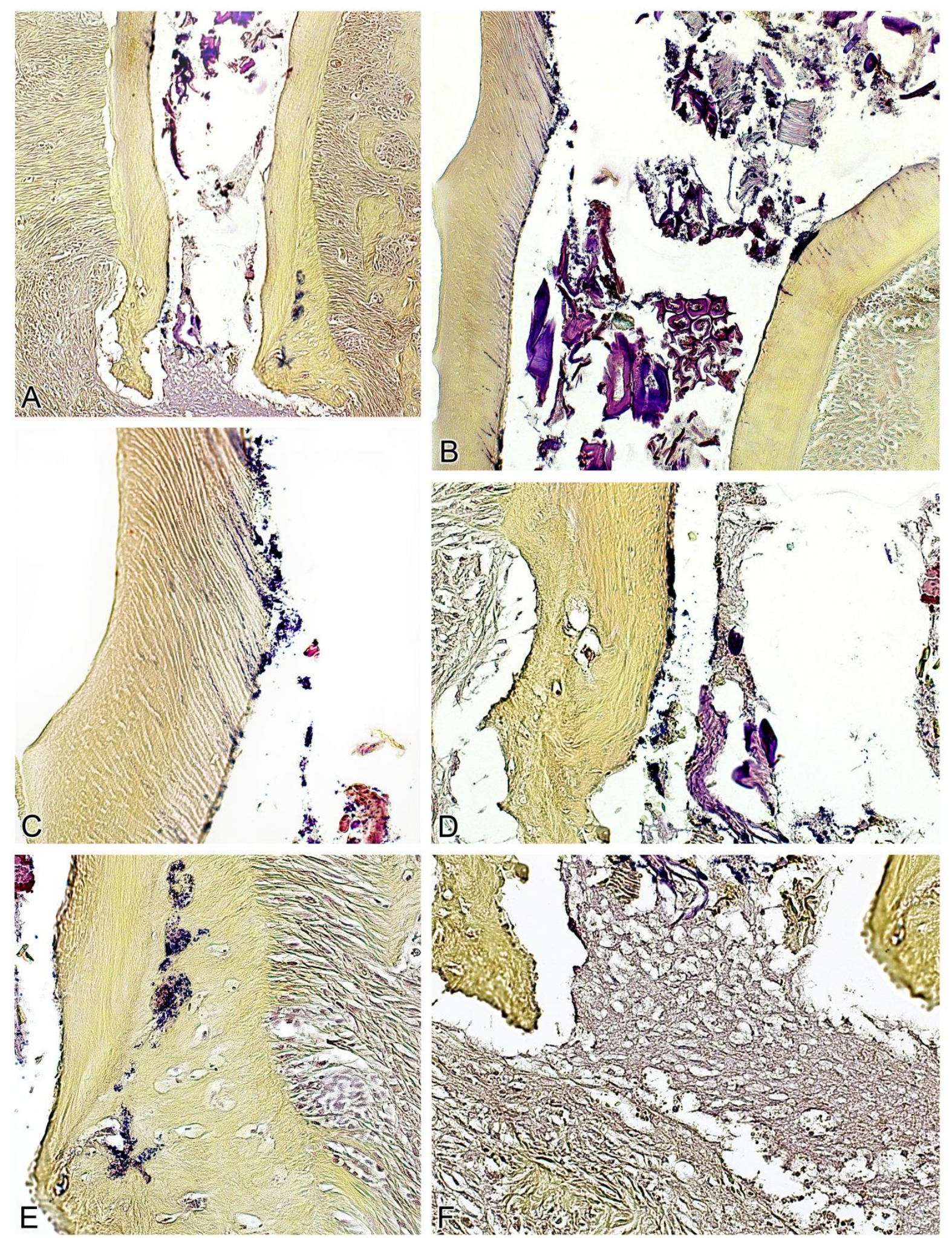

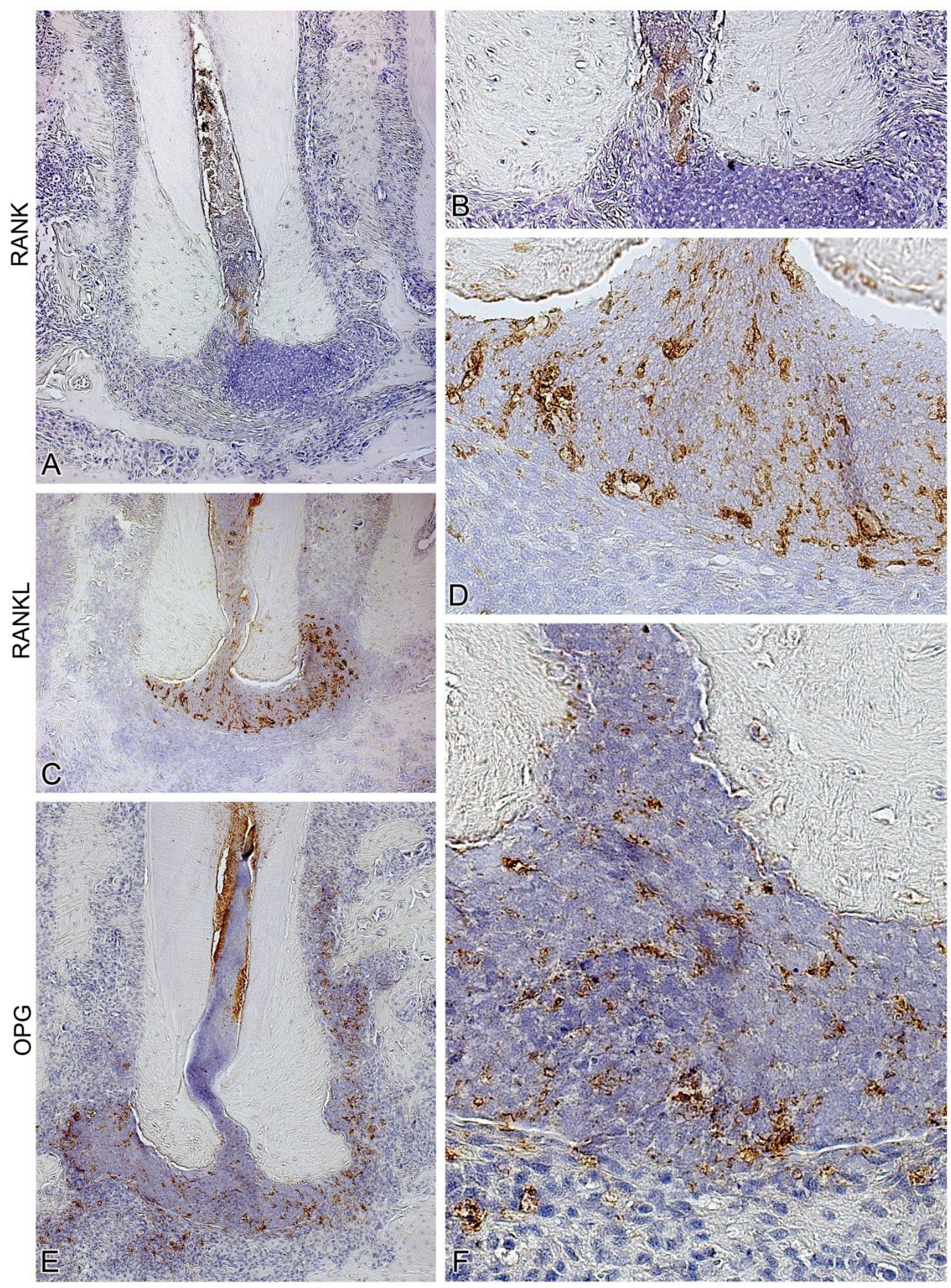